SRNL-STI-2011-00075

Revision 0

Keywords: $S C I X, D W P F, C P C$

Retention: Permanent

\title{
SCIX Impact on DWPF CPC
}

D. C. Koopman

June 2011

Savannah River National Laboratory Savannah River Nuclear Solutions, LLC Aiken, SC 29808

Prepared for the U.S. Department of Energy under contract number DE-AC09-08SR22470.

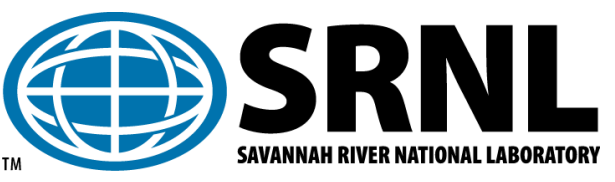


SRNL-STI-2011-00075

Revision 0

\section{DISCLAIMER}

This work was prepared under an agreement with and funded by the U.S. Government. Neither the U.S. Government or its employees, nor any of its contractors, subcontractors or their employees, makes any express or implied:

1. warranty or assumes any legal liability for the accuracy, completeness, or for the use or results of such use of any information, product, or process disclosed; or

2. representation that such use or results of such use would not infringe privately owned rights; or

3. endorsement or recommendation of any specifically identified commercial product, process, or service.

Any views and opinions of authors expressed in this work do not necessarily state or reflect those of the United States Government, or its contractors, or subcontractors.

\section{Printed in the United States of America \\ Prepared for \\ U.S. Department of Energy}




\section{REVIEWS AND APPROVALS}

AUTHORS:

D. C. Koopman, Process Technology Programs

Date

TECHNICAL REVIEW:

M. E. Stone, Process Technology Programs

Date

APPROVAL:

C. C. Herman, Manager

Date

Process Technology Programs

F. M. Pennebaker, Manager

Date SRNL SCIX Program

S. L. Marra, Manager

Date

Environmental \& Chemical Process Technology Research Programs

J. E. Occhipinti, Waste Solidification Engineering Date

T. H. Huff, SCIX Engineering

Date 
SRNL-STI-2011-00075

Revision 0

\section{EXECUTIVE SUMMARY}

A program was conducted to systematically evaluate potential impacts of the proposed Small Column Ion Exchange (SCIX) process on the Defense Waste Processing Facility (DWPF) Chemical Processing Cell (CPC). The program involved a series of interrelated tasks. Past studies of the impact of crystalline silicotitanate (CST) and monosodium titanate (MST) on DWPF were reviewed. Paper studies and material balance calculations were used to establish reasonable bounding levels of CST and MST in sludge. Following the paper studies, Sludge Batch 10 (SB10) simulant was modified to have both bounding and intermediate levels of MST and ground CST. The SCIX flow sheet includes grinding of the CST which is larger than DWPF frit when not ground. Nominal ground CST was not yet available, therefore a similar CST ground previously in Savannah River National Laboratory (SRNL) was used. It was believed that this CST was over ground and that it would bound the impact of nominal CST on sludge slurry properties.

Lab-scale simulations of the DWPF CPC were conducted using SB10 simulants with no, intermediate, and bounding levels of CST and MST. Tests included both the Sludge Receipt and Adjustment Tank (SRAT) and Slurry Mix Evaporator (SME) cycles. Simulations were performed at high and low acid stoichiometry. A demonstration of the extended CPC flowsheet was made that included streams from the site interim salt processing operations. A simulation using irradiated CST and MST was also completed. An extensive set of rheological measurements was made to search for potential adverse consequences of CST and MST and slurry rheology in the CPC.

Based on the testing, no significant adverse impacts were noted in the following areas:

- $\quad$ SRAT acid demand decreased slightly as MST and CST displaced sludge solids.

- SRAT and SME maximum hydrogen generation rates were lower in tests with CST and MST.

- Other CPC chemistry was only mildly impacted by the presence of CST and MST.

- Sodium appeared to leach from the MST and CST into the supernate

- CST and MST otherwise remained insoluble with detection limits

- CST and MST elements, other than silicon, were not found in the off-gas condensates (off-gas silicon is believed to come from antifoam degradation)

- A small increase in iron solubility was noted that could impact criticality calculations that take credit for insoluble iron (also Ti could be included with the existing poisons)

- The caustic portion of solid MST did not cause an appreciable shift in predicted acid demand

- Significant sodium alumino-silicate formation was not indicated

- No significant impact of CST and MST irradiation was noted

- Sludge, SRAT product, and SME product rheological properties under normal shear rates were improved (made less viscous) by the presence of CST and MST.

- SME product solids with CST and MST will likely be easier to resuspend than traditional SME product solids.

In addition, DWPF could experience a variety of potential benefits from the incorporation of CST and MST into the starting sludge. These include: 
- Dilution of the sludge likely means dilution of mercury and noble metals. Dilution of mercury reduces stripping time in the SRAT, while dilution of noble metals reduces the risk of excessive hydrogen generation.

- Combining CST and MST with sludge extends the duration of a sludge batch at a fixed canister production rate.

- Processing with higher total solid content slurries through DWPF may be possible once CST and MST are fully integrated into the SRAT receipt sludge, since yield stress values dropped as CST and MST levels were increased.

Some potential operational issues exist with integrating SCIX with DWPF:

- Ground CST is to be transferred into the DWPF feed tank, e.g. Tank 40. Ground CST has shown a tendency to form a fairly shear resistant cake once it has been allowed to settle. CST transfers should be immediately blended into the feed tank sludge solids, since these solids appear to mitigate CST cake formation. Thorough flushing of the CST transfer lines may be necessary as well to prevent the lines from plugging over time.

- This study assumed no impact on the concentrations of dissolved species and no significant impact on the wt\% insoluble solids from the CST transfers. Some dilution of both is more likely; especially if a lot of flush water is required to clear the CST to DWPF feed tank transfer piping. Consequently, it may become routine to decant supernate from the DWPF feed tank back to the tank farm in order to maintain the $\mathrm{wt} \%$ insoluble content of the DWPF feed at an acceptable level. Ground CST fines may be returned to the tank farm evaporators potentially creating additional issues there with alumino-silicate formation.

- Process data suggested some increased foaming sensitivity of the caustic SRAT receipt slurry to the presence of CST and MST. Caustic slurry foaming and its mitigation are not as well understood as acidic slurry foaming and mitigation. Simulant tests have consistently underestimated the foaminess of real caustic slurries in DWPF. Increased antifoam demand could lead to excessive melter feed total organic carbon content.

- Dissolution of some iron above normal historical SRAT processing levels was observed in some runs. The observed increases were small, but may not have bound the phenomenon, in which case there could be a nontrivial impact on criticality calculations and assumptions for the CPC. The iron dissolution is potentially unrelated to the presence of the SCIX species.

The SCIX CPC impact program was conducted in parallel with a program to evaluate the impact of SCIX on the final DWPF glass waste form and on the DWPF melter throughput. The studies must be considered together when evaluating the full impact of SCIX on DWPF.

Due to the fact that the alternant flowsheet for DWPF has not been selected, this study did not consider the impact of proposed future alternative DWPF CPC flowsheets. The impact of the SCIX streams on DWPF processing using the selected flowsheet need to be considered as part of the technical baseline studies for coupled processing with the selected flowsheet. In addition, the downstream impact of aluminum dissolution on waste containing CST and MST has not yet been evaluated. The current baseline would not subject CST to the aluminum dissolution process and technical concerns with performing the dissolution with CST have been expressed. Should this option become feasible, the downstream impact should be considered. The main area of concern for DWPF from aluminum dissolution is an impact on rheology. The SCIX project is planning for SRNL to complete MST, CST, and sludge rheology testing to evaluate any expected changes. 
SRNL-STI-2011-00075

Revision 0

The impact of ground CST transport and flush water on the DWPF CPC feed tank (and potential need for decanting) has not been defined or studied. 


\section{TABLE OF CONTENTS}

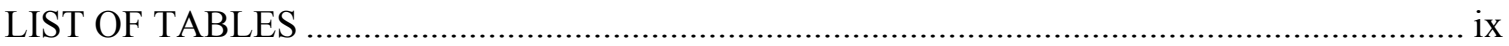

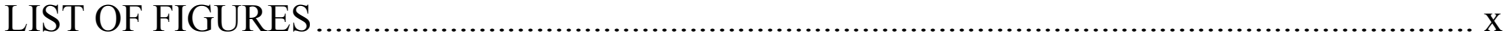

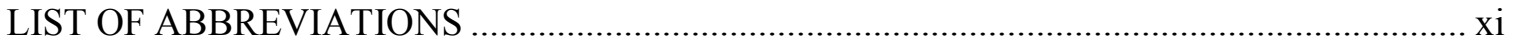

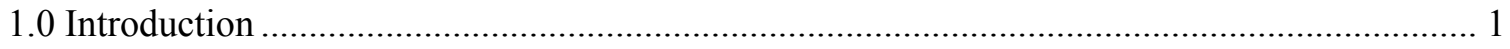

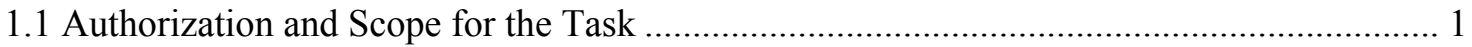

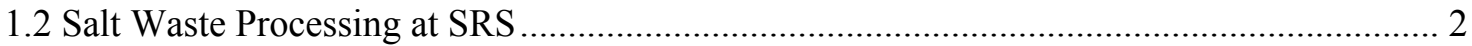

1.3 Review of Prior CPC Work Related to CST and MST ..................................................... 3

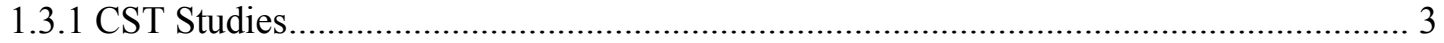

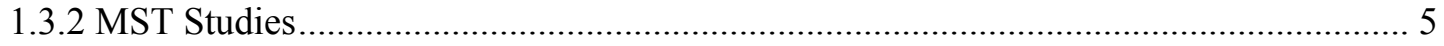

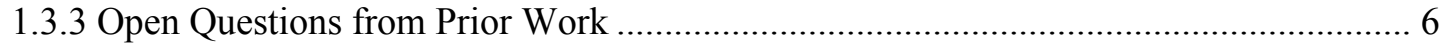

2.0 Experimental Procedure and Analytical Methods ................................................................... 7

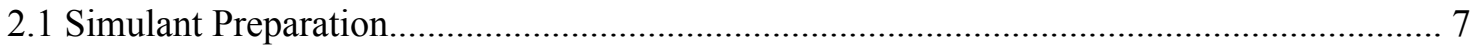

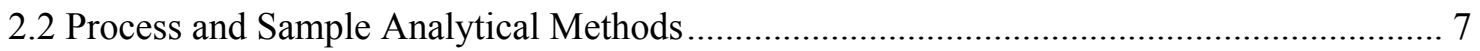

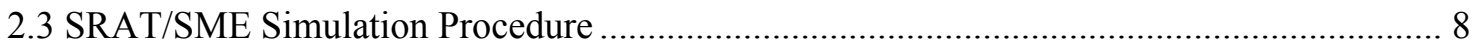

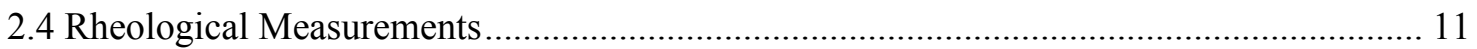

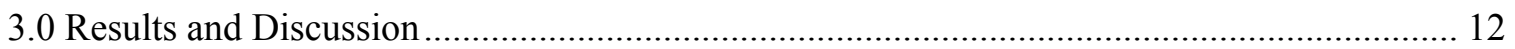

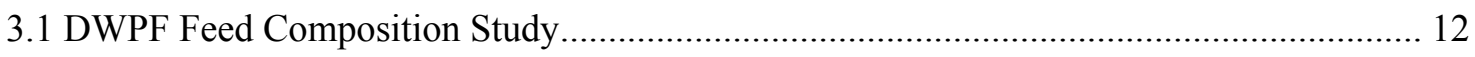

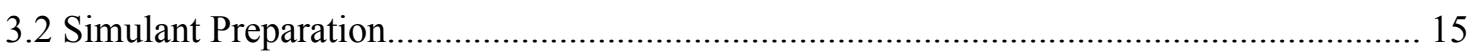

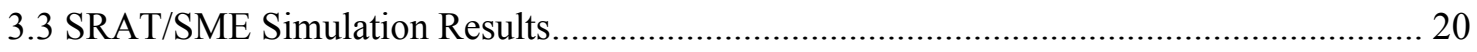

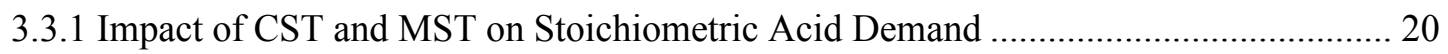

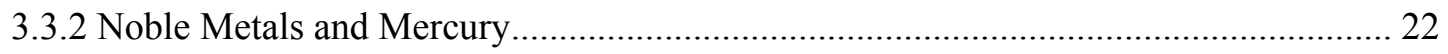

3.3.3 Impact of Caustic Boiling Before Nitric Acid Addition ............................................. 23

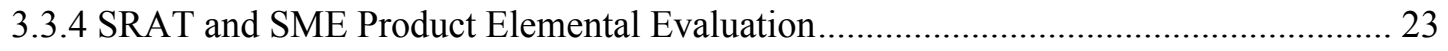

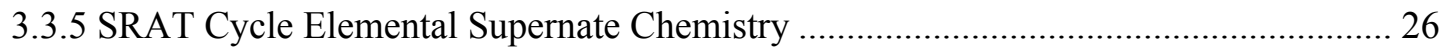

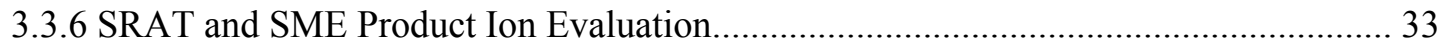

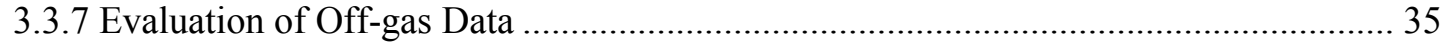

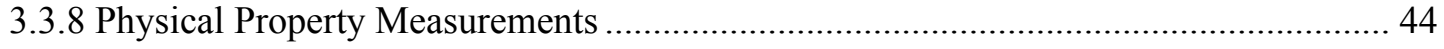

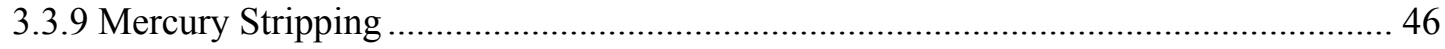

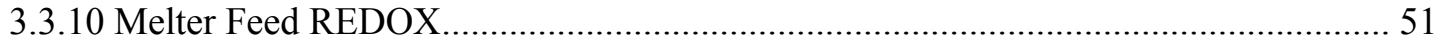

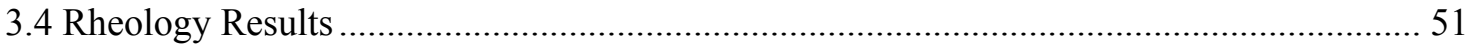

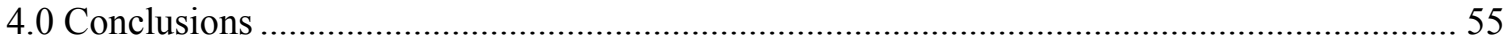


SRNL-STI-2011-00075

Revision 0

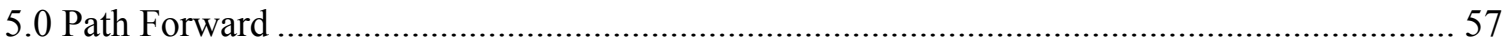

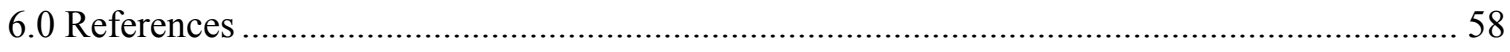

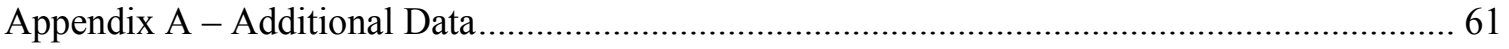




\section{LIST OF TABLES}

Table 1. Distribution of SB10 oxides in SRAT receipt slurry................................................. 14

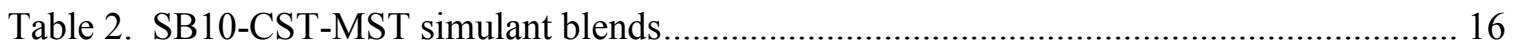

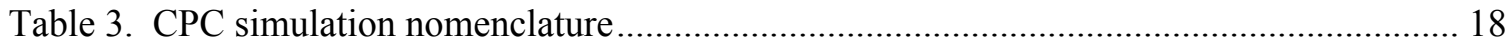

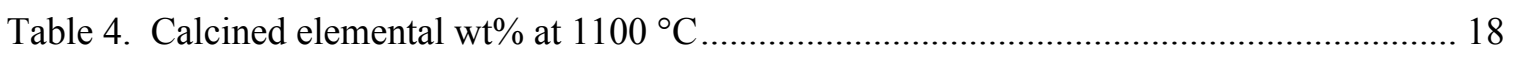

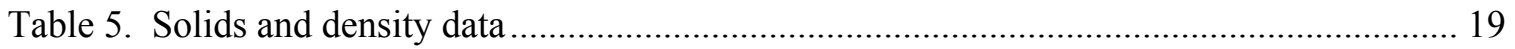

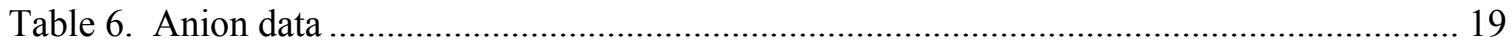

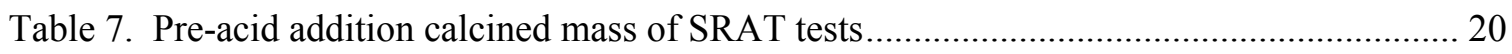

Table 8. Stoichiometric acid calculation results, moles acid/L slurry ......................................... 21

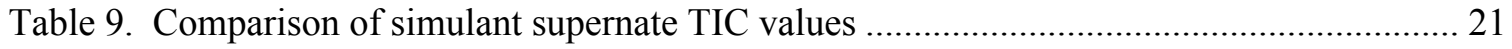

Table 10. Individual contributions to stoichiometric acid calculation in SCIX4 ........................ 22

Table 11. Noble metal and mercury concentrations, wt $\%$ dried solids ...................................... 22

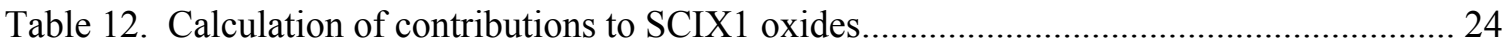

Table 13. SCIX1 without CST and MST versus baseline sludge composition ............................. 25

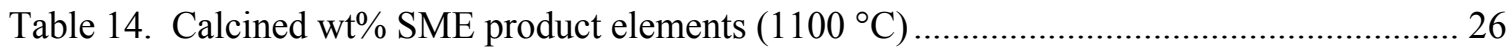

Table 15. Dissolved element concentrations, $\mathrm{mg} / \mathrm{L}$, following acid addition .............................. 27

Table 16. Percent of element dissolved following acid addition.................................................. 28

Table 17. Percent of element dissolved during reflux - low acid ................................................ 29

Table 18. Percent of element dissolved during reflux - high acid ........................................... 30

Table 19. Percent of element dissolved - SCIX4 alpha strike test comparison ........................... 32

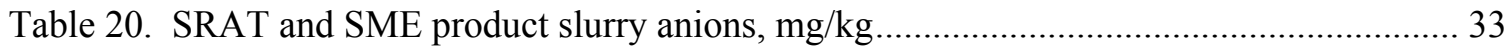

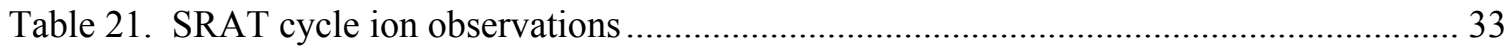

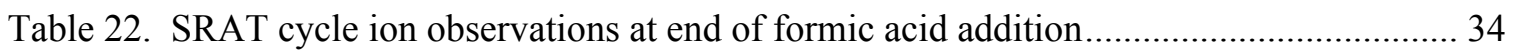

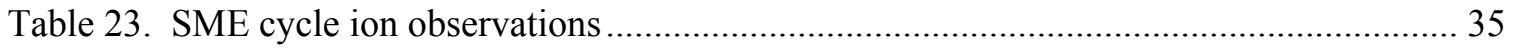

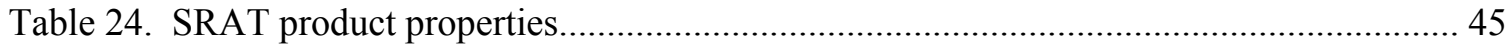

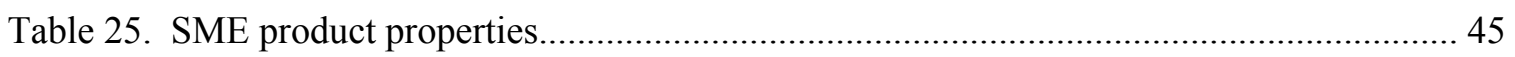

Table 26. REDOX Comparison - Predicted versus Measured.................................................... 51

Table 27. Comparison of simulants with/without CST and MST ............................................ 51

Table 28. Impact of caustic boiling on simulants containing CST and MST ............................... 52

Table 29. Comparison of SRAT products with/without CST and MST ...................................... 52

Table 30. Comparison of fresh SME products with/without CST and MST ............................... 53

Table 31. Comparison of aged SME products with/without CST and MST .............................. 53

Table 32. Comparison of 8-week settled SME products with/without CST and MST ................ 54

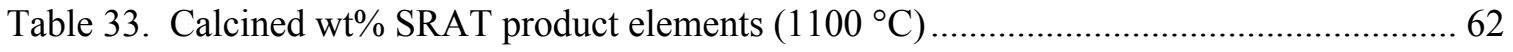




\section{LIST OF FIGURES}

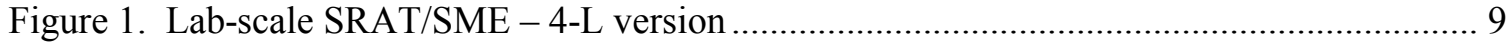

Figure 2. Evolution of oxide fraction versus SRAT cycle number ........................................... 14

Figure 3. Drum 4-A CST particle size distribution ( $\mathrm{M}_{\mathrm{V}}=1.53$ micron) ...................................... 16

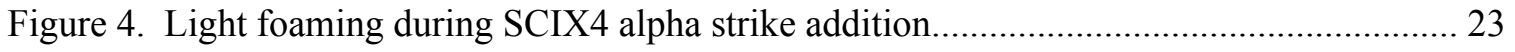

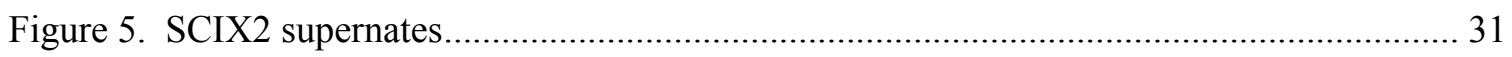

Figure 6. Low acid hydrogen generation comparison - SRAT ................................................... 36

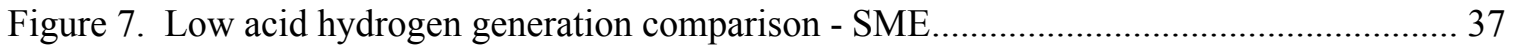

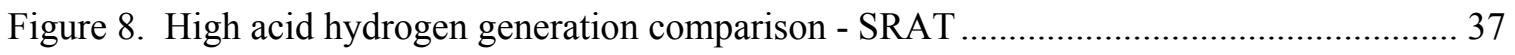

Figure 9. High acid hydrogen generation comparison - SME .............................................. 38

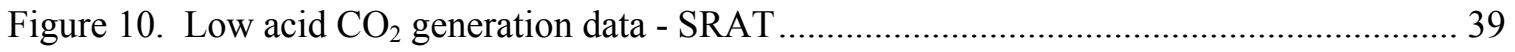

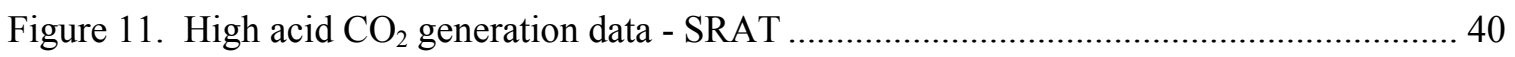

Figure 12. High acid $\mathrm{CO}_{2}$ generation data - SRAT boiling .................................................... 40

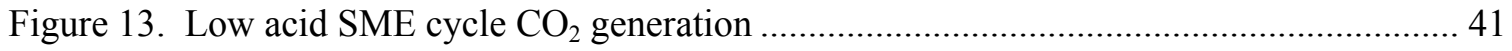

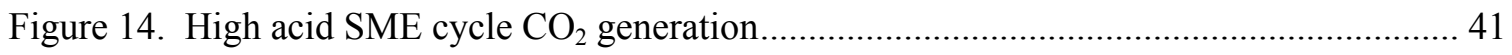

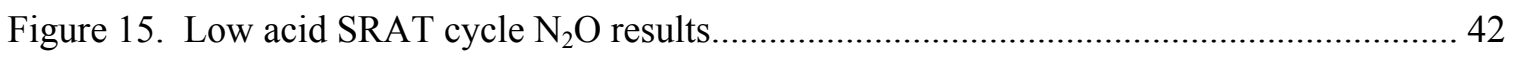

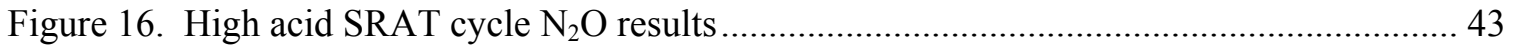

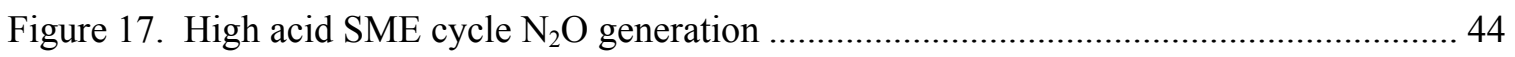

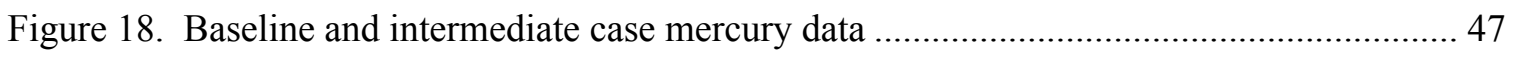

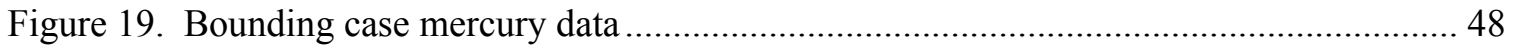

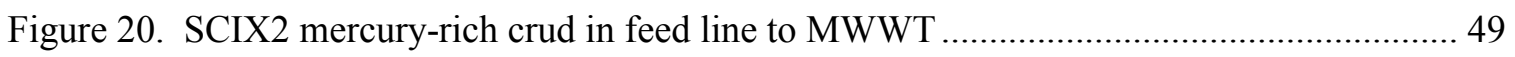

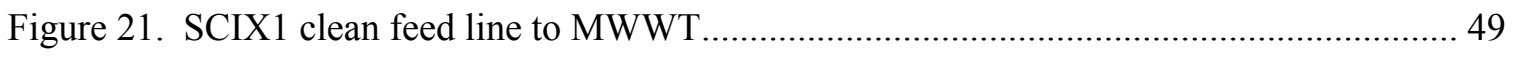

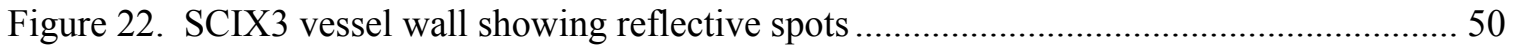

Appendix

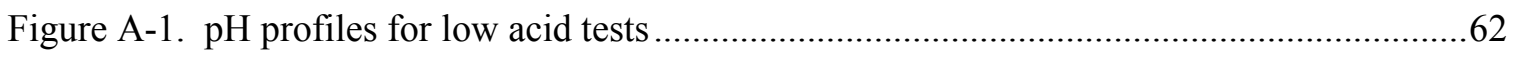

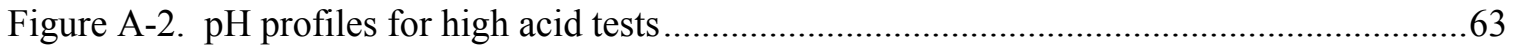


SRNL-STI-2011-00075

Revision 0

\section{LIST OF ABBREVIATIONS}

$\begin{array}{ll}\text { ACTL } & \text { Aiken County Technology Laboratory } \\ \text { AD } & \text { Analytical Development } \\ \text { ARP } & \text { Actinide Removal Process } \\ \text { CPC } & \text { Chemical Processing Cell } \\ \text { CS } & \text { Calcined solids } \\ \text { CSSX } & \text { Caustic Side Solvent Extraction } \\ \text { CST } & \text { Crystalline Silicotitanate } \\ \text { DI } & \text { De-ionized } \\ \text { DS } & \text { Dissolved Solids } \\ \text { DWPF } & \text { Defense Waste Processing Facility } \\ \text { E\&CPT } & \text { Environmental and Chemical Processing Technology } \\ \text { FAVC } & \text { Formic Acid Vent Condenser } \\ \text { GC } & \text { Gas Chromatography } \\ \text { GFPS } & \text { Glass Feed Preparation System } \\ \text { IC } & \text { Ion Chromatography } \\ \text { ICP-AES } & \text { Inductively Coupled Plasma-Atomic Emission Spectroscopy } \\ \text { IS } & \text { Insoluble solids } \\ \text { MCU } & \text { Modular CSSX Unit } \\ \text { MST } & \text { Monosodium Titanate } \\ \text { MWWT } & \text { Mercury Water Wash Tank } \\ \text { NIST } & \text { National Institute of Standards and Technology } \\ \text { PSAL } & \text { Process Science Analytical Laboratory } \\ \text { RedOx } & \text { Reduction-Oxidation } \\ \text { SB10 } & \text { Sludge Batch 10 } \\ \text { SCIX } & \text { Small Column Ion Exchange } \\ \text { SME } & \text { Slurry Mix Evaporator } \\ \text { SRAT } & \text { Sludge Receipt and Adjustment Tank } \\ \text { SRNL } & \text { Savannah River National Laboratory } \\ \text { SRS } & \text { Savannah River Site } \\ \text { SS } & \text { Soluble solids } \\ \text { SWPF } & \text { Salt Waste Processing Facility } \\ \text { TIC } & \text { Total inorganic carbon } \\ \text { TS } & \text { Total solids } \\ \text { TTAQP } & \text { Task Technical and Quality Assurance Plan } \\ \text { TTR } & \text { Task Technical Request } \\ \text { VSL } & \text { Vitreous State Laboratory } \\ & \end{array}$




\subsection{Introduction}

Background information relevant to this task is covered in this section, including a description of the scope of work, the portion of the scope covered by this report, an overview of how salt processing at the Savannah River Site (SRS) is anticipated to integrate into the Defense Waste Processing Facility (DWPF), and a review of prior work on the impact of alternative salt processing technologies on DWPF.

\subsection{Authorization and Scope for the Task}

The Environmental and Chemical Process Technology (E\&CPT) Research Programs section of Savannah River National Laboratory (SRNL) was requested to evaluate the impact of the proposed Small Column Ion Exchange (SCIX) salt treatment process on the DWPF Chemical Processing Cell (CPC). ${ }^{1}$ A "Task Technical and Quality Assurance Plan" (TTQAP) was issued in response to a Technical Task Request (TTR). ${ }^{2}$ The TTQAP considers the combined impact of the proposed SCIX process operated in parallel with the Salt Waste Processing Facility (SWPF) currently under construction at the SRS.

The ultimate purpose of this task was to conduct lab-scale testing to evaluate the behavior and performance of monosodium titanate (MST) and ground crystalline silicotitanate (CST) when added to the feed for the DWPF Sludge Receipt and Adjustment Tank (SRAT) during CPC preparation of melter feed. The experimental testing was divided into several phases. The initial phase was conducted with available MST and ground CST material (not irradiated). It used the baseline DWPF flowsheet and current assumptions for the bounding process volumes of MST and CST. The second phase was conducted with irradiated MST and CST that became available in December of 2010. A fully coupled CPC flowsheet was also tested (DWPF with SCIX and SWPF operating in parallel). If changes to the SCIX flowsheet are identified, or if a new flowsheet (i.e. alternative reductant) is chosen for DWPF, then a third phase of evaluation/testing could be performed to confirm that the findings from the initial phases are still valid.

The above TTR requested SRNL to validate the existing DWPF flowsheet and to establish a coupled operations flowsheet (sludge, MST/sludge, cesium strip effluent, and SCIX streams) for use with compositions representative of sludges to be processed starting in the 2014 time period. Simulated sludge, SWPF MST/entrained sludge, SWPF strip effluent, and SCIX streams (MST and CST) were used to conduct these studies. The overall evaluation included calculations, paper studies, and scoping DWPF flowsheet simulations in order to:

- Define a realistic bounding composition of MST and CST for testing.

- Prepare simulants for CPC testing at bounding and intermediate MST and CST concentrations.

- Determine hydrogen and other off-gas generation rates with varying quantities of acid during CPC operations.

- Find the acid quantities and processing times required for mercury removal, nitrite destruction, reduction-oxidation (REDOX) control, and rheology adjustments in the SRAT.

- Perform a parametric study of the SRAT and Slurry Mix Evaporator (SME) cycles.

- Validate the weight percent total solids and target waste loadings for the SME used in the Liquid Waste System plan requirements, SRR-LWP-2009-00001, Rev. 15 (50\% total solids, $40 \%$ waste loading). 
- Make any observations of foaming, air entrainment, and/or loss of heat transfer capabilities in the SRAT/SME or any indication of excessive off-gas deposits leading to potential plugging of equipment.

- Measure flow curves and calculate rheological model parameters (yield stress and plastic viscosity) for the SRAT and SME product slurries.

- Identify any significant impact of irradiation on the two titanate species with regards to hydrogen generation and other CPC processing concerns.

- Evaluate the suspension characteristics of settled SME slurry solids using rheological vane measurements.

Future testing could include work related to the following:

- Follow-up testing based on changes to the SCIX and/or DWPF flowsheets defined as changes are made. Extensive changes may require more than simple confirmatory testing.

- The impact of in-tank aluminum dissolution on sludge containing CST and MST may be investigated to determine if the downstream (DWPF) processing properties are altered differently than when CST and MST are absent.

The impact studies of coupled operations and of irradiation of CST and MST have been completed as part of Phase II along with all of the planned flowsheet testing for Phase I. These results are presented in Section 3.0 of this report. The aluminum dissolution study, if performed, would complete Phase II as laid out in the TTQAP. Significant SCIX or DWPF flowsheet changes would constitute Phase III, should it become necessary.

\subsection{Salt Waste Processing at SRS}

Tank Farm radioactively contaminated waste at SRS can be broadly divided into two types, sludge waste containing the insoluble materials, and salt waste containing water soluble contaminants combined with sodium salts. SRS currently has two salt waste treatment processes operating in series to reduce the volume of salt waste. The Actinide Removal Process (ARP) is a small scale version of the first part of the SWPF process (alpha strike). ARP uses MST addition to sorb strontium and actinides from salt solutions. Its impact on the DWPF has already been evaluated in that context, and the MST waste slurry is currently being processed through the DWPF.

ARP is used to prepare feed for the Modular CSSX Unit (MCU), where CSSX stands for Caustic Side Solvent eXtraction. The ARP/MCU combination constitutes a pilot scale version of the SWPF. The impact of CSSX on DWPF has also been evaluated, and the MST and cesium-rich wastes are currently being processed through the DWPF. ARP/MCU supplies decontaminated salt solution to the SRS Saltstone facility. The Saltstone facility, which is also currently operational, takes the treated salt waste and converts it into a cementitious waste form for permanent storage at SRS. DWPF is presently able to process with sludge only, sludge plus ARP, sludge plus MCU, or sludge plus both using a common processing strategy and frit.

Both SCIX and SWPF will use MST to sorb strontium and actinides from the aqueous salt waste. SCIX will perform MST sorption in one of the million gallon waste tanks at SRS, e.g. Tank 41. SWPF will have dedicated equipment for actinide removal, or an "alpha strike", on the front end of the process. SWPF follows actinide removal with solvent extraction of cesium. The postextraction salt solution is suitable to send to Saltstone. SCIX uses ion exchange columns to 
remove cesium and also produces a decontaminated salt solution that is suitable to send to Saltstone.

The radioactive elements recovered during salt processing by ARP, MCU, SWPF, and SCIX are all intended to eventually combine with the radioactive waste sludge (the insoluble radioactive wastes) in the DWPF CPC. There they will subsequently be converted into a stable glass waste form in the DWPF melter and poured into stainless steel canisters for geologically long term storage. Additional waste streams may also be fed to DWPF for conversion into glass waste forms. Examples include the products from fluidized bed steam reforming (projected to be used to remove the waste in Tank 48) and some of the materials recovered during tank cleaning and canyon closure operations.

The radionuclide enriched salt waste processing byproduct streams are sent to DWPF by different routes. MST from the SCIX process is to be sent to a DWPF sludge batch preparation (wash) tank (e.g. Tank 51 today). Transfers are projected to occur several times per year. Should partial desorption of the actinides occur after transfer, the majority of any stable dissolved species would be returned to the Tank Farm during sludge batch washing operations. Freshly precipitated actinides, however, should remain in the tank. MST from SWPF is to be sent to DWPF for subsequent direct addition to the DWPF SRAT in the CPC. The SCIX ion exchange resin is CST. Once CST is loaded with cesium, the CST will be ground to reduce particle size and transferred to the DWPF sludge batch feed tank (e.g. Tank 40). Any potential desorbed cesium would be fed to DWPF, unless it became necessary to decant excess aqueous phase material from the DWPF feed tank. In that case, desorbed cesium would be recycled to the Tank Farm for subsequent reprocessing. Cesium recovered in SWPF will be sent in a dilute acid stream directly to DWPF, where the original plan was to add it to the SRAT at boiling following acid addition.

SCIX approaches half of SWPF in capacity in terms of volume of salt solution processed per year. Operating both processes in parallel increases the rate that salt waste can be processed at SRS and accelerates closure of the SRS waste storage tanks. Consequently, combined salt processing can increase the rate that salt processing effluents are sent to DWPF by about 1.3-1.5 times as much compared to SWPF alone. SRNL has done some prior work on the impact of MST from the ARP on DWPF which is analogous to the SWPF alpha strike though smaller in magnitude. SRNL has also done some prior work on the impact of CST on DWPF as part of the evaluation of alternative salt processing technologies to replace the tetraphenyl borate in-tank precipitation process in the late 1990's. None of the prior DWPF CPC impact evaluation work, however, has considered MST and CST in combination or at the levels now projected.

\subsection{Review of Prior CPC Work Related to CST and MST}

\subsubsection{CST Studies}

CST was designed to sorb Cs-137, Sr-90, and several other radionuclides from highly alkaline solutions containing large quantities of sodium. Oak Ridge National Laboratory demonstrated the sorption effectiveness prior to vitrification of the cesium-loaded CST plus glass formers in the SRNL Shielded Cells. ${ }^{3}$ An alternative to the original SRS in-tank precipitation process for salt waste treatment was developed based on CST technology. This process involved removal of strontium and actinides with MST followed by treatment of the partially treated salt solution in large CST ion exchange columns for cesium removal. Preliminary assessments of potential DWPF impacts from CST were made in the 1998-2000 period. 
The first CPC impact study was completed using HM (outdated, but near bounding) levels of noble metals and mercury. ${ }^{4}$ HM waste was produced by the $\underline{H}$-Canyon Modified Purex separation process. (The HM basis is now known to overstate the significance of palladium relative to rhodium and ruthenium.) Three size ranges of CST were tested with what is now referred to as Sludge Batch 1B (SB1B) simulant. CST was present at a concentration equivalent to $10 \%$ in the glass waste form. Up to $40 \%$ more hydrogen was produced in the SRAT and $10 \%$ in the SME in the tests with CST compared to the baseline test. CST size was not a factor. The Dow Corning antifoam used in those tests performed poorly with and without CST in the system (Dow Corning antifoam is no longer used in DWPF).

Larger scale testing of CST with SB1B simulant was completed in the $1 / 240^{\text {th }}$ scale Glass Feed Preparation System (GFPS) in 1999 (scaled by volume, or about $1 / 6^{\text {th }}$ scale linearly). ${ }^{5}$ Testing was performed with nominal sized CST and with size-reduced CST. SB1B levels of mercury and noble metals were used. No increase in hydrogen generation was seen in the SRAT cycle when CST loaded with non-radioactive cesium and noble metals was present compared to baseline tests. SME cycle hydrogen increased with size-reduced CST and decreased with as-received CST relative to the baseline. Changes in hydrogen generation rates were relatively modest.

Supporting bench scale testing to the GFPS runs showed no increase in hydrogen generation relative to the baseline case, but indicated that size-reduced CST created a more catalytically active system than as-received CST. ${ }^{6}$ The GFPS testing produced sufficient SME product to perform pilot-scale testing of the DWPF Hydragard ${ }^{\mathbb{R}}$ sampler. $^{7}$ The testing showed that sizereduced CST sampled in a representative manner, and that it also had no adverse impact on the sludge to frit ratio at the Hydragard ${ }^{\mathbb{B}}$ sample point relative to grab samples of the bulk tank contents. An earlier phase of Hydragard ${ }^{\mathbb{B}}$ testing confirmed that as-received CST would plug the sampler. It was recognized that nominal size CST particles were not an acceptable feed to DWPF, and CPC further testing with as-received CST was halted.

Rheology work was performed in support of the above testing using slurries with size-reduced CST. ${ }^{8,9}$ Two 1999 melter feeds, one $35 \%$ sludge and $65 \%$ frit on an oxide basis, and one $26.7 \%$ sludge, $8.3 \% \mathrm{CST}$, and $65 \%$ frit on an oxide basis, were compared over the range of $39-51 \mathrm{wt} \%$ total solids. Rheological properties were nearly identical. Conversely, two 2000 melter feeds, one $26 \%$ sludge and $74 \%$ frit on an oxide basis, and the other $25.5 \%$ sludge, $7.1 \%$ CST, and $67.4 \%$ frit on an oxide basis showed a three-fold increase in yield stress for the melter feed containing CST. The primary difference between the two studies was that in the 1999 study, CST displaced sludge oxides while in the 2000 study CST displaced frit oxides. The rheological behavior is what would be expected if size-reduced CST acted more like sludge than frit. The follow-up study indicated that the increase in yield stress of the 2000 CST melter feed was equivalent to about a $4-5 \%$ increase in sludge oxide content. The ratio of $7.1 \%$ CST to the $4-5$ wt $\%$ sludge oxides that were relatively equivalent rheologically becomes close to one when the values are converted to wt\% insoluble oxides on a dried solids basis (the calcine factor for the sludge solids was roughly 0.79 for SB1B simulant). This calculation confirmed that the sizereduced CST was similar, but not identical, to insoluble sludge solids rheologically.

CST impact studies on DWPF were terminated following the recommendation of an external technical review board that SRS pursue cesium solvent extraction as the preferred technology for the alternative salt waste processing facility. Glass impact studies were also performed during the period of the CPC and rheology testing, but those results are more relevant to the updated glass studies being performed and reported in 2010-2011 and are not discussed further here. 


\subsubsection{MST Studies}

A decision was made to construct two interim salt waste processing facilities at SRS in order to accelerate salt waste processing which otherwise would not commence until the commissioning of SWPF. One facility would use the CSSX chemistry to remove cesium combined with the MST sorption of actinides. The result was the Modular CSSX Unit (MCU). The MCU also was used to test solvent extraction processing of real wastes at roughly pilot plant scale.

The second facility was ARP. ARP used MST sorption in existing spare tanks. ARP processes contaminated salt solution in upstream of MCU. Studies of the impact of ARP on the DWPF CPC began near the time that Sludge Batch 3 (SB3) was being readied for transfer into the DWPF feed tank. MCU studies began in earnest during simulant testing for Sludge Batch 4 (SB4).

The ARP process produced a stream containing MST to be sent to the DWPF SRAT that was higher in soluble acid consumers and lower in insoluble acid consumers than the typical DWPF sludge waste feed. Consequently, the stream would need to be added to the SRAT at boiling while still caustic in order to concentrate it to sludge solids levels. If this were not done, the mass of equivalent sludge oxides produced per SRAT batch would fall, and this would adversely impact waste throughput in DWPF (installing a larger volume SRAT was not considered a viable option). The ARP boiling period, however, added to the overall SRAT batch cycle time.

Additional acid demand was also identified in the ARP stream. The SRAT would have to be sampled after ARP addition/concentration to determine the combined acid requirement due to the sludge waste-ARP waste combination. At the time that this decision was made, the CPC was not the rate-limiting part of DWPF. The extended hold point for SRAT receipt sampling following ARP addition, plus additional boiling time, would potentially cause the $\mathrm{CPC}$ to become ratelimiting. The coupled CPC operations became rate limiting for DWPF when processing mercuryrich sludges that required more than 12 hours of SRAT reflux time to strip mercury down to the SRAT product mercury specification $(0.45 \mathrm{wt} \%$ in the SRAT product solids at that time $)$.

Several strategies for combining ARP waste with sludge were documented along with an evaluation of the impact of the ARP on hydrogen generation. ${ }^{10,11}$ The ARP addition strategies that were investigated considered various sequences of combining and concentrating a volume of ARP (1,000-3,000 gallons) with 6,000 gallons of fresh sludge waste (divided into two 3,000 gallon transfers) in the SRAT. All sequences tested performed about equally well. Tests did not indicate any foaminess at boiling, but subsequent radioactive tests in the SRNL Shielded Cells and DWPF operational experience both indicated that foaminess is a processing issue during caustic boiling.

The ARP hydrogen generation study considered a bounding volume of 9,000 gallons of ARP combined into 6,000 gallons of fresh sludge in the SRAT. This study showed a potential weakness in the DWPF stoichiometric acid equation developed by Hsu and Marek. Early DWPF sludge batches required $125-150 \%$ or more of the calculated stoichiometric demand to achieve nitrite destruction and produce rheologically acceptable slurries as well as causing catalytic hydrogen generation to occur in the SRAT rather than in downstream equipment. The ARP contribution to the total demand appeared to be satisfactorily processed with roughly $100 \%$ of the calculated requirement. Consequently, a SRAT batch with a bounding ARP volume had a significant increase in the calculated stoichiometric acid demand (due to the presence of a maximum ARP demand in addition to the sludge demand). The application of a stoichiometric correction factor developed for sludge-only processing (125-150\%) caused a significant increase 
in the quantity of excess acid, since the factor was excessive for the fraction of the calculated total SRAT acid demand that originated in the ARP stream. The increased excess acid led to an increase in hydrogen generation rate that exceeded the DWPF SRAT limit in SB3 testing. It was recommended that the stoichiometric correction factor be lowered as the volume of ARP added to a SRAT batch was increased to compensate for this potential issue in future sludge batches. ${ }^{11}$

SB4 testing focused on the impact/fate of the organic solvents present in the strip effluent stream containing the cesium removed in MCU. Since prior SRAT simulation work had shown a tendency for the nitrite ion to react with certain organic species to form tarry compounds, it was recommended that the strip effluent be added to the SRAT following the post-acid addition dewatering step (after which the majority of the nitrite was destroyed). It was also desired to add the strip effluent solvent to the SRAT at boiling to prevent build-up of volatile organic compounds in the vessel. Volatile organic compounds contribute to the flammability concerns in the CPC off-gas system. Lab-scale testing proceeded with the post-acid addition at boiling strategy. The simulated MCU strip effluent was added to the SRAT at a rate equivalent to the SRAT boil-up rate (approximately constant volume operation).

Two sets of five consecutive SRAT simulations were performed to study organic accumulation in the CPC equipment. ${ }^{12,13}$ Isopar $^{\circledR} \mathrm{L}$ mostly went into the CPC off-gas system where only small amounts were condensed by the SRAT condenser and chilled Formic Acid Vent Condenser (FAVC). Of these, more was found in post-run vessel solvent rinses than in the actual condensate samples removed during processing. Roughly half of the organic "modifier" remained in either the SRAT product or the SRAT vessel. Some evidence for chemical modification and decomposition of the modifier was evident in mass spectrometry scans on the samples.

Simulant flowsheet testing for Sludge Batches 5, 6, and 7 (SB5-SB7) have each included one demonstration run of the coupled flowsheet. These have ARP slurry addition and concentration prior to acid addition at a ratio of 7,000 gallons ARP to 6,000 of fresh sludge and MCU strip effluent addition following acid addition and dewatering at a ratio of 8,000 gallons of MCU effluent per 6,000 gallons of fresh sludge. These values bound those in an earlier material balance document. ${ }^{14}$ The CPC tests are performed to demonstrate that the chosen acid addition strategy is suitable to meet DWPF processing goals. The simulated MCU stream for these tests has been made by preparing a $0.033 \mathrm{M}$ nitric acid solution with no organics, since a single SRAT/SME experiment has a very limited potential for monitoring the trace organic species (also the organic impact on processing was minimal, and such testing is quite costly). The processing data, however, do include the impact of the MST contribution from the ARP stream. The three coupled flowsheet tests for SB5-SB7 were all successfully completed using the recommended stoichiometric acid correction factor developed from the simpler simulant SRAT simulations.

\subsubsection{Open Questions from Prior Work}

Based on the body of prior work with MST and CST separately, it was anticipated that there might be some new issues with hydrogen generation, rheology, foaminess, CST behavior during caustic boiling, etc. associated with the larger quantities of MST and CST being proposed with SCIX versus the amounts present in prior tests. In addition, the previous tests were never performed with significant amounts of CST and MST together in the equipment at the same time, so any potential interaction between CST and MST could have escaped detection. Concerns here included potential rheological interactions under both caustic and acidic conditions at elevated temperatures up to and including boiling. 
SRNL-STI-2011-00075

Revision 0

\subsection{Experimental Procedure and Analytical Methods}

The CPC testing with SCIX involved special simulant preparations, simulant characterizations, CPC simulations, and supporting rheology work. A description of the experimental procedures and analytical methods is given in this section of the report.

\subsection{Simulant Preparation}

SB10 simulant was prepared for the study of the proposed Tank 48 steam reforming impact on the DWPF CPC. ${ }^{19}$ This study occurred shortly before the beginning of the SCIX impact study. SB10 is the batch that Tank 48 steam reforming is most likely to impact, and it was also projected to be one of the higher acid demand sludge batches in the future (i.e. a conservative choice for the SCIX testing). SB10 simulants containing varying amounts of CST and MST were prepared for this study. Both as-received CST and MST slurries were washed with SB10 supernate 4-5 times and then trimmed to the target supernate $\mathrm{wt} \%$ solids using sodium salts in the same ratios as in the SB10 supernate. The adjusted CST and MST slurries were higher in insoluble solids than the SB10 simulant.

Blends for the CPC simulations were then prepared from combinations of SB10 simulant, adjusted CST simulant, adjusted MST simulant, SB10 supernate, and de-ionized (DI) water to simulate a bounding case, an intermediate case, a bounding case with the alpha strike MST held out, and a bounding case with the CST and some MST held out for irradiation (additional details on the tests are given in Section 3). Irradiation delivered a $100 \mathrm{Mrad}$ dose to the slurries during 346 hours in the SRNL ${ }^{60}$ Co source. Each unique simulant blend was subsequently characterized for chemical composition, solids content, density, and rheology.

\subsection{Process and Sample Analytical Methods}

CPC testing was performed in the SRNL 4-L lab-scale SRAT/SME equipment at the Aiken County Technology Laboratory (ACTL). The automated data acquisition system developed for the 4-L SRAT rigs was used to collect electronic data on a computer. Collected data included SRAT slurry temperature, constant temperature water bath temperatures feeding the SRAT condenser and FAVC, slurry $\mathrm{pH}$, SRAT mixer speed and torque, and air and helium purge flows (helium is used as an internal standard and is set to $0.5 \%$ of the nominal SRAT air purge flow while air is set to 99.5\%). Cumulative acid addition volume data were collected from the automated dispensers using an algorithm that matches the indicated total on the dispenser.

Raw gas chromatograph (GC) data were acquired on separate computers dedicated to each instrument. Back-up computer and GC data were recorded manually at 20 minute intervals. Vessel pressure was recorded manually at these times. Condensate production rate at boiling was determined using a volume calibrated Mercury Water Wash Tank (MWWT) and a stop watch. The condensate rate was adjusted to the target rate by manually changing the power input to the SRAT heating mantle.

The chilled off-gas leaving the FAVC was passed through a Nafion dryer in counter-current flow with a dried air stream to reduce the moisture content at the GC inlet. Agilent 3000A micro GC's 
were used on all five new runs as well as the two earlier baseline runs. The GC columns were baked out before runs. Column-A in the GC can collect data related to $\mathrm{He}, \mathrm{H}_{2}, \mathrm{O}_{2}, \mathrm{~N}_{2}, \mathrm{NO}$, and $\mathrm{CO}$, while column-B can collect data related to $\mathrm{CO}_{2}, \mathrm{~N}_{2} \mathrm{O}$, and water. GC's were calibrated with National Institute of Standards and Technology (NIST) traceable standard calibration gases containing $0.499-0.500$ vol $\% \mathrm{He}, 1.000$ vol $\% \mathrm{H}_{2}, 20.00$ vol $\% \mathrm{O}_{2}, 51.50-51.511 \mathrm{vol} \% \mathrm{~N}_{2}, 24.49$ $24.50 \mathrm{vol} \% \mathrm{CO}_{2}$, and $2.50 \mathrm{vol} \% \mathrm{~N}_{2} \mathrm{O}$ (several different calibration gases were used; each individual calibration gas had a precisely defined concentration for each gas, not a range). The calibration was verified prior to starting the SRAT cycle and after completing the SME cycle. Room air was used to give a two point calibration for $\mathrm{N}_{2}$, which has a mildly nonlinear response over the range of $0-80 \%$. No evidence for $\mathrm{CO}$ generation was obtained while examining the region of the chromatogram where it would elute ( $\mathrm{CO}$ was not expected based on results from the past ten years).

Process samples were analyzed by various methods. Slurry and supernate elemental compositions were determined by inductively coupled plasma-atomic emission spectroscopy (ICP-AES) at the Process Science Analytical Laboratory (PSAL). Slurry samples were calcined at $1100^{\circ} \mathrm{C}$. The main advantage of this approach is to permit easier comparisons between SRAT product elements and sludge elements to confirm proper SRAT batching. Noble metals and mercury are trimmed uniquely to each SRAT, and their concentrations are known more accurately from material balance considerations than they could be from ICP-AES analyses. The noble metals are sufficiently small in concentration that they do not impact the values for the sludge elements, while mercury is converted to volatile elemental mercury which should be lost during calcination.

SRAT cycle, SRAT product, and SME product slurry mercury samples were submitted to PSAL for elemental analysis by ICP-AES. Selected dewatering condensate samples were checked for dissolved mercury by ICP-AES. Soluble slurry anions were determined by ion chromatography (IC) on 100-fold weighted dilutions of slurry with water followed by filtration to remove the remaining insoluble solids. Samples of SRAT cycle slurries, SRAT and SME product slurries, and SRAT and SME cycle condensates were analyzed by Analytical Development (AD) using cation chromatography for ammonium ion (cation IC).

Slurry base equivalents (as equivalent moles $\mathrm{NaOH}$ per kg slurry) were determined by the PSAL auto titrator on 20-fold diluted samples of the various starting slurries titrated with $0.1 \mathrm{M} \mathrm{HCl}$ solution to a $\mathrm{pH} 7$ endpoint. Analytical and process $\mathrm{pH}$ probes were calibrated against standard solutions at $\mathrm{pH} 4$ and 10, and then checked against a $\mathrm{pH} 7$ standard. Samples of the various starting simulants, as well as a SRAT receipt sample following the alpha strike addition in the extended processing run, were submitted to AD for total inorganic carbon analysis of both the starting slurry and the slurry supernate. Samples were analyzed by PSAL for both slurry and supernate density using the Anton-Parr instrument. Supernate was obtained by centrifuging slurry well past the point of visual clarity and then drawing sample aliquots from the clear liquid.

\subsection{SRAT/SME Simulation Procedure}

The 4-L lab-scale SRAT equipment was used for these tests. CPC simulations were performed in pairs in adjacent hoods except for the last (fifth) one. Round-the-clock operations were used to simulate actual DWPF processing. The trimmed SRAT receipt volume was about 2.9 L. A photo of the 4-L rig with the ammonia scrubber is shown in Figure 1. 


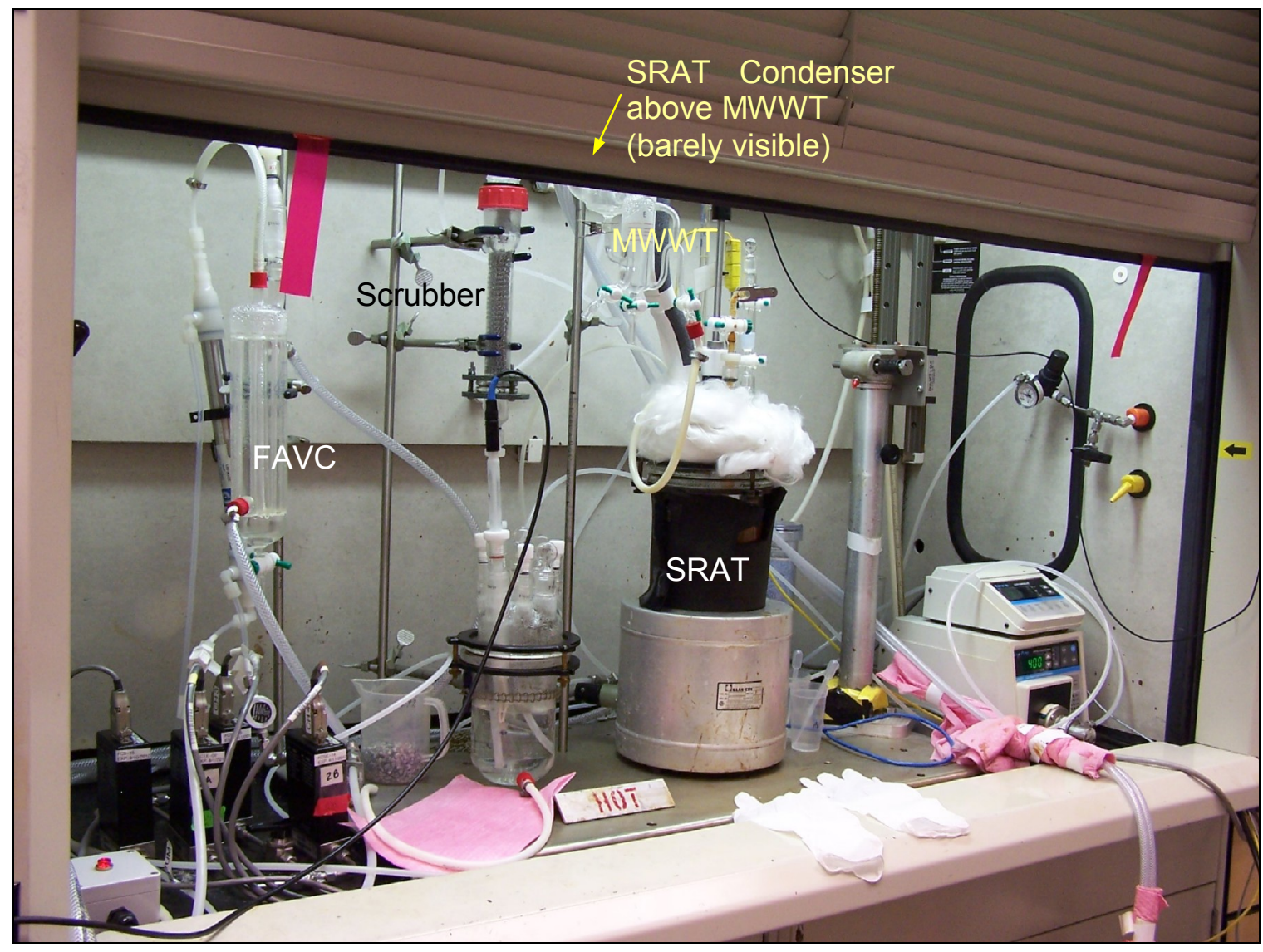

Figure 1. Lab-scale SRAT/SME - 4-L version

The reservoir below the ammonia scrubber was charged with a solution of $749 \mathrm{~g}$ of DI water and $1 \mathrm{~g}$ of $50 \mathrm{wt} \%$ nitric acid. This solution was recirculated by a MasterFlex driven Micropump ${ }^{\mathbb{B}}$ gear pump at about $300 \mathrm{~mL}$ per minute to a spray nozzle at the top of the packed section. The scrubber was operated to collect ammonia released into the SRAT or SME off-gas stream for quantification. The scrubber was designed to recover as much ammonia vapor as possible rather than to model the performance of the DWPF ammonia scrubbers.

Initial acid addition calculations were based on the Koopman minimum acid requirement equation. ${ }^{21}$

$$
\frac{\text { moles acid }}{\text { L slurry }}=\text { base equivalents }+H g+\text { soluble } T I C+1.5 *(C a+M g)+1.0 * \text { nitrite }+1.5 * M n
$$

TIC is total inorganic carbon. Two different stoichiometric adjustment factors were used in the seven acid calculations, $100 \%$ and $150 \%$. Acid calculations were also performed using the current DWPF algorithm for comparison:

$$
\frac{\text { moles acid }}{L \text { slurry }}=\text { base equivalents }+2 * \text { total TIC }+0.75 * \text { nitrite }+1.2 * \mathrm{Mn}+\mathrm{Hg}
$$

The results of these two calculations for the various simulants are summarized in Section 3.3. 
Total acid was partitioned between formic and nitric acids using the latest REDOX equation. ${ }^{15}$ Assumptions of $15-30 \%$ formate losses and of 5\% to $15 \%$ nitrite-to-nitrate conversions were also needed to enable this calculation to be performed. These assumptions gave the fraction of the total acid moles that was formic acid in the range of $0.83-0.88$.

Scaled design basis DWPF SRAT/SME processing conditions were generally used. The SRAT and SME cycles, however, did not have a heel from a prior batch. The acid calculation was based on the original simulant composition, not on a sample taken after caustic boiling at reflux. Since no additions or removals (other than samples) were made, the concentrations of the acid consumers historically remain constant within our ability to pull a representative slurry sample from the SRAT vessel and get a new analysis. Off-gas data show no evolutions of $\mathrm{NO}_{\mathrm{x}}$ or $\mathrm{CO}_{2}$ during caustic boiling that might suggest chemical reactions were occurring that could modify the acid requirement. The total acid addition (moles of acid) was adjusted for the mass of SRAT slurry removed as samples prior to acid addition.

The processing strategy used was as follows:

- $\quad$ The SRAT air purge was scaled to $230 \mathrm{scfm}$ in DWPF.

- A 200 ppm antifoam addition was made prior to caustic boiling.

- Caustic sludge was boiled for a minimum of two hours when CST or MST was present.

- Sludge was cooled to $93^{\circ} \mathrm{C}$ for nitric acid addition.

- A 100 ppm antifoam addition was made following nitric acid addition.

- Formic acid addition was made at $93{ }^{\circ} \mathrm{C}$.

- Both acids were added at two gallons per minute scaled from 6,000 gallons to $2.5 \mathrm{~L}$.

- A 500 ppm antifoam addition was made following formic acid addition.

- Boiling assumed a condensate production rate of 5,000 lbs/hr at DWPF scale.

- SRAT dewatering took about three hours to produce a $25 \mathrm{wt} \%$ total solids slurry.

- Reflux followed dewatering. The end of the 12-hour reflux period defined the end of the SRAT cycle (about 15 total hours at boiling).

- The SME air purge was scaled to $74 \mathrm{scfm}$ in DWPF.

- A 100 ppm antifoam addition was made at the start of the SME cycle.

- Two frit-water-formic acid additions were made targeting $40 \%$ waste oxide loading.

- The SME was dewatered following each frit slurry addition.

- The final SME solids target was $50 \mathrm{wt} \%$.

Further lab-scale operational details are given in the current version of the CPC simulation procedure. ${ }^{16}$ A sample was taken following caustic boiling to check for adverse impacts on slurry rheology. Ten to fifteen samples were taken during the SRAT cycle to monitor major reactions. Major species were checked immediately after acid addition. Samples were pulled during boiling to monitor suspended and dissolved mercury in the SRAT slurry. These samples were pulled directly into digestion vials to eliminate potential segregation of mercury during subsampling/aliquoting steps. A similar method was used to obtain samples of the SRAT and SME product slurries for mercury. These were obtained while the vessel contents were still mixing, but after they had cooled to $90{ }^{\circ} \mathrm{C}$ (definitely stopped boiling, and no longer steam stripping).

Additional SRAT product samples were taken for compositional and solids analyses after the product had cooled further. The MWWT and FAVC were drained, and the condensates weighed after both the SRAT and SME cycle. The MWWT was temporarily removed from the apparatus after the SRAT cycle, and as much free mercury as possible was collected for weighing. The 
MWWT was re-installed for the SME but not refilled. Selected SRAT and SME samples were submitted for ammonium ion analysis.

\subsection{Rheological Measurements}

Two types of rheological measurements were made during this program. Traditional flow curves were generated on sludges, SRAT products, and SME products using established DWPF rheology protocols. ${ }^{17}$ These three systems exhibit pseudo-homogeneous rheological behavior over the ranges of insoluble solids typically encountered in DWPF. The flow curve data were used to linearly fit the Bingham plastic model yield stress and consistency (plastic viscosity). Bingham plastic model parameters are a strong function of the $\mathrm{wt} \%$ insoluble solids (or volume percent insoluble solids), so efforts were made to keep this quantity in a fairly narrow range to permit comparisons between the results from the seven different process simulations.

SME product samples were allowed to sit for eight weeks. A compacted layer of settled solids formed under a layer of clear supernate. A vane yield strength measurement was made on the settled solids from each of the simulations. Two samples of approximately $250 \mathrm{~mL}$ each were taken from each SME product and stored undisturbed until the time for the measurement. Measurements were made using the Haake RS600 rheometer at ACTL. The FL22 vane was inserted into the settled solids to a depth marked on the vane. The vane was then rotated at 0.3 rpm for 90 seconds (not quite a half revolution). The initial resistance of the settled solids to movement resulted in a rapid increase in torque on the vane (shear stress), followed by a breakdown of the matrix and free rotation of the vane sensor with a resulting reduction in required torque. The test was designed as an initial evaluation of whether or not the presence of CST and MST with sludge and frit would present any significant solids suspension issues compared to the baseline tests without CST and MST. 
SRNL-STI-2011-00075

Revision 0

\subsection{Results and Discussion}

The DWPF CPC impact study involved several parts. The first part involved a paper evaluation of the impact of projected SCIX and SWPF operating levels on the composition of the DWPF feed tank for a given sludge batch. The second part involved the preparation of SB10 simulants containing various amounts of MST and CST (both as-made and irradiated). The third part included lab-scale simulations of the DWPF SRAT and SME cycles to produce samples and offgas data for analysis. The fourth part of the study focused on rheological impacts of MST and CST on CPC slurries at various conditions.

\subsection{DWPF Feed Composition Study}

SB10 was selected as the basis sludge system for evaluating the impact of both SCIX and Tank 48 fluidized bed steam reforming on the DWPF CPC. A hypothetical material balance for SB10 in a DWPF feed tank was prepared for a set of operating assumptions.

DWPF assumptions included:

- 325 canisters per year

- $40 \%$ waste loading (non-frit oxide loading)

- $3,850 \mathrm{lbs}$ of glass per canister

- $332,300 \mathrm{~kg}$ of sludge oxides (heel sludge plus fresh sludge) constitutes the sludge part of SB10 (waste not contributed to the batch from SCIX or SWPF)

- 3,410 kg of waste oxides fed per SRAT batch (sludge, CST, and MST oxides combined)

○ 66.5 SRAT batches per year (fewer if batches are larger)

- All past and future sludge batches have the SB10 sludge component compositions

- Required to close an iterative balance on the starting and ending heel composition in the DWPF feed tank

- About 80,000 kg of waste oxides in DWPF feed tank at end of SB10 (140,000 gallon heel size)

SWPF assumptions included:

- $\quad 3.1 \mathrm{~kg}$ MST oxides/hour

- 9,390,000 gallons salt solution processed per year

○ $0.8 \mathrm{~g} \mathrm{MST} / \mathrm{L}$ salt solution (two strike scenario) ${ }^{18}$

- $95.47 \%$ oxides in MST

- SWPF attainment equals DWPF attainment (both run or SWPF does not run)

- No entrained sludge in alpha strike stream to DWPF

SCIX assumptions included:

- Three 3-month CST column campaigns per year with one month between campaigns for inter-tank transfers, an MST strike, and other miscellaneous operations

- $8,770 \mathrm{~kg} \mathrm{CST} / 3$ month campaign $(27,000 \mathrm{~kg} \mathrm{CST} / \mathrm{yr})$

- About 1,646 kg of CST transferred to DWPF feed tank every 2-3 SRAT cycles

$\circ$ Only during the 3 month campaigns when the CST column is operating

- Timing/quantity forced to be consistent with the other assumptions over the duration of SB10 
- $6,500 \mathrm{~kg} \mathrm{MST} / \mathrm{yr}$; a third of the total transferred to DWPF feed preparation tank every four months (tank where the future sludge batch is being prepared)

$\circ$ Up to 5.2 transfers of 800,000 gallons in/out of SCIX tank per year (3 nominal)

- $0.4 \mathrm{~g} \mathrm{MST} / \mathrm{L}$ salt solution added to SCIX tank

- Number of MST transfers to the DWPF feed preparation tank is a function of the length of SB10 processing in DWPF. (In reality MST would be transferred into SB11 slurry while SB10 was being processed in DWPF, but the assumption has already been made that all sludge batches are identical to SB10 in constraining the initial and final compositions of the DWPF feed tank to be equal. This constraint was made in order to close the iteration of the accumulation of MST and CST in the heel of the prior batch, SB9, which has also been set equivalent to SB10. In other words, the material balance approximates a fully evolved state in the Tank Farm after many years of SCIX and SWPF operation, not the transitional state that would exist during the first few sludge batches after SCIX and SWPF start-ups where lower CST and MST concentrations would be likely.)

- A fresh SCIX cycle is just starting simultaneously with the start of SB10 processing in DWPF (a SCIX cycle occurs with each filling of the SCIX processing tank with fresh salt waste solution prior to the MST strike and subsequent treatment steps).

The rationale for some of the assumptions was to obtain the maximum quantity of MST and CST in the DWPF feed tank by the end of SB10 processing; for example, entrained sludge was eliminated from SCIX and SWPF streams, since the sludge acts as a diluent for the MST and CST. SCIX MST was increased assuming that more salt waste could be processed than indicated by the loading capacity of the CST column (5.2 instead of 3 salt solution transfers per year at 800,000 gallons per transfer), since the SCIX MST usage is a weak source of MST in DWPF compared to the SWPF alpha strike.

SWPF contributed a constant charge of MST to every DWPF batch under the assumptions above. The amount was as arbitrary as the selection of the SRAT batch size, and the two numbers are tied together. SCIX CST column transfers to the DWPF feed tank tended to occur about once every three SRAT cycles, or about once every two weeks. DWPF processing was allowed to continue drawing down the DWPF feed tank mass without SCIX CST additions during the month between 3-month SCIX processing cycles (this is not bounding, but is reasonable).

The nominal SB10 batch, assuming no SCIX or SWPF processes are operating in parallel, would have taken $332,300 \mathrm{~kg}$ of sludge oxides down to $80,000 \mathrm{~kg}$ of sludge oxides over 405 days to maintain the target canister production rate. There were 74 SRAT cycles in SB10 in this scenario at $3,410 \mathrm{~kg}$ of waste oxides per SRAT product to SME vessel transfer.

The salt processing modified SB10 batch started with $332,300 \mathrm{~kg}$ of sludge oxides, $2,170 \mathrm{~kg}$ of MST oxides from the previous sludge batch heel, $10,350 \mathrm{~kg}$ of MST oxides coming in with the new washed feed from the DWPF feed prep tank (cumulative SCIX contribution during previous sludge batch cycle), and $20,600 \mathrm{~kg}$ of CST oxides from the previous sludge batch heel. With continuous alpha strike contributions from SWPF, this feed lasted for 603 days, or 110 SRAT batches, while maintaining the target canister production rate. The first result of high SCIX and SWPF throughput was an extension of the length of SB10 in DWPF by nearly $50 \%$ over the duration without the salt processing options.

Instead of a DWPF feed tank heel of $80,000 \mathrm{~kg}$ of sludge oxides, the heel at the end of SB10 with the assumed SCIX and SWPF impacts was $57,700 \mathrm{~kg}$ of sludge oxides, $2,170 \mathrm{~kg}$ of MST oxides, and $20,600 \mathrm{~kg}$ of CST oxides. 
The fraction of waste oxides that were sludge, MST, or CST in the SRAT feed varied from the beginning to the end of the SB10 processing period. The range is summarized in Table 1.

Table 1. Distribution of SB10 oxides in SRAT receipt slurry

\begin{tabular}{|l|c|c|c|}
\hline \hline & \% sludge oxide & \% MST oxide & \% CST oxide \\
\hline First SRAT batch & 80.1 & 15.0 & 5.0 \\
\hline Final SRAT batch & 63.1 & 14.3 & 22.6 \\
\hline
\end{tabular}

The MST to the first SRAT batch of SB10 is about $80 \%$ from a just completed SWPF alpha strike transfer to the SRAT. The remaining $20 \%$ is from the contents of the DWPF feed tank. The DWPF feed tank MST was roughly $83 \%$ from MST generated during the 603 days of SB9 and added to the DWPF feed preparation tank (SB10 wash tank) along with $17 \%$ accumulated heel MST in the DWPF feed tank from the SB9 heel (assumed to be 140,000 gallons, or $80,000 \mathrm{~kg}$ of oxides, like the DWPF feed tank heel). The fractions of both sludge and MST in SB10 SRAT batches fall as SB10 is processed. The semi-regular SCIX CST transfers to the DWPF feed tank slowly dilute the MST and sludge (on an oxide basis). The impact on the SRAT receipt composition is larger for sludge because it all comes from the DWPF feed tank, while most of the MST comes directly to the SRAT from SWPF.

The evolution of the oxide fractions is non-linear with respect to SRAT batch. The calculated model evolution for SB10 is shown graphically in Figure 2.

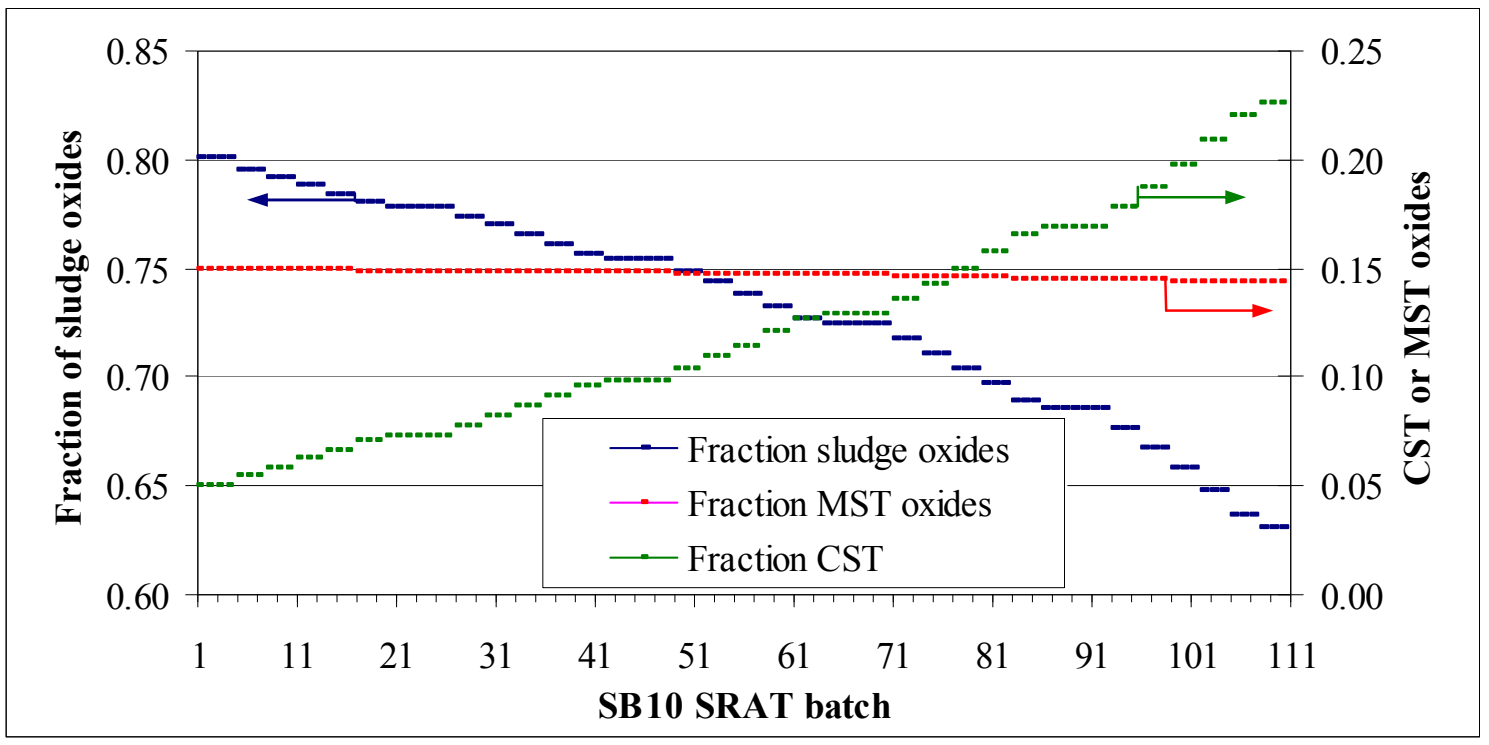

Figure 2. Evolution of oxide fraction versus SRAT cycle number

The periods where the sludge and CST fractions appear to be holding nearly constant are the SCIX outages between batches in the SCIX processing tank. Only about 35\% of the change in oxide fraction occurred by the mid-point SRAT batch of SB10 (\#55), while $65 \%$ of the change occurred during the final half of SB10. 
Cumulative SB10 processing under the bounding assumptions favored MST consumption over CST consumption. SB10, as calculated for 111 SRAT batches, yielded 274,500 kg of sludge oxides $(73 \%), 55,200 \mathrm{~kg}$ of MST oxides (15\%), and 45,600 $\mathrm{kg}$ of CST oxides (12\%) going into about 537 canisters at $40 \%$ waste loading. The no CST-MST case yielded 361 canisters at $40 \%$ waste loading. Raising the DWPF canister production rate above 325 per year is bounded by the above analysis, since the net result would be to increase sludge oxides relative to MST and CST oxides in the CPC.

While the above calculations enabled a reasonable bounding simulant to be defined for the SCIX CPC impact study, they did not address the water balance of the proposed flowsheet changes, only the impact of the changing waste oxides. Transfers of sluiced and ground CST to the DWPF feed tank will dilute both the soluble and insoluble solids content of the DWPF feed tank over time, making it necessary to decant supernate for recycle to the Tank Farm. The expected volume of water accompanying a CST column transfer was not available. In any case, dilution of the SRAT feed reduces acid demand and does not lead to a conservative case for the CPC impact study. CST fines could potentially be entrained in the recycle supernate when decanting the DWPF feed tank. Settled CST fines were found to be somewhat sticky or gummy in water, and CST in decanted supernate could potentially seed formation of sodium aluminosilicates when processed through the Tank Farm evaporators.

\subsection{Simulant Preparation}

SB10 simulant had already been prepared and tested at the time that the DWPF impact study for SCIX began. ${ }^{19}$ Slurries of CST and MST were available within SRNL for combining with the SB10 simulant. MST was from Harrell Industries, lot \#102209. CST is discussed in more detail in the next paragraph. It was decided to maintain the supernate concentration constant in all of the SB10-CST-MST blends to control the number of independent variables in the DWPF SRAT acid requirement calculation. Therefore, the CST and MST slurries were washed with SB10 supernate to displace the initial supernate and simplify blending.

CST had been size-reduced to a volume mean diameter of about 1.6 microns a number of years earlier by D. F. Bickford. Size reduction had produced a significant fraction of sub-micron fines that presented certain challenges in preparing/washing the CST slurry. Gravity settling the CST proved prohibitively time-consuming. Centrifugation was required to settle the fines in a reasonable time, and a resonant mixer was required to disperse the centrifuge cake back into a slurry following each wash/decant cycle. Normal shear rates in the aqueous phase (those from using a mixer or hand-shaking) against the settled CST solids produced essentially no suspension of particles which seemed to have formed a clay-like cake. Re-establishing the CST slurry was far more challenging than comparable work with sludge simulants or with MST. The same equipment was used to prepare the MST, but the MST solids did not require as aggressive an approach during centrifuging or remixing as the CST. MST was already a fine particle, and it did not require grinding, unlike the CST.

A particle size profile for the ground CST is given in Figure 3. While not identical to the particles of ground CST prepared at Vitreous State Laboratory (VSL) with the proposed SCIX grinder, the rheological properties of sludge-rich samples containing Bickford and VSL ground CST were statistically indistinguishable. ${ }^{20}$ (Rheological differences between the two forms of ground CST were detectable in slurries that were not pre-dominantly (>90\%) CST.) 


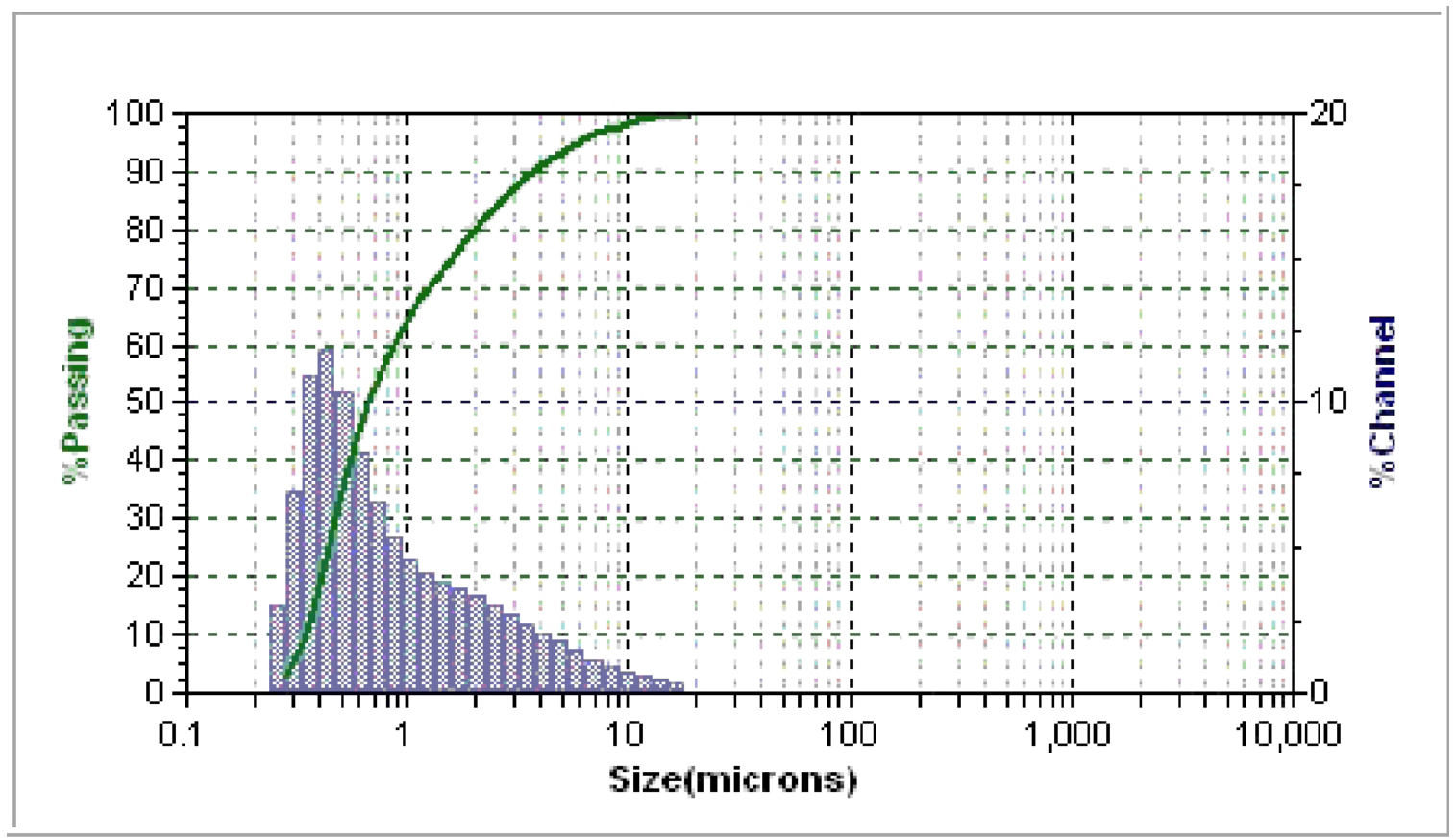

Figure 3. Drum 4-A CST particle size distribution $\left(\mathrm{M}_{\mathrm{v}}=1.53\right.$ micron)

The oxide values for the first and last SRAT batches of SB10 in Table 1 were taken as starting points in preparing the bounding and intermediate blends of SB10 with CST and MST for CPC testing. MST was increased $10 \%$ above the value in the first SRAT batch, and CST was increased $10 \%$ above the value in the last SRAT batch to define the bounding blend. The intermediate blend had half the CST and MST oxide concentrations of the bounding blend. Oxide targets for the bounding and intermediate blends are given in Table 2 along with the values for the first and last SRAT receipt sludge composition from the bounding analysis.

Table 2. SB10-CST-MST simulant blends

\begin{tabular}{||l|c|c|c||}
\hline \hline & \% sludge oxide & \% MST oxide & \% CST oxide \\
\hline First SRAT batch & 80.1 & 15.0 & 5.0 \\
\hline Final SRAT batch & 63.1 & 14.3 & 22.6 \\
\hline Bounding blend & 59.0 & 16.5 & 24.5 \\
\hline Intermediate blend & 78.4 & 8.25 & 12.25 \\
\hline
\end{tabular}

While the intermediate blend MST oxide percentage does not fall in the range calculated under the bounding assumptions (14.3-15\%) in Section 3.1, the major source of MST is projected to be SWPF. The SWPF alpha strike MST supplied to a given SRAT batch could range anywhere from zero to the SWPF bounding quantity. Consequently, it was necessary to consider the entire range of MST oxides as potential feeds to the DWPF SRAT.

While questions of rheology, foaminess, mercury stripping, etc. can be studied in virtually any CPC simulation, the issues of hydrogen generation and suitability of the DWPF acid equation require testing at different levels of total acid per liter slurry. Two issues were identified that might be of concern. First, CST-MST combinations provide new substrate material for the catalytically active noble metals present in the waste slurries processed by DWPF. This could alter noble metal catalysis. The CST and/or MST might also be catalytically active on their own 
for conversion of formic acid into hydrogen at high enough concentrations. Second, MST or $\mathrm{NaTi}_{2} \mathrm{O}_{5} \mathrm{H}$, might undergo the reaction:

$$
\mathrm{NaTi}_{2} \mathrm{O}_{5} \mathrm{H} \rightarrow \mathrm{NaOH}+2 \mathrm{TiO}_{2}
$$

to provide additional caustic (acid demand) to the SRAT slurry. If this reaction only occurred at processing temperatures $\left(90-103{ }^{\circ} \mathrm{C}\right)$, then the room temperature base equivalents titration term in the DWPF stoichiometric acid equation would not detect this acid demand. In that case, the ability to destroy nitrite ion at a constant low acid stoichiometry would be expected to get progressively worse as the MST content of the feed slurry increased. Potential small differences from lower MST levels used in prior test programs have been obscured by the typical analytical variations in the larger contributors to the DWPF stoichiometric acid demand.

Available data for SB10 baseline simulant had been obtained at $100 \%$ and $150 \%$ of the stoichiometric acid requirement calculated by the Koopman minimum acid equation. ${ }^{19}$ Residual nitrite was found in the $100 \%$ acid test $(1,400 \mathrm{mg} / \mathrm{kg}$ SRAT product). Nitrite slightly exceeded the DWPF product specification, but it gave a measurable baseline for future tests at $100 \%$ stoichiometry with MST and CST incorporated into the simulant. Two additional tests were planned at $100 \%$, one with bounding SB10-CST-MST simulant and one with intermediate SB10CST-MST simulant, to study the potential impact of salt processing streams on nitrite ion destruction.

The SB10 baseline test at $150 \%$ acid stoichiometry achieved a maximum hydrogen generation rate of $1.04 \mathrm{lbs} / \mathrm{hr}$ during the SRAT and $0.76 \mathrm{lbs} / \mathrm{hr}$ during the SME. These exceeded the DWPF design basis limits of 0.65 and $0.223 \mathrm{lbs} / \mathrm{hr}$ for the SRAT and SME, respectively. Testing was planned at bounding CST and MST concentrations with high acid stoichiometry to see if hydrogen generation rates became better or worse. Several tests were planned:

- The first was a standard SRAT simulation at $150 \%$ acid stoichiometry with all components of the bounding simulant in the vessel from the beginning.

- The second was an extended SRAT simulation at 150\% acid stoichiometry where the majority of the MST was held out of the starting simulant and added in a much more diluted form at caustic boiling. The overall formulation of this simulant was identical to the first test by the start of nitric acid addition (same masses of SB10 simulant, CST slurry in SB10 supernate, and MST slurry in SB10 supernate).

- The third was similar to the first except that all of the CST and a portion of the MST were irradiated in the SRNL ${ }^{60}$ Co source. SWPF MST sees relatively little dose compared to SCIX MST. All CST is expected to be loaded with cesium, and the average residence time in the DWPF feed tank would be measured in months. The purpose of irradiation was to see if it would activate the titanium for hydrogen formation catalysis.

This report covers seven CPC simulations. Two of these are SB10 baseline tests from the earlier Tank 48 study. The other five include various types/amounts of CST-MST blended into SB10 simulant. Each simulation was given a name to identify it. These names are summarized in Table 3 in the order in which they were performed. 
Table 3. CPC simulation nomenclature

\begin{tabular}{||l|l||}
\hline Name & Description \\
\hline SB10-100 & SB10 simulant at $100 \%$ acid stoichiometry (no MST or CST) \\
\hline SB10-150 & SB10 simulant at $150 \%$ acid stoichiometry (no MST or CST) \\
\hline SCIX1 & Bounding CST-MST simulant at $100 \%$ acid stoichiometry \\
\hline SCIX2 & Bounding CST-MST simulant at $150 \%$ acid stoichiometry \\
\hline SCIX3 & Intermediate CST-MST simulant at $100 \%$ acid stoichiometry \\
\hline SCIX4 & Bounding CST-MST simulant at $150 \%$ acid stoichiometry-extended run \\
\hline SCIX5 & Bounding, irradiated CST-MST simulant at $150 \%$ acid stoichiometry \\
\hline \hline
\end{tabular}

SB10-100 and SB10-150 are also known as SB10-7 and SB10-8, but are referred to here with the modified names to track the acid stoichiometry more easily in the text

Future phases of the SCIX CPC impact study may need to study the impact of a sludge-CST mixture that has undergone aluminum dissolution or the impact of an alternative DWPF flowsheet, such as the glycolic-formic acid blend alternative to the current use of formic acid as the primary reductant.

Table 4 presents the elemental analytical composition data for the SB10 simulant, the intermediate blend simulant, the bounding blend simulant, the extended SRAT cycle simulant following the alpha strike caustic boiling period, and the irradiated simulant. Results are averages of two values measured by ICP-AES.

Table 4. Calcined elemental $\mathrm{wt} \%$ at $1100{ }^{\circ} \mathrm{C}$

\begin{tabular}{|l|c|c|c|c|c||}
\hline \hline & $\begin{array}{c}\text { Baseline } \\
\text { SB10 }\end{array}$ & $\begin{array}{c}\text { Intermediate } \\
\text { CST-MST }\end{array}$ & $\begin{array}{c}\text { Bounding } \\
\text { CST-MST }\end{array}$ & $\begin{array}{c}\text { Bounding } \\
\text { Extended }\end{array}$ & $\begin{array}{c}\text { Bounding } \\
\text { Irradiated }\end{array}$ \\
\hline $\mathrm{Al}$ & 6.66 & 5.55 & 4.03 & 4.20 & 3.94 \\
\hline $\mathrm{Ba}$ & 0.22 & 0.20 & 0.15 & 0.13 & 0.13 \\
\hline $\mathrm{Ca}$ & 2.50 & 2.03 & 1.49 & 1.59 & 1.53 \\
\hline $\mathrm{Ce}$ & 0.72 & 0.60 & 0.46 & 0.45 & 0.44 \\
\hline $\mathrm{Cr}$ & 0.14 & 0.13 & 0.13 & 0.08 & 0.08 \\
\hline $\mathrm{Cu}$ & 0.06 & 0.11 & 0.04 & 0.05 & 0.05 \\
\hline $\mathrm{Fe}$ & 27.9 & 23.8 & 17.3 & 17.8 & 16.0 \\
\hline $\mathrm{K}$ & 0.20 & 0.20 & 0.23 & 0.22 & 0.25 \\
\hline $\mathrm{La}$ & 0.25 & 0.20 & 0.15 & 0.14 & 0.15 \\
\hline $\mathrm{Mg}$ & 0.33 & 0.27 & 0.20 & 0.19 & 0.19 \\
\hline $\mathrm{Mn}$ & 5.35 & 4.40 & 3.20 & 3.22 & 3.00 \\
\hline $\mathrm{Na}$ & 14.7 & 16.4 & 17.5 & 16.1 & 19.1 \\
\hline $\mathrm{Nb}$ & 0.0 & 1.58 & 3.25 & 2.83 & 2.87 \\
\hline $\mathrm{Ni}$ & 0.74 & 0.69 & 0.49 & 0.43 & 0.44 \\
\hline $\mathrm{Pb}$ & 0.19 & 0.27 & 0.23 & 0.21 & 0.22 \\
\hline $\mathrm{Si}$ & 2.24 & 2.54 & 3.06 & 3.00 & 3.10 \\
\hline $\mathrm{Ti}$ & $<0.01$ & 5.62 & 11.8 & 12.0 & 11.2 \\
\hline $\mathrm{Zn}$ & 0.07 & 0.05 & 0.04 & 0.04 & 0.05 \\
\hline $\mathrm{Zr}$ & 0.45 & 1.58 & 3.80 & 2.57 & 2.72 \\
\hline
\end{tabular}

The straight bounding simulant, extended run simulant, and irradiated simulant elemental compositions should be virtually identical by recipe. Variations in the table, however, are close to, or exceed, the $\pm 10 \%$ level expected, e.g. for $\mathrm{Fe}, \mathrm{Na}, \mathrm{Nb}$, and $\mathrm{Zr}$. This could be an issue of 
concern, if it happens regularly with high MST-CST content samples. In this case, one or more of the samples submitted for analysis may simply have had a somewhat incorrect ratio of insoluble to supernate solids.

Table 5 presents $\mathrm{wt}^{\%} \%$ solids and density data for the five simulants. All results are averages of two measurements. The supernate density of all simulants was approximately $1.055 \mathrm{~g} / \mathrm{mL}$.

Table 5. Solids and density data

\begin{tabular}{||l|c|c|c|c|c||}
\hline \hline Property & $\begin{array}{c}\text { Baseline } \\
\text { SB10 }\end{array}$ & $\begin{array}{c}\text { Intermediate } \\
\text { CST-MST }\end{array}$ & $\begin{array}{c}\text { Bounding } \\
\text { CST-MST }\end{array}$ & $\begin{array}{c}\text { Bounding } \\
\text { Extended }\end{array}$ & $\begin{array}{c}\text { Bounding } \\
\text { Irradiated }\end{array}$ \\
\hline $\mathrm{Wt} \% \mathrm{TS}$ & 17.8 & 19.7 & 18.7 & 18.6 & 18.3 \\
\hline $\mathrm{Wt} \% \mathrm{IS}$ & 11.2 & 13.7 & 12.8 & 12.6 & 12.7 \\
\hline $\mathrm{Wt} \% \mathrm{SS}$ & 6.69 & 6.08 & 5.81 & 6.07 & 5.56 \\
\hline $\mathrm{Wt} \% \mathrm{DS}$ & 7.53 & 7.03 & 6.67 & 6.94 & 6.37 \\
\hline $\mathrm{Wt} \% \mathrm{CS}$ & 14.4 & 15.7 & 15.5 & 15.0 & 15.0 \\
\hline Slurry Dens & 1.15 & 1.16 & 1.16 & 1.15 & 1.14 \\
\hline
\end{tabular}

TS - total solids, IS - insoluble solids, SS - soluble solids, DS - dissolved solids, CS - calcined solids. Slurry density is in $\mathrm{g} / \mathrm{mL}$.

Table 6 gives the results of weighted dilution slurry preparations for IC (nitrite, nitrate, sulfate, chloride, and fluoride) as well as the results of a slurry titration to $\mathrm{pH} 7$ to determine the equivalent hydroxide content and values of total inorganic carbon (taken as a measure of carbonate in either the supernate phase or total slurry).

Table 6. Anion data

\begin{tabular}{|l|c|c|c|c|c|}
\hline Property & $\begin{array}{c}\text { Baseline } \\
\text { SB10 }\end{array}$ & $\begin{array}{c}\text { Intermediate } \\
\text { CST-MST }\end{array}$ & $\begin{array}{c}\text { Bounding } \\
\text { CST-MST }\end{array}$ & $\begin{array}{c}\text { Bounding } \\
\text { Extended }\end{array}$ & $\begin{array}{c}\text { Bounding } \\
\text { Irradiated }\end{array}$ \\
\hline $\mathrm{NO}_{2}^{-}, \mathrm{mg} / \mathrm{kg}$ & 9,440 & 9,660 & 9,390 & 8,590 & 9,840 \\
\hline $\mathrm{NO}_{3}^{-}, \mathrm{mg} / \mathrm{kg}$ & 5,690 & 5,370 & 5,450 & 5,400 & 5,300 \\
\hline $\mathrm{SO}_{4}{ }^{\prime}, \mathrm{mg} / \mathrm{kg}$ & 310 & 260 & 250 & 240 & 380 \\
\hline $\mathrm{Cl}^{-}, \mathrm{mg} / \mathrm{kg}$ & $<100$ & $<100$ & $<100$ & 235 & $<100$ \\
\hline $\mathrm{F}^{-}, \mathrm{mg} / \mathrm{kg}$ & $<100$ & $<100$ & $<100$ & $<100$ & $<100$ \\
\hline Equiv OH, M & 0.91 & 0.95 & 0.94 & 0.91 & 0.95 \\
\hline $\begin{array}{l}\text { Supernate TIC, } \\
\text { mg/L }\end{array}$ & 1,150 & 1,540 & 1,400 & 1,740 & 1,590 \\
\hline Slurry TIC, mg/kg & 1,350 & 2,100 & 1,900 & n.a. & n.a. \\
\hline
\end{tabular}

n.a. - not analyzed (since slurry TIC was not needed in the stoichiometric acid calculation)

The extended run simulant sample had the noble metal and mercury trim chemicals in it, while the other samples were of untrimmed simulant. Chloride ion was above the detection limit in the extended run result, because the $\mathrm{RuCl}_{3}$ addition occurred prior to sampling. The SB10 TIC values appear to be slightly low compared to the other four simulants (but SB10 had the same supernate composition targets including sodium carbonate). This potential understatement of acid demand may explain why insufficient acid was added to destroy nitrite below $1,000 \mathrm{mg} / \mathrm{kg}$ at $100 \%$ acid stoichiometry in the SB10 baseline testing.

Some fine tuning was performed with each SB10-CST-MST simulant as it was batched and trimmed into the 4-L SRAT vessel. Varying masses of rinse water and pre-acid addition sample size were used to bring the acid requirements, calcined solids masses, anion concentrations, etc. 
into a narrower window. The SRAT target was to stay close to $465 \mathrm{~g}$ of calcined solids at the start of acid addition to put all tests on an equivalent number of canister basis and to match the conditions of the two earlier SB10 baseline simulant tests without CST or MST.

\subsection{SRAT/SME Simulation Results}

Five SCIX SRAT/SME simulations were completed for comparison to a pair of baseline simulations without MST or CST. Baseline tests contained $466 \mathrm{~g}$ of calcined oxides. To make the five runs with MST and CST comparable in terms of canister production at $40 \%$ waste loading, this value was adopted as the target for the five SCIX runs. It was also desired to keep the supernate composition nearly constant over five different blends. The two goals were met by adding simulant and dilution water to the SRAT, then removing a sample containing the excess calcined oxides prior to acid addition. The results were distributed around the target value as shown in Table 7.

Table 7. Pre-acid addition calcined mass of SRAT tests

\begin{tabular}{|l|c|c|c|c|c|}
\hline & SB10 & SCIX1, 2 & SCIX3 & SCIX4 & SCIX5 \\
\hline Calcined oxide mass, g & 466 & 483 & 471 & 484 & 461 \\
\hline
\end{tabular}

The average SRAT of the seven tests in this report contained $473 \mathrm{~g}$ of calcined oxides with a maximum variation of $2.5 \%$. The following sections within Section 3.3 discuss individual aspects of the SRAT/SME simulations related to the process chemistry and physical property changes.

\subsubsection{Impact of CST and MST on Stoichiometric Acid Demand}

As CST and MST slurried in SB10 supernate were added to baseline SB10A simulant, the calculated stoichiometric acid demand was found to change. Fresh measurements of the inputs to the potential acid equations under investigation in SRNL were made on the feeds to the runs. The calculated minimum acid requirement by the Koopman minimum acid equation ${ }^{21}$ is given in Table 8 along with the actual addition and the stoichiometric factor that would give the actual addition based on the minimum acid from the current DWPF stoichiometric acid equation (HsuMarek-Eibling equation).

Two values for the stoichiometric acid demand are given for SCIX4 in Table 8. One is based on the composite of the "parts" (CST-SB10-low MST and alpha strike MST evaluated independently for acid demand and combined mathematically), while the second is based on a composite sample pulled from the 4-L SRAT following the alpha strike addition and concentration with everything "blended" together. The "parts" version is slightly different due to small changes in dilution that were made to better adjust the mass of calcined solids being processed relative to SCIX1 and SCIX2. 
Table 8. Stoichiometric acid calculation results, moles acid/L slurry

\begin{tabular}{|l|c|c|c|c|}
\hline & $\begin{array}{c}\text { Koopman } \\
\text { Stoichiometry }\end{array}$ & $\begin{array}{c}\text { Koopman Min. } \\
\text { moles/L }\end{array}$ & $\begin{array}{c}\text { Actual addition, } \\
\text { moles/L }\end{array}$ & $\begin{array}{c}\text { Equivalent } \\
\text { DWPF factor }\end{array}$ \\
\hline SB10-100 & $100 \%$ & 1.69 & 1.69 & $108 \%$ \\
\hline SB10-150 & $150 \%$ & 1.69 & 2.53 & $163 \%$ \\
\hline SCIX1 & $100 \%$ & 1.59 & 1.59 & $98 \%$ \\
\hline SCIX2 & $150 \%$ & 1.59 & 2.38 & $147 \%$ \\
\hline SCIX3 & $100 \%$ & 1.72 & 1.72 & $99 \%$ \\
\hline SCIX4 parts & $151 \%$ & 1.54 & 2.33 & $148 \%$ \\
\hline SCIX4 blend & $144 \%$ & 1.44 & 2.33 & $142 \%$ \\
\hline SCIX5 & $150 \%$ & 1.60 & 2.40 & $147 \%$ \\
\hline
\end{tabular}

The minimum acid demand by the Koopman equation went from 1.69 to 1.72 to 1.59 moles/L as the concentrations of MST and CST went from none to intermediate to bounding. The lack of a trend may be an artifact of the basis used for calculating the minimum acid, since the expected trend was a smooth decrease as the MST and CST were increased.

SCIX1 and SCIX3 successfully destroyed nitrite in the SRAT to $<100 \mathrm{mg} / \mathrm{kg}$ SRAT product slurry. The $100 \%$ acid baseline test, SB10-100, failed to destroy nitrite as effectively with 1,440 $\mathrm{mg} / \mathrm{kg}$ SRAT product slurry. The baseline simulant analysis for supernate TIC was $20-30 \%$ low compared to the SCIX simulants. All simulants used the same recipe to prepare the supernate composition, so supernate TIC concentration should have been constant. The low value for this input likely contributed to the unsuccessful nitrite destruction in the baseline run at low acid.

A comparison of supernate TIC, slurry nitrite, and slurry nitrate is given in Table 9 to show the relatively narrower ranges (in percent) that were achieved for slurry nitrite and nitrate compared to TIC. The variation in relative ranges must be due to analytical issues, since the relative proportions of sodium carbonate, sodium nitrate, and sodium nitrite were held constant in all adjustments to the supernate of the baseline simulant, CST slurry, and/or MST slurry.

Table 9. Comparison of simulant supernate TIC values

\begin{tabular}{|l|c|c|c||}
\hline Simulant & $\begin{array}{c}\text { TIC } \\
\mathbf{m g} / \mathbf{L}\end{array}$ & $\begin{array}{c}\text { Nitrate } \\
\mathbf{m g} / \mathbf{k g}\end{array}$ & $\begin{array}{c}\text { Nitrite } \\
\mathbf{m g} / \mathbf{k g}\end{array}$ \\
\hline SB10 Baseline & 1,150 & 5,700 & 9,400 \\
\hline Intermediate MST-CST & 1,540 & 5,400 & 9,700 \\
\hline Bounding MST-CST & 1,440 & 5,400 & 9,400 \\
\hline Bounding-Irradiated & 1,590 & 5,300 & 9,800 \\
\hline
\end{tabular}

The $6.5 \%$ difference in the acid demand of the two SCIX4 cases can also be traced back to the measurements of the inputs to the Koopman minimum stoichiometric acid equation, Table 10. There are small variations in every term, including a $28 \%$ change in the value for the supernate carbonate based on the supernate TIC measurement. SCIX4 will be treated as another " $150 \%$ " stoichiometry run in the discussion that follows, since that was the original target, and since the two measurements bracket the target value. 
Table 10. Individual contributions to stoichiometric acid calculation in SCIX4

\begin{tabular}{||l|c|c||}
\hline Term & Pre-blend value, moles & SRAT receipt value, moles \\
\hline Base equivalents & 2.401 & 2.490 \\
\hline Nitrite ion & 0.636 & 0.620 \\
\hline Supernate carbonate & 0.309 & 0.398 \\
\hline Manganese & 0.280 & 0.292 \\
\hline Calcium & 0.179 & 0.197 \\
\hline Magnesium & 0.040 & 0.039 \\
\hline Mercury & 0.048 & 0.050 \\
\hline
\end{tabular}

The cumulative impact of the SCIX4 measurement uncertainties on the inputs to the stoichiometric acid equation helps to define the minimum acceptable range of stoichiometric factors between successful nitrite destruction and excessive hydrogen generation. It is desirable to pick a target in the available stoichiometric range such that a SRAT batch where measurement uncertainties compound rather than cancel out is still successful.

\subsubsection{Noble Metals and Mercury}

Noble metals and mercury are trimmed into the lab-scale SRAT prior to most DWPF process simulations rather than being incorporated into the sludge simulant preparation. This approach has been shown to be bounding with respect to catalytic hydrogen generation. ${ }^{22}$ Flexibility to adjust the noble metal concentrations gives greater freedom in designing CPC simulations. Noble metal concentrations had to be specified for the five SCIX SRAT runs. To control the impact of mercury on processing, all of the testing was done at $1.614 \pm 0.006 \mathrm{wt} \% \mathrm{Hg}$ in the dried starting solids.

A dual approach was adopted for setting the noble metal concentrations. Noble metals were added to SB10-CST-MST blends as if all solids were sludge solids in the runs at $150 \%$ stoichiometry to give the maximum catalytic hydrogen generation under the assumption that the sludge solids have higher noble metal concentrations than the CST or MST slurries (the $150 \%$ runs were designed to bound the hydrogen generation behavior). Noble metals were added to the blends tested at $100 \%$ acid assuming that only the sludge solids contained noble metals. Since noble metals catalyze nitrite destruction, ${ }^{23}$ this approach seemed conservative with respect to evaluating the ability of the predicted quantity of minimum acid to destroy nitrite. The dual approach led to the noble metal and mercury matrix given in Table 11.

Table 11. Noble metal and mercury concentrations, wt $\%$ dried solids

\begin{tabular}{|l|c|c|c|c|c|c|}
\hline & $\begin{array}{c}\text { Koopman } \\
\text { Stoichiometry }\end{array}$ & Ag & Pd & Rh & Ru & Hg \\
\hline SB10-100 & $100 \%$ & 0.0142 & 0.0066 & 0.0233 & 0.112 & 1.619 \\
\hline SB10-150 & $150 \%$ & 0.0142 & 0.0066 & 0.0233 & 0.112 & 1.619 \\
\hline SCIX1 & $100 \%$ & 0.0092 & 0.0043 & 0.0151 & 0.073 & 1.619 \\
\hline SCIX2 & $150 \%$ & 0.0142 & 0.0066 & 0.0233 & 0.112 & 1.619 \\
\hline SCIX3-Intermediate & $100 \%$ & 0.0121 & 0.0056 & 0.0198 & $0.073^{\dagger}$ & 1.608 \\
\hline SCIX4 & $150 \%$ & 0.0142 & 0.0066 & 0.0233 & 0.112 & 1.619 \\
\hline SCIX5 & $150 \%$ & 0.0142 & 0.0066 & 0.0233 & 0.112 & 1.619 \\
\hline
\end{tabular}

$\dagger 0.095 \%$ Ru was desired for SCIX3, but only $0.073 \%$ was added 
SCIX3 calculations had a typographical error in the ruthenium determination that led to a trim addition that was below the intended target. This error was in a direction that did not impact the conservatism of the design with respect to evaluating nitrite destruction (given that nitrite destruction was successfully accomplished). Ruthenium has also been found to be considerably less active than rhodium or palladium during nitrite destruction.

\subsubsection{Impact of Caustic Boiling Before Nitric Acid Addition}

The five SCIX tests included caustic boiling to evaluate the potential negative impacts of boiling CST and MST under caustic conditions such as sodium alumino-silicate formation. SCIX4 included the addition of the alpha strike MST in slurry form with dewatering over an 11.2 hour period. The other four SCIX runs had a two hour boiling period under a gentle reflux. The GC data showed negligible off-gas generation during caustic boiling. There was a little increase in foaminess in SCIX4, Figure 4.

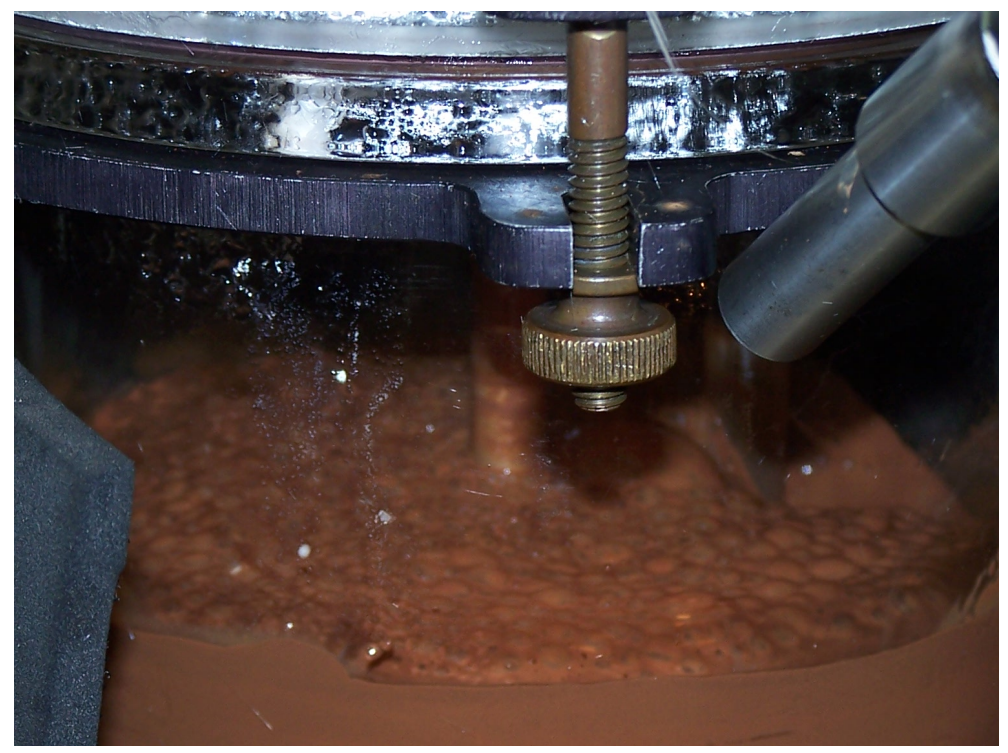

Figure 4. Light foaming during SCIX4 alpha strike addition

The rheological data on samples obtained at the end of caustic boiling are discussed in Section 3.4. The rheology results showed no obvious adverse impacts from boiling the MST and CST under caustic conditions.

\subsubsection{SRAT and SME Product Elemental Evaluation}

Five tests were performed with CST and MST included in the simulant. Together, these two species contain $\mathrm{Ti}, \mathrm{Na}, \mathrm{Si}, \mathrm{Zr}$, and $\mathrm{Nb}$. Subsequently, they become loaded with cesium, strontium, actinides, etc. The typical sludge simulant is low in $\mathrm{Cs}$, $\mathrm{Ti}, \mathrm{Si}$, and $\mathrm{Zr}$ and contains no $\mathrm{Nb}$. Should SCIX become operational, it may be necessary to quantitatively estimate the concentrations of CST and MST in the sludge waste feed to DWPF from radioactive sample analyses in order to prepare simulants of the SRAT feed for testing. Bounding cases for CST and MST can be studied, but it will still be necessary to get to the MST and CST free composition of a sludge batch in order to prepare the simulant recipe. 
A preliminary attempt was made to use a SRAT product analysis to confirm the quantities of CST and MST in the SB10 simulant according to the batching calculations. The attempt used the SCIX1 results. $\mathrm{Nb}$ was used to set insoluble CST mass. Masses of the other four CST elements were then deducted from the SCIX1 total values. The remaining Ti was used to determine MST (none in SB10 simulant alone). Ti and Na were deducted from the CST adjusted SCIX1 values. Sodium in both the CST and MST simulant slurries was adjusted from the insoluble ratio to the other elements in the resins to a slurried in SB10 supernate basis (this required knowledge of the individual CST and MST slurries, but is a step that could be skipped when developing a simulant recipe). The sodium adjustment allowed removal of the supernate salt oxides associated with the MST and CST from the sludge oxides and the supernate salt oxides in the baseline SB10 simulant. The result of this calculation compared to the three slurry oxide targets is given in Table 12 .

Table 12. Calculation of contributions to SCIX1 oxides

\begin{tabular}{|l|c|c|}
\hline & Target fraction & Calculated fraction \\
\hline Sludge oxides and supernate & 59.0 & 58.4 \\
\hline CST oxides and supernate & 24.5 & 23.0 \\
\hline MST oxides and supernate & 16.5 & 18.6 \\
\hline
\end{tabular}

The three results obtained from calculations using the SRAT product elements are approximately correct. After extracting the CST and MST slurries from the blended material and renormalizing, the remaining species should match the baseline SB10 simulant. A comparison of the rescaled calcined elements from SCIX1 SRAT product after removing MST and CST and their supernate sodium is given in Table 13 along with the directly measured calcined elemental values for the MST-CST free baseline simulant. 
SRNL-STI-2011-00075

Revision 0

Table 13. SCIX1 without CST and MST versus baseline sludge composition

\begin{tabular}{|l|c|c|}
\hline & $\begin{array}{c}\text { Baseline } \\
\text { SB10 }\end{array}$ & $\begin{array}{c}\text { SCIX1 } \\
\text { recalculated }\end{array}$ \\
\hline $\mathrm{Al}$ & 6.66 & 7.12 \\
\hline $\mathrm{Ba}$ & 0.22 & 0.20 \\
\hline $\mathrm{Ca}$ & 2.50 & 2.32 \\
\hline $\mathrm{Ce}$ & 0.72 & 0.69 \\
\hline $\mathrm{Cr}$ & 0.14 & 0.14 \\
\hline $\mathrm{Cu}$ & 0.06 & 0.09 \\
\hline $\mathrm{Fe}$ & 27.9 & 27.7 \\
\hline $\mathrm{K}$ & 0.20 & 0.43 \\
\hline $\mathrm{La}$ & 0.25 & 0.23 \\
\hline $\mathrm{Mg}$ & 0.33 & 0.30 \\
\hline $\mathrm{Mn}$ & 5.35 & 5.12 \\
\hline $\mathrm{Na}$ & 14.7 & 14.1 \\
\hline $\mathrm{Nb}$ & 0.0 & 0.0 \\
\hline $\mathrm{Ni}$ & 0.74 & 0.66 \\
\hline $\mathrm{Pb}$ & 0.19 & 0.33 \\
\hline $\mathrm{Si}$ & 2.24 & 2.52 \\
\hline $\mathrm{Ti}$ & $<0.01$ & 0.0 \\
\hline $\mathrm{Zn}$ & 0.07 & 0.06 \\
\hline $\mathbf{Z r}$ & $\mathbf{0 . 4 5}$ & $\mathbf{0 . 8 1}$ \\
\hline
\end{tabular}

While generally good agreement was obtained for nearly all of the elements, there was a large positive error with zirconium. The error suggests that the fraction of CST calculated from $\mathrm{Nb}$ may have been low, as was also indicated by Table 12. An adjustment to the CST oxide fraction could be made using good judgment in order to reduce the $\mathrm{Zr}$ error without impacting the other CST elements too greatly to produce a refined result. That option, however, would not be available if the values were from a DWPF batch prep tank sample analysis (unless all individual sludge compositions and masses to the batch were known independently on a CST and MST free basis). Ultimately, it may be difficult to quantify the MST and CST in mixed DWPF feed more accurately than shown above with the available sample analysis methods, but it will be necessary to do this calculation to prepare future simulants of DWPF feed containing CST and MST (following start-up of SCIX).

The remaining SRAT product elemental analyses are given in Appendix A. They generally match the compositions of the starting simulants given in Table 4. SME product elemental analyses are given in Table 14 for the runs with CST and MST along with a composite of the two SB10 baseline runs for comparison. Results are the average of two analyses for each SME product. SCIX3 is the intermediate case and should not match the other four SCIX compositions. 
Table 14. Calcined wt\% SME product elements $\left(1100{ }^{\circ} \mathrm{C}\right)$

\begin{tabular}{|c|c|c|c|c|c|c|}
\hline & SB10 & SCIX1 & SCIX2 & SCIX3 & SCIX4 & SCIX5 \\
\hline $\mathrm{Al}$ & 3.03 & 1.93 & 1.93 & 2.44 & 1.76 & 1.84 \\
\hline $\mathrm{B}$ & 1.32 & 1.41 & 1.43 & 1.36 & 1.45 & 1.34 \\
\hline $\mathrm{Ba}$ & 0.10 & 0.05 & 0.05 & 0.08 & 0.06 & 0.05 \\
\hline $\mathrm{Ca}$ & 1.08 & 0.55 & 0.56 & 0.87 & 0.62 & 0.69 \\
\hline $\mathrm{Ce}$ & n.a. & 0.16 & 0.16 & 0.22 & 0.14 & 0.15 \\
\hline $\mathrm{Cr}$ & 0.07 & 0.03 & 0.03 & 0.06 & 0.05 & 0.04 \\
\hline $\mathrm{Cu}$ & n.a. & 0.03 & 0.03 & 0.03 & 0.03 & 0.02 \\
\hline $\mathrm{Fe}$ & 12.2 & 6.34 & 6.26 & 9.01 & 5.90 & 6.71 \\
\hline $\mathrm{K}$ & 0.11 & 0.13 & 0.13 & 0.13 & 0.14 & 0.14 \\
\hline $\mathrm{La}$ & n.a. & 0.05 & 0.05 & 0.08 & 0.05 & 0.05 \\
\hline $\mathrm{Li}$ & 2.09 & 2.03 & 2.06 & 2.12 & 2.24 & 2.24 \\
\hline $\mathrm{Mg}$ & 0.16 & 0.09 & 0.092 & 0.12 & 0.08 & 0.08 \\
\hline $\mathrm{Mn}$ & 1.92 & 1.18 & 1.17 & 1.57 & 1.01 & 1.20 \\
\hline $\mathrm{Na}$ & 9.06 & 9.78 & 9.82 & 9.85 & 10.10 & 11.05 \\
\hline $\mathrm{Nb}$ & n.a. & 1.09 & 1.07 & 0.49 & 0.87 & 1.52 \\
\hline $\mathrm{Ni}$ & 0.36 & 0.16 & 0.17 & 0.23 & 0.14 & 0.17 \\
\hline $\mathrm{Pb}$ & 0.16 & 0.08 & 0.08 & 0.10 & 0.07 & 0.08 \\
\hline $\mathrm{Si}$ & 23.5 & 22.9 & 23.2 & 23.2 & 24.6 & 22.3 \\
\hline $\mathrm{Ti}$ & 0.04 & 4.34 & 4.23 & 2.22 & 3.99 & 4.56 \\
\hline $\mathrm{Zn}$ & 0.03 & 0.01 & 0.02 & 0.03 & 0.03 & 0.02 \\
\hline $\mathrm{Zr}$ & 0.29 & 1.17 & 1.14 & 0.73 & 1.04 & 1.17 \\
\hline $\mathrm{n}$ & & & & & \\
\hline
\end{tabular}

n.a. - not analyzed for SB10 (Nb not analyzed, but none added to SB10 system)

SCIX3 was obviously unlike the four bounding cases as expected (higher in Al, Fe, Mn, etc, lower in $\mathrm{Zr}$, Ti, etc.). Boron and lithium wt\%'s are essentially constant, since all five SME products targeted a $40 \%$ waste oxide loading in glass $(60 \%$ frit 418 for the balance). $\mathrm{Nb}$ was relatively variable across the four bounding case runs $(0.87-1.52 \mathrm{wt} \%)$.

\subsubsection{SRAT Cycle Elemental Supernate Chemistry}

Samples of SRAT slurry were separated to recover the aqueous phase to evaluate any changes to the dissolution chemistry due to the presence of CST and MST in the system. Samples were obtained immediately following formic acid addition in all seven runs. Single samples were obtained six hours into reflux in the two baseline runs, while pairs of samples at four and eight hours into reflux were obtained in the five SCIX runs. SRAT product samples were also analyzed for dissolved elements in all seven runs.

Raw concentration data for the supernate following acid addition are given in Table 15. The three low acid runs are on the left side and the four high acid runs are on the right side. 
Table 15. Dissolved element concentrations, $\mathrm{mg} / \mathrm{L}$, following acid addition

\begin{tabular}{|c|c|c|c|c|c|c|c|}
\hline & $\begin{array}{c}\text { SB10 } \\
\mathbf{1 0 0 \%}\end{array}$ & $\begin{array}{c}\text { SCIX3 } \\
\text { Inter }\end{array}$ & $\begin{array}{c}\text { SCIX1 } \\
\text { Bound }\end{array}$ & $\begin{array}{c}\text { SB10 } \\
\mathbf{1 5 0 \%}\end{array}$ & $\begin{array}{c}\text { SCIX2 } \\
\text { Bound }\end{array}$ & $\begin{array}{c}\text { SCIX4 } \\
\text { Ext }\end{array}$ & $\begin{array}{c}\text { SCIX5 } \\
\text { Irrad }\end{array}$ \\
\hline $\mathrm{Al}$ & 1.8 & 8.7 & 5.1 & 190 & 240 & 160 & 270 \\
\hline $\mathrm{Ba}$ & $<0.01$ & 5.2 & 9.0 & 78 & 21 & 12 & 33 \\
\hline $\mathrm{Ca}$ & 3890 & 2970 & 1860 & 3870 & 2050 & 2160 & 1900 \\
\hline $\mathrm{Ce}$ & n.a. & 11 & 2.0 & n.a. & 44 & 29 & 67 \\
\hline $\mathrm{Cr}$ & $<0.01$ & $<0.1$ & $<0.1$ & 5.8 & 5.4 & $<0.1$ & 6.6 \\
\hline $\mathrm{Cu}$ & 0.9 & 7.7 & 3.5 & 44 & 17 & 16 & 11 \\
\hline $\mathrm{Fe}$ & $<0.01$ & 0.30 & 0.86 & 17 & 79 & 310 & 840 \\
\hline $\mathrm{K}$ & 500 & 370 & 220 & 490 & 200 & 310 & 200 \\
\hline $\mathrm{Mg}$ & 380 & 260 & 150 & 420 & 160 & 150 & 150 \\
\hline $\mathrm{Mn}$ & 3,720 & 5,080 & 2,670 & 8,690 & 4,240 & 4,350 & 4,060 \\
\hline $\mathrm{Na}$ & $\mathrm{n} . \mathrm{a}$. & 27,100 & 29,200 & n.a. & 28,100 & 29,000 & 26,900 \\
\hline $\mathrm{Nb}$ & $\mathrm{n} . \mathrm{a}$. & 0.64 & $<1.0$ & n.a. & $<1.0$ & 0.60 & $<1.0$ \\
\hline $\mathrm{Ni}$ & $<0.01$ & 120 & 74 & 480 & 180 & 120 & 220 \\
\hline $\mathrm{Rh}$ & 0.45 & 27 & 15 & 33 & 2.7 & 4.4 & $<10$ \\
\hline $\mathrm{Ru}$ & $<1.0$ & 4.4 & 2.6 & 22 & 4.2 & 3.4 & $<10$ \\
\hline $\mathrm{S}$ & 1 & 66 & 80 & 35 & 81 & 74 & 83 \\
\hline $\mathrm{Si}$ & 0.5 & 110 & 49 & 26 & 74 & 92 & 87 \\
\hline $\mathrm{Ti}$ & $<0.01$ & $<0.1$ & 0.97 & $<0.01$ & 0.98 & $<0.1$ & 1.3 \\
\hline $\mathrm{Zn}$ & $<0.01$ & 1.0 & $<0.1$ & 14 & 5.8 & 2.5 & 7.9 \\
\hline $\mathrm{Zr}$ & 0.01 & $<0.1$ & 0.46 & 0.20 & 0.13 & $<0.1$ & $<1.0$ \\
\hline
\end{tabular}

n.a. - not analyzed ( $\mathrm{Na}$ assumed to be $100 \%$ soluble and $\mathrm{Nb}$ not present for SB10) minimum detection limits are derived from the dilutions run for each sample

Supernate sample results were converted to a percentage of the element dissolved. The aqueous phase concentration in $\mathrm{mg} / \mathrm{L}$ supernate was converted to $\mathrm{mg} / \mathrm{kg}$ supernate using the supernate density (or a reasonable estimate of the density). The elemental concentration in $\mathrm{mg} / \mathrm{kg}$ supernate was converted to $\mathrm{mg} / \mathrm{kg}$ slurry using the $\mathrm{wt} \%$ insoluble solids concentration of the SRAT product. The total elemental concentration in $\mathrm{mg} / \mathrm{kg}$ slurry was calculated from the $\mathrm{wt} \%$ element in the calcined solids and the wt $\%$ calcined solids. The supernate and slurry elemental concentrations in $\mathrm{mg} / \mathrm{kg}$ were divided to produce the percent in solution. The procedure was slightly modified for the samples prior to dewatering where the $\mathrm{wt} \%$ insoluble solids value of the SRAT product was adjusted for dilution by the dewatered condensate. The $\mathrm{mg} / \mathrm{kg}$ values of the total elements were also adjusted for dewatering, and the resulting two adjustments essentially cancelled out.

Table 16 gives the percent dissolution results following acid addition. In reading this and the next table, it should be noted that the CST and MST reduced the overall concentration of normal sludge elements in the five SCIX runs, so a similar percentage represents a reduction in concentration when compared to the baseline. The analyses that are shown with a less than sign mean that the aqueous phase concentration was below the detection limit. Generally, the detection limit was $1 \mathrm{mg} / \mathrm{L}$ or lower (1 ppm), except for Rh and Ru in SCIX5 where it was 10 $\mathrm{mg} / \mathrm{L}$. The detection limit for titanium was $0.01 \mathrm{mg} / \mathrm{L}$. Potassium percentages may be overstated, since there is often some loss of slurry potassium as $\mathrm{K}_{2} \mathrm{O}$ during calcination (the denominator of the percentage calculation) of SRAT product slurry samples (generally not an issue for SME products that form a glass matrix during calcination). 
Table 16. Percent of element dissolved following acid addition

\begin{tabular}{|c|c|c|c|c|c|c|c|}
\hline & $\begin{array}{c}\text { SB10 } \\
\mathbf{1 0 0 \%}\end{array}$ & $\begin{array}{c}\text { SCIX3 } \\
\text { Inter }\end{array}$ & $\begin{array}{c}\text { SCIX1 } \\
\text { Bound }\end{array}$ & $\begin{array}{c}\text { SB10 } \\
\mathbf{1 5 0 \%}\end{array}$ & $\begin{array}{c}\text { SCIX2 } \\
\text { Bound }\end{array}$ & $\begin{array}{c}\text { SCIX4 } \\
\text { Ext }\end{array}$ & $\begin{array}{c}\text { SCIX5 } \\
\text { Irrad }\end{array}$ \\
\hline $\mathrm{Al}$ & 0.01 & 0.1 & 0.1 & 1.5 & 3.5 & 2.3 & 4.2 \\
\hline $\mathrm{Ba}$ & $<$ & 2.2 & 4.7 & 19 & 12 & 5.4 & 19 \\
\hline $\mathrm{Ca}$ & 81 & 72 & 84 & 80 & 97 & 87 & 89 \\
\hline $\mathrm{Ce}$ & n.a. & 1.3 & 0.3 & n.a. & 6.8 & 4.4 & 12 \\
\hline $\mathrm{Cr}$ & $<$ & $<$ & $<$ & 2 & 4 & $<$ & 5 \\
\hline $\mathrm{Cu}$ & 0.9 & n.c. & $<$ & n.c. & 25 & n.c. & 21 \\
\hline $\mathrm{Fe}$ & $<$ & $<$ & $<$ & 0.03 & 0.3 & 0.1 & 3.4 \\
\hline $\mathrm{K}$ & 100 & 90 & 53 & 100 & 58 & 71 & 50 \\
\hline $\mathrm{Mg}$ & 59 & 63 & 55 & 57 & 60 & 51 & 59 \\
\hline $\mathrm{Mn}$ & 37 & 75 & 55 & 88 & 94 & 89 & 99 \\
\hline $\mathrm{Na}$ & n.a. & 100 & 100 & n.a. & 100 & 100 & 100 \\
\hline $\mathrm{Nb}$ & none & $<$ & $<$ & none & $<$ & 0.01 & $<$ \\
\hline $\mathrm{Ni}$ & $<$ & 14 & 12 & 31 & 28 & 19 & 36 \\
\hline $\mathrm{Rh}$ & 1 & 61 & 49 & 73 & 5.5 & 8 & $<$ \\
\hline $\mathrm{Ru}$ & $<$ & 3 & 2 & 10 & 1.8 & 1.3 & $<$ \\
\hline $\mathrm{Si}$ & 0.01 & 2.6 & $<$ & 0.7 & 1.5 & 1.8 & 1.9 \\
\hline $\mathrm{Ti}$ & $<$ & $<$ & $<$ & $<$ & 0.01 & $<$ & 0.01 \\
\hline $\mathrm{Zn}$ & $<$ & 1.1 & $<$ & 10 & 11 & 4 & 13 \\
\hline $\mathrm{Zr}$ & $<0.01$ & $<$ & $<$ & 0.02 & $<$ & $<$ & $<$ \\
\hline
\end{tabular}

n.c. $\quad-$ not calculable because slurry concentration was below detection limit

n.a. - not analyzed

$<\quad-$ below detection limit in the aqueous phase

Typically, more $\mathrm{Mn}$ is dissolved at the end of acid addition in a high acid run than in a low acid run. That trend was followed in both the baseline and the SCIX tests. Roughly $80 \%$ of the slurry calcium seems to dissolve in a typical SRAT cycle, and that trend was followed by all systems. Nickel and zinc require lower $\mathrm{pH}$ conditions to dissolve significantly. They did not dissolve appreciably in low acid runs and were only partially dissolved at high acid. Magnesium percent solubility was fairly constant across the seven runs, but the concentration fell with increasing $\mathrm{CST}$ and MST. Elements such as $\mathrm{Ba}, \mathrm{Ce}, \mathrm{Cr}$, and $\mathrm{Cu}$ are minor components and as such have fairly large uncertainties associated with their calculated percent dissolutions. Dissolved sulfur, presumably as sulfate ion, was fairly consistent across the testing except in the low acid baseline run where very little dissolution was indicated. Dissolution percentages were not calculated for sulfur due to below detection limit slurry results.

Potential impacts of CST and MST were noted as follows:

- Sodium was indicated as $100 \%$ dissolved. This is normal for sludge only systems, but it appears that the insoluble sodium in the MST and CST was leached into the supernate in the five SCIX runs.

- $\mathrm{Zr}, \mathrm{Ti}, \mathrm{Si}$, and $\mathrm{Nb}$ were generally insoluble (primarily associated with CST and MST), though an increase in soluble Si was seen in the bounding SCIX runs at high acid

- Potassium solubility was apparently suppressed in the presence of CST and MST. The calculation for the percent potassium in solution often gives results in the $150-200 \%$ range due to loss of the element as a volatile species in the total slurry elements by 
calcined solids. Consequently, results of order $50 \%$ in solution here may even be overstated by up to a factor of two.

- Noble metal solubility is dependent on nitrite destruction, $\mathrm{pH}$, and other processing conditions. Rh dissolution in the high acid SCIX runs, however, appears to be suppressed, and hydrogen generation generally associated with $\mathrm{Rh}$ also appeared to be suppressed (see Section 3.3.7).

Results from samples during reflux and at the end of reflux (12 hour samples are also SRAT product samples) are given in Table 17 for the low acid stoichiometry tests. The three tests are listed in order of increasing MST and CST content.

Table 17. Percent of element dissolved during reflux - low acid

\begin{tabular}{|c|c|c|c|c|c|c|c|c|}
\hline & $\begin{array}{c}\text { SB10 } \\
\mathbf{6} \mathbf{~ h r}\end{array}$ & $\begin{array}{c}\text { SB10 } \\
\mathbf{1 2} \mathbf{~ h r}\end{array}$ & $\begin{array}{c}\text { SCIX3 } \\
\mathbf{4} \mathbf{~ h r}\end{array}$ & $\begin{array}{c}\text { SCIX3 } \\
\mathbf{8} \mathbf{~ h r}\end{array}$ & $\begin{array}{c}\text { SCIX3 } \\
\mathbf{1 2} \mathbf{~ h r}\end{array}$ & $\begin{array}{c}\text { SCIX1 } \\
\mathbf{4} \mathbf{~ h r}\end{array}$ & $\begin{array}{c}\text { SCIX1 } \\
\mathbf{8} \mathbf{~ h r}\end{array}$ & $\begin{array}{c}\text { SCIX1 } \\
\mathbf{1 2} \mathbf{~ h r}\end{array}$ \\
\hline $\mathrm{Al}$ & 0.01 & $<$ & 0.03 & 0.03 & 0.01 & 0.02 & 0.01 & 0.02 \\
\hline $\mathrm{Ba}$ & 6 & $<$ & 1.5 & 1.3 & 1.2 & 0.5 & 0.4 & $<$ \\
\hline $\mathrm{Ca}$ & 69 & 65 & 51 & 50 & 57 & 61 & 56 & 52 \\
\hline $\mathrm{Ce}$ & n.a. & n.a. & 0.2 & 0.1 & 0.1 & 0.03 & 0.02 & 0.01 \\
\hline $\mathrm{Cr}$ & $<$ & $<$ & $<$ & 1.5 & $<$ & $<$ & $<$ & $<$ \\
\hline $\mathrm{Cu}$ & 0.7 & $<$ & $<$ & $<$ & 50 & 57 & 0.4 & 0.4 \\
\hline $\mathrm{Fe}$ & $<$ & $<$ & 0.01 & $<$ & 0.1 & 0.1 & $<$ & $<$ \\
\hline $\mathrm{K}$ & 100 & 100 & 84 & 86 & 2 & $<$ & 56 & 37 \\
\hline $\mathrm{Mg}$ & 55 & 56 & 51 & 51 & 64 & 49 & 44 & 45 \\
\hline $\mathrm{Mn}$ & 9 & 5 & 31 & 23 & 19 & 13 & 9 & 8 \\
\hline $\mathrm{Na}$ & n.a. & 100 & 88 & 87 & 100 & 100 & 100 & 100 \\
\hline $\mathrm{Nb}$ & - & - & $<$ & $<$ & $<0.05$ & $<$ & $<$ & $<$ \\
\hline $\mathrm{Ni}$ & $<$ & $<$ & 0.2 & $<$ & $<$ & 0.1 & $<$ & $<$ \\
\hline $\mathrm{Rh}$ & 1.5 & $<$ & 2 & 2 & $<$ & $<$ & $<$ & $<$ \\
\hline $\mathrm{Ru}$ & $<$ & $<$ & $<$ & $<$ & $<$ & $<$ & $<$ & $<$ \\
\hline $\mathrm{Si}$ & 0.7 & 0.2 & 6.6 & 3.3 & 0.2 & 2.2 & 1.2 & 0.2 \\
\hline $\mathrm{Ti}$ & $<$ & $<$ & $<$ & $<$ & $<$ & $<$ & $<$ & $<$ \\
\hline $\mathrm{Zn}$ & $<$ & $<$ & $<$ & $<$ & $<$ & $<$ & $<$ & $<$ \\
\hline $\mathrm{Zr}$ & $<$ & $<$ & $<$ & $<$ & $<$ & $<$ & $<$ & $<$ \\
\hline
\end{tabular}

Suppressed K solubility was seen in the SCIX samples (may have ion exchanged with the CST which was not loaded with Cs for simulant tests; CST prefers $\mathrm{K}$ to $\mathrm{Na}$ ). Ca solubility seemed somewhat lower in percent and also lower in $\mathrm{mg} / \mathrm{L}$ in the SCIX runs at low acid during reflux. This could be due to the formation of an insoluble $\mathrm{Ca}$ compound from one of the supernate anions. Since SCIX1 and SCIX3 had less total Ca than SB10, but comparable amounts of supernate anions, the formation of an insoluble $\mathrm{Ca}$ species would drop a larger fraction of the $\mathrm{Ca}$ out of solution in the two SCIX runs than in the baseline run. Aluminum and iron were essentially insoluble in the low acid runs.

Results for three runs at high acid are given in Table 18. These three SRAT cycles had essentially identical process timelines. SCIX4 was also high acid, but had the extended alpha 
strike and acidic MCU additions during processing. It will be discussed separately following the discussion of SCIX2, SCIX5, and the SB10 high acid run.

Table 18. Percent of element dissolved during reflux - high acid

\begin{tabular}{|c|c|c|c|c|c|c|c|c|}
\hline & $\begin{array}{c}\text { SB10 } \\
\mathbf{6} \mathbf{~ h r}\end{array}$ & $\begin{array}{c}\text { SB10 } \\
\mathbf{1 2} \mathbf{~ h r}\end{array}$ & $\begin{array}{c}\text { SCIX2 } \\
\mathbf{4} \mathbf{~ h r}\end{array}$ & $\begin{array}{c}\text { SCIX2 } \\
\mathbf{8} \mathbf{~ h r}\end{array}$ & $\begin{array}{c}\text { SCIX2 } \\
\mathbf{1 2} \mathbf{~ h r}\end{array}$ & $\begin{array}{c}\text { SCIX5 } \\
\mathbf{4} \mathbf{~ h r}\end{array}$ & $\begin{array}{c}\text { SCIX5 } \\
\mathbf{8} \mathbf{~ h r}\end{array}$ & $\begin{array}{c}\text { SCIX5 } \\
\mathbf{1 2} \mathbf{~ h r}\end{array}$ \\
\hline $\mathrm{Al}$ & 0.01 & 0.01 & 0.5 & 0.1 & 0.2 & 1.1 & 3.9 & 1.1 \\
\hline $\mathrm{Ba}$ & 15 & n.a. & 10 & 10 & 3 & 15 & 12 & 7 \\
\hline $\mathrm{Ca}$ & 81 & 71 & 96 & 88 & 92 & 89 & 91 & 95 \\
\hline $\mathrm{Ce}$ & n.a. & n.a. & 5 & 3 & 2 & 12 & 10 & 10 \\
\hline $\mathrm{Cr}$ & 0.1 & $<$ & 0.4 & $<$ & 0.2 & 1.2 & 0.7 & 1.0 \\
\hline $\mathrm{Cu}$ & n.c. & n.c. & 1 & 1 & 2 & 2 & 1 & 1 \\
\hline $\mathrm{Fe}$ & 0.3 & $<$ & 8.1 & 4.6 & 2.3 & 14 & 12 & 12 \\
\hline $\mathrm{K}$ & 100 & 100 & 58 & 66 & 83 & 55 & 55 & 36 \\
\hline $\mathrm{Mg}$ & 60 & 59 & 73 & 66 & 78 & 70 & 71 & 76 \\
\hline $\mathrm{Mn}$ & 64 & 20 & 89 & 80 & 89 & 98 & 97 & 100 \\
\hline $\mathrm{Na}$ & n.a. & 100 & 100 & 100 & 100 & 100 & 100 & 100 \\
\hline $\mathrm{Nb}$ & - & - & $<$ & $<$ & $<$ & $<$ & $<$ & $<$ \\
\hline $\mathrm{Ni}$ & 3 & $<$ & 20 & 11 & 11 & 31 & 26 & 25 \\
\hline $\mathrm{Rh}$ & 1 & $<$ & $<$ & $<$ & $<$ & $<$ & $<$ & $<$ \\
\hline $\mathrm{Ru}$ & $<$ & $<$ & $<$ & $<$ & $<$ & $<$ & $<$ & $<$ \\
\hline $\mathrm{Si}$ & 2 & 0.5 & 1 & 1 & 1 & 2 & 2 & 2 \\
\hline $\mathrm{Ti}$ & $<$ & $<$ & $<$ & $<$ & $<$ & $<$ & $<$ & $<$ \\
\hline $\mathrm{Zn}$ & $<$ & $<$ & 11 & 4 & 2 & 13 & 11 & 9 \\
\hline $\mathrm{Zr}$ & $<$ & $<$ & $<$ & $<$ & $<$ & $<$ & $<$ & $<$ \\
\hline
\end{tabular}

Some of the differences in SCIX5 relative to other tests may be due to the lower total solids concentration during reflux. SCIX5 was targeted for about $840 \mathrm{~g}$ of condensate removal during dewatering, but only about $540 \mathrm{~g}$ of condensate was actually removed. This factor caused the 4 and 8 hour samples, as well as the SRAT product, to come roughly one hour sooner than in the other tests. There was also about $10 \%$ more supernate phase to carry soluble ions than in the other tests. The $10 \%$ higher Mn dissolution might simply be because there was $10 \%$ more supernate if it is at saturation.

The rheological properties during SCIX5 reflux were also considerably less viscous. This condition could impact bubble retention and gas absorption (that is, it could reduce the efficiency of supernate $\mathrm{CO}_{2}$ absorption by reducing the contact time between $\mathrm{CO}_{2}$ bubbles and the bulk slurry). It has been hypothesized that $\mathrm{CO}_{2}$ from formate destruction is absorbed in the supernate and forms insoluble carbonate or bicarbonate salts with dissolved Mn during reflux. While formate was actively destroyed during reflux in the SCIX runs, the extent of Mn dissolution was not greatly impacted.

An increase in $\mathrm{Ca}$ and $\mathrm{Mg}$ dissolution extent was seen in the two bounding runs, but this may be related to the reduced total masses of these two elements after dilution with CST and MST. The higher extents of $\mathrm{Ca}, \mathrm{Mg}$, and $\mathrm{Mn}$ dissolution in the SCIX SRAT products would be expected to result in lower yield stress slurries at a given $\mathrm{wt} \%$ total solids. Corresponding rheology data that 
ultimately supported this hypothesis are presented in Section 3.4. While SCIX2 and SCIX5 results are not identical, it is not obvious that any of the small differences are due to anything other than the slightly different $\mathrm{pH}$ values during SRAT reflux processing

A surprising increase in iron dissolution was seen in the SCIX high acid runs compared to both the low acid runs and to general sludge batch flowsheet simulations. Iron generally does not dissolve appreciably in SRAT simulations with the current DWPF flowsheet. The aqueous phases of selected SCIX2 and SCIX5 samples were dark yellow to red-brown instead of light yellow or clear in a $15-\mathrm{mL}$ sample vial, Figure 5.

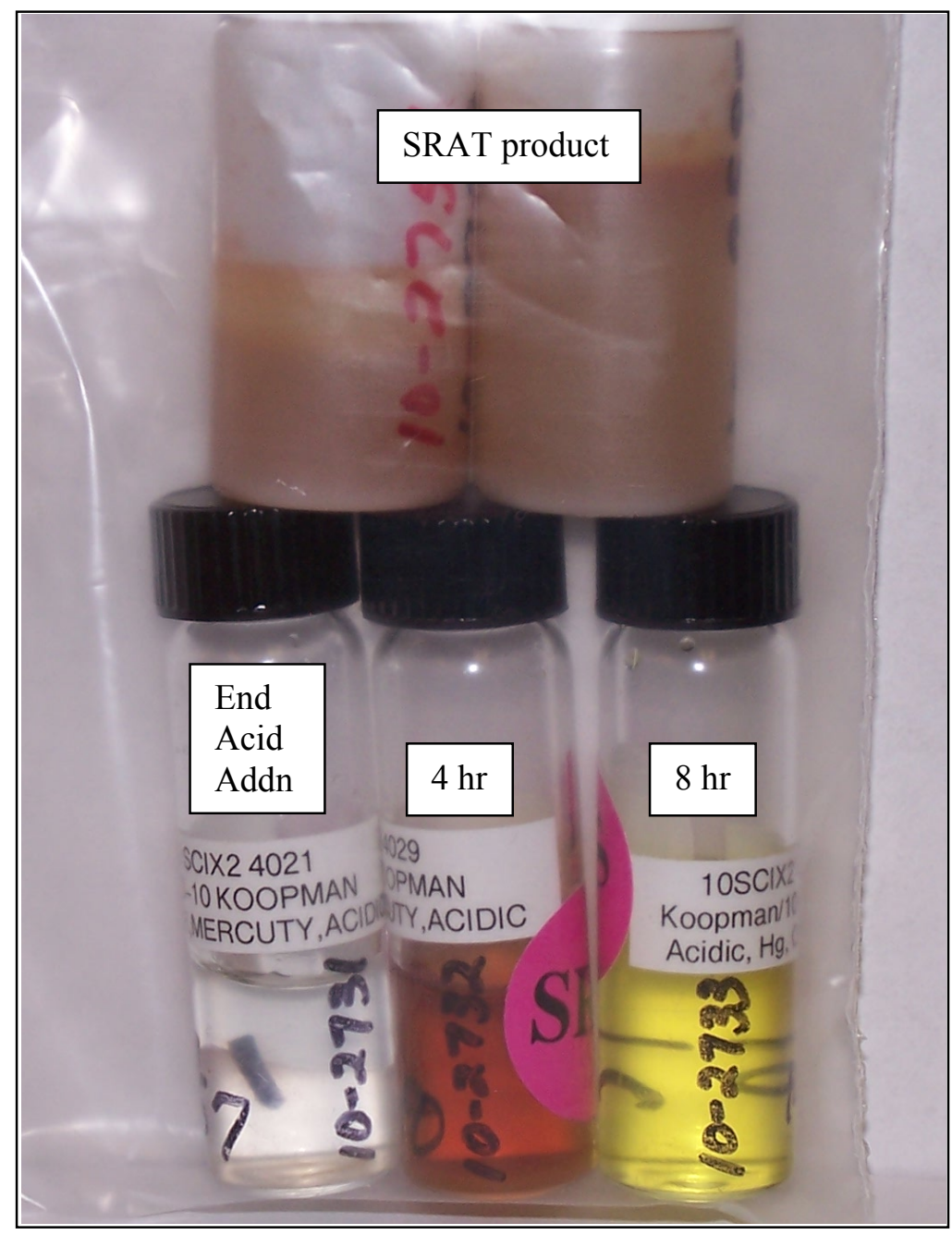

Figure 5. SCIX2 supernates

The top two samples in Figure 5 are from the SRAT product. The bottom row in the glass vials are the samples (left to right) after acid addition, four hours into reflux (brown), and eight hours into reflux (golden yellow). There was no indication that the increased iron solubility was large enough to be a criticality concern to DWPF, but this iron dissolution behavior was unusual compared to historical sludge batch flowsheet test results.

SCIX4 was run with an SWPF alpha strike while under caustic boiling (rather than an ARP addition) prior to acid addition plus a dilute nitric acid addition simulating the Cs effluent during 
boiling between SRAT dewatering and SRAT reflux. SCIX4 is compared to the baseline run and the matching bounding case, SCIX2, in Table 19. For SCIX4, 4 hours and 8 hours mean 4 hours into effluent addition and 8 hours into effluent addition rather than 4 and 8 hours into reflux.

Table 19. Percent of element dissolved - SCIX4 alpha strike test comparison

\begin{tabular}{|c|c|c|c|c|c|c|c|c|}
\hline & $\begin{array}{c}\text { SB10 } \\
\mathbf{6} \mathbf{~ h r}\end{array}$ & $\begin{array}{c}\text { SB10 } \\
\mathbf{1 2} \mathbf{~ h r}\end{array}$ & $\begin{array}{c}\text { SCIX2 } \\
\mathbf{4} \mathbf{~ h r}\end{array}$ & $\begin{array}{c}\text { SCIX2 } \\
\mathbf{8} \mathbf{~ h r}\end{array}$ & $\begin{array}{c}\text { SCIX2 } \\
\mathbf{1 2} \mathbf{~ h r}\end{array}$ & $\begin{array}{c}\text { SCIX4 } \\
\mathbf{4} \mathbf{~ h r}\end{array}$ & $\begin{array}{c}\text { SCIX4 } \\
\mathbf{8} \mathbf{~ h r}\end{array}$ & $\begin{array}{c}\text { SCIX4 } \\
\mathbf{1 2} \mathbf{~ h r}\end{array}$ \\
\hline $\mathrm{Al}$ & 0.01 & 0.01 & 0.5 & 0.1 & 0.2 & 0.3 & 0.1 & 0.2 \\
\hline $\mathrm{Ba}$ & 15 & n.a. & 10 & 10 & 3 & 49 & 39 & 25 \\
\hline $\mathrm{Ca}$ & 81 & 71 & 96 & 88 & 92 & 73 & 75 & 89 \\
\hline $\mathrm{Ce}$ & n.a. & n.a. & 5 & 3 & 2 & 3.4 & 2.2 & 2.3 \\
\hline $\mathrm{Cr}$ & 0.1 & $<$ & 0.4 & $<$ & 0.2 & $<$ & $<$ & $<$ \\
\hline $\mathrm{Cu}$ & n.c. & n.c. & 1 & 1 & 2 & n.c. & n.c. & n.c. \\
\hline $\mathrm{Fe}$ & 0.3 & $<$ & 8.1 & 4.6 & 2.3 & 4.6 & 2.9 & 1.2 \\
\hline $\mathrm{K}$ & 100 & 100 & 58 & 66 & 83 & 68 & 76 & 100 \\
\hline $\mathrm{Mg}$ & 60 & 59 & 73 & 66 & 78 & 52 & 55 & 66 \\
\hline $\mathrm{Mn}$ & 64 & 20 & 89 & 80 & 89 & 72 & 70 & 61 \\
\hline $\mathrm{Na}$ & n.a. & 100 & 100 & 100 & 100 & 85 & 88 & 100 \\
\hline $\mathrm{Nb}$ & - & - & $<$ & $<$ & $<$ & 0.01 & 0.02 & $<0.02$ \\
\hline $\mathrm{Ni}$ & 3 & $<$ & 20 & 11 & 11 & 12 & 7 & 7 \\
\hline $\mathrm{Rh}$ & 1 & $<$ & $<$ & $<$ & $<$ & 1.8 & 1.7 & $<$ \\
\hline $\mathrm{Ru}$ & $<$ & $<$ & $<$ & $<$ & $<$ & $<$ & $<$ & $<$ \\
\hline $\mathrm{Si}$ & 2 & 0.5 & 1 & 1 & 1 & 1 & 1 & 1 \\
\hline $\mathrm{Ti}$ & $<$ & $<$ & $<$ & $<$ & $<$ & $<$ & $<$ & $<$ \\
\hline $\mathrm{Zn}$ & $<$ & $<$ & 11 & 4 & 2 & 4 & 1 & $<$ \\
\hline $\mathrm{Zr}$ & $<$ & $<$ & $<$ & $<$ & $<$ & $<$ & $<$ & $<$ \\
\hline
\end{tabular}

SCIX4 had slightly lower $\mathrm{Ca}, \mathrm{Mg}$, and Mn solubility than the other high acid SCIX runs. $\mathrm{Ba}$ reached fairly high extents of dissolution in SCIX4, though it is a relatively minor species in the sludge solids. This increase is not likely due to $\mathrm{pH}$, since SCIX4 was expected to run at slightly higher $\mathrm{pH}$ values than SCIX2 or SCIX5 following formic acid addition.

The reflux period produced essentially the same conclusions that were drawn from the samples following formic acid addition. It was also noted that:

- There was a chance for increased iron solubility at high acid.

- $\mathrm{Wt} \%$ dissolved solids increased and insoluble solids decreased as CST and MST were increased (see also Section 3.3.8) for essentially constant total solids.

- Slower processing may lead to increased extents of precipitation for $\mathrm{Mn}, \mathrm{Mg}$, and $\mathrm{Ca}$.

Generally, the supernate element data did not indicate any potentially significant negative impacts to DWPF from processing with CST and MST at the bounding levels of this study. Results from the DWPF alternate flowsheet testing using glycolic acid, however, show the potential to change some of these conclusions. ${ }^{24}$ Zirconium dissolution levels were anywhere from 9-82\% depending on acid stoichiometry. The potential exists for glycolic acid to attack the $\mathrm{Zr}$ in the CST binder and release pure, small silico-titanate crystals from the ion exchange solid matrix. The impact to 
settling rate and rheology from this process on the SRAT and SME slurries could be more significant than the data presented here indicate (current data might not bound that scenario).

\subsubsection{SRAT and SME Product Ion Evaluation}

IC is used to track key ions during SRAT and SME processing such as nitrite, formate, nitrate, and ammonium ions as well as lesser anions such as chloride and sulfate. Ion mass concentrations on a slurry basis are summarized in Table 20 .

Table 20. SRAT and SME product slurry anions, $\mathrm{mg} / \mathrm{kg}$

\begin{tabular}{|l|r|r|r|r|r||}
\hline & SCIX1 & SCIX2 & SCIX3 & SCIX4 & SCIX5 \\
\hline SRAT & & & & & \\
\hline Formate & 50,500 & 60,500 & 53,950 & 57,150 & 61,200 \\
\hline Nitrate & 22,700 & 20,050 & 19,550 & 22,650 & 28,500 \\
\hline Sulfate & 460 & 1,410 & $<100$ & 130 & $<100$ \\
\hline Chloride & 270 & 330 & 240 & 310 & 240 \\
\hline SME & & & & & \\
\hline Formate & 49,700 & 60,800 & 56,600 & 55,700 & 58,850 \\
\hline Nitrate & 21,550 & 26,050 & 20,100 & 21,200 & 27,150 \\
\hline Sulfate & 250 & 300 & 100 & 160 & 120 \\
\hline Chloride & 260 & 320 & 230 & 310 & 250 \\
\hline \hline
\end{tabular}

SCIX1 may be mildly contaminated for chloride by $\mathrm{pH}$ probe solution.

Raw anion results were incorporated into SRAT and SME cycle material balance calculations. Key observations for the SRAT cycle are given in Table 21. Nitrite ion was destroyed to $<100$ $\mathrm{mg} / \mathrm{kg}$ in all but the $100 \% \mathrm{SB} 10-100$ baseline simulant run where it was about $1,450 \mathrm{mg} / \mathrm{kg}$ in the SRAT product.

Table 21. SRAT cycle ion observations

\begin{tabular}{|l|c|c|c|c|}
\hline Run & $\begin{array}{c}\text { Acid } \\
\text { Stoichiometry }\end{array}$ & $\begin{array}{c}\text { Formate } \\
\text { Consumption }\end{array}$ & $\begin{array}{c}\text { Overall (net) } \\
\text { Nitrate loss }\end{array}$ & $\begin{array}{c}\text { Ammonium } \\
\text { detected }\end{array}$ \\
\hline SB10 baseline & $100 \%$ & $26 \%$ & $0 \%$ & none \\
\hline SB10 baseline & $150 \%$ & $35 \%$ & $27 \%$ & none \\
\hline SCIX1 bounding & $100 \%$ & $19 \%$ & $0 \%$ & none \\
\hline SCIX2 bounding & $150 \%$ & $28 \%$ & $6 \%$ & none \\
\hline SCIX3 intermediate & $100 \%$ & $15 \%$ & $8 \%$ & none \\
\hline SCIX4-extended & $150 \%$ & $33 \%$ & $14 \%$ & none \\
\hline SCIX5-irradiated & $150 \%$ & $20 \%$ & $3 \%$ & none \\
\hline
\end{tabular}

There was no net nitrite-to-nitrate conversion by the end of the SRAT cycle. Early DWPF sludge batches had $10-30 \%$ nitrite-to-nitrate conversion as indicated by a net increase in total nitrate during the SRAT cycle. The evaluation of catalytic ammonium ion formation during SB6 studies included a conversion route from nitrate to ammonium that took several steps (nitrogen changes oxidation state by eight during the reaction sequence). ${ }^{25}$ In the SCIX-SB10 testing, nitrate was destroyed without the appearance of ammonium ion. It was noted that the SRAT $\mathrm{pH}$ ran lower than in recent sludge batch studies where ammonium ion formation was detected. 
Based on the earlier work, it appears that nitrate was converted to nitrite and/or NO, two of the intermediates in the ammonium ion formation reaction scheme. The nitrite and NO thus formed subsequently desorbed from the catalytic substrate into the supernate where they were either destroyed (nitrite by residual acid) or released into the off-gas. In Section 3.3.7, the GC data for $\mathrm{N}_{2} \mathrm{O}$ show that a small residual amount of $\mathrm{N}_{2} \mathrm{O}$ was produced during reflux in most of the runs. This $\mathrm{N}_{2} \mathrm{O}$ is consistent with a release of nitrite ion back into the supernate and subsequent conversion to $\mathrm{N}_{2} \mathrm{O}$ by identical chemistry to that which occurs during formic acid addition with the nitrite ion found in the feed sludge supernate.

Both the net molar formate loss and the percentage formate loss during the SRAT cycle were generally mitigated by the presence of MST and CST. This was potentially due to the lower stoichiometric acid demand of the bounding SB10-CST-MST simulant. Tests at $150 \%$ of the minimum acid had roughly 5-7\% less extra acid in moles than the SB10 baseline run at $150 \%$. The intermediate MST-CST simulant had slightly higher acid demand than the SB10 baseline, and its formate loss fell in between that of the two $100 \%$ runs. The alpha strike-MCU run, SCIX4, also had significant formate loss in addition to relatively high nitrate loss. This extra loss is attributed to some additional processing time and to somewhat higher $\mathrm{pH}$ values during reflux (2.3\% of the total SRAT acid addition was included in the MCU stream which contributed to the higher $\mathrm{pH}$ values).

Intermediate characterization of the SRAT anions following acid addition confirmed that the nitrite-to-nitrate conversion reaction was still occurring during the SCIX runs as nitrite from the starting sludge was destroyed. Calculations for reaction progress at the end of formic acid addition are given in Table 22. The calculation of the extent of nitrite-to-nitrate conversion at the end of acid addition is subject to propagation of uncertainties in the chemical analyses when nitrite is not essentially destroyed (low acid runs). A formate loss of roughly $5-10 \%$ is fairly typical for SRAT acid addition at 4-L scale with nominal acid feed rates and sludge that undergoes some manganese reduction and nitrite destruction. The calculated results are summarized in Table 22.

Table 22. SRAT cycle ion observations at end of formic acid addition

\begin{tabular}{|l|c|c|c|c|}
\hline Run & $\begin{array}{c}\text { Acid } \\
\text { Stoichiometry }\end{array}$ & $\begin{array}{c}\text { Nitrite } \\
\text { Destruction }\end{array}$ & $\begin{array}{c}\text { Nitrite-to- } \\
\text { nitrate } \\
\text { conversion }\end{array}$ & $\begin{array}{c}\text { Formate } \\
\text { Consumption }\end{array}$ \\
\hline SB10 baseline & $100 \%$ & $24 \%^{\dagger}$ & none & $11 \%$ \\
\hline SB10 baseline & $150 \%$ & $89 \%$ & none & $9 \%$ \\
\hline SCIX1 bounding & $100 \%$ & $23 \%^{\dagger}$ & $43 \%^{\dagger}$ & $4 \%$ \\
\hline SCIX2 bounding & $150 \%$ & $100 \%$ & $47 \%$ & (negative) \\
\hline SCIX3 intermediate & $100 \%$ & $48 \%{ }^{\dagger}$ & $20 \%$ & $1 \%$ \\
\hline SCIX4-extended & $150 \%$ & $100 \%$ & $32 \%$ & $11 \%$ \\
\hline SCIX5-irradiated & $150 \%$ & $100 \%$ & $47 \%$ & $11 \%$ \\
\hline
\end{tabular}

$\dagger-$ marked values contain potentially significant propagation of uncertainties

The end of acid addition nitrite-to-nitrate conversions of the five SCIX runs indicate that the actual nitrate losses in these runs were even greater than those given in Table 21. The loss reported there did not include any nitrate formed from nitrite-to-nitrate conversion, but Table 22 indicates that nitrite-to-nitrate conversion did in fact occur to some unknown net extent prior to or in parallel with nitrate destruction. 
No excess nitrate was detected in the two SB10 baseline run samples following acid addition $(100 \%$ or $150 \%)$. This is a fairly unusual result for a seemingly normal sludge simulant. It may indicate that an analytical bias was present when these samples were analyzed. There is also some supernate nitrate ion data available for these two runs which suggest that there may have been about $10 \%$ more nitrate present than was found in the caustic quenched slurry samples that form the basis for the calculations above. The low formate losses of SCIX2 and SCIX3 at the end of acid addition are probably the result of analytical uncertainties as well. Off-gas $\mathrm{CO}_{2}$ data does not support the absence of formate destruction during acid addition in any of the runs.

Formate and nitrate masses were tracked through the SME cycle, since they have a primary impact on the glass reduction-oxidation chemistry in the DWPF melter. Only small changes in formate and nitrate are typically observed during the SME cycle unless a fairly long cycle is performed (such as one with five canister decon water additions and concentrations in addition to frit additions) or when the SRAT product is particularly catalytically active going into the SME cycle (such as SB10 at $150 \%$ acid was in this study). Small anion changes were the typical outcome of the five SCIX run SME cycles, Table 23, and ammonium ion was never detected in the samples that were analyzed (presumably due to the mildly acidic $\mathrm{pH}$ values). The most likely run for ammonium ion production would have been SB10 at $150 \%$ acid. The high acid baseline run reached a $\mathrm{pH}$ of nearly seven by the end of the SME cycle. Since this run was free of MST and CST, the ammonium ion issue was not pursued further.

Table 23. SME cycle ion observations

\begin{tabular}{|l|c|c|c|c|}
\hline Run & $\begin{array}{c}\text { Acid } \\
\text { Stoichiometry }\end{array}$ & $\begin{array}{c}\text { Formate } \\
\text { Consumption }\end{array}$ & $\begin{array}{c}\text { SME Nitrate } \\
\text { Loss }\end{array}$ & $\begin{array}{c}\text { Ammonium } \\
\text { detected }\end{array}$ \\
\hline SB10 baseline & $100 \%$ & $0 \%$ & $3 \%$ & no \\
\hline SB10 baseline & $150 \%$ & $23 \%$ & $6 \%$ & Not analyzed \\
\hline SCIX1 bounding & $100 \%$ & $4 \%$ & $0 \%$ & no \\
\hline SCIX2 bounding & $150 \%$ & $5 \%$ & $3 \%$ & no \\
\hline SCIX3 intermediate & $100 \%$ & $(2 \%)$ & $(7 \%)$ & no \\
\hline SCIX4-extended & $150 \%$ & $7 \%$ & $5 \%$ & no \\
\hline SCIX5-irradiated & $150 \%$ & $7 \%$ & $3 \%$ & Not analyzed \\
\hline \hline
\end{tabular}

As the off-gas data show in Section 3.3.7, the baseline case at $150 \%$ acid was still quite catalytically active during the SME cycle and produced considerable hydrogen and $\mathrm{CO}_{2}$. The remaining data indicate that the $100 \%$ stoichiometry tests had minimal anion changes during the SME cycles, while the $150 \%$ tests had only slightly higher formate and nitrate losses than the $100 \%$ tests. The general finding from the anion data was that there was an absence of negative impacts from the presence of MST and CST in the SB10 system studied using the current DWPF flowsheet.

\subsubsection{Evaluation of Off-gas Data}

Off-gas data serve several purposes. The main use is to evaluate the potential risk of flammability in the DWPF off-gas system from the catalytic generation of hydrogen gas. Data on $\mathrm{CO}_{2}$ and $\mathrm{N}_{2} \mathrm{O}$ provide additional information about process chemistry and can also serve as crosschecks on the equivalency of the starting materials in a series of related process simulations. For example, the first main surge in $\mathrm{CO}_{2}$ generation is due to the destruction of carbonate ions. This 
feature should be similar from test to test for a given starting material such as the bounding CSTMST-SB10 blend. Additional processing of the off-gas data provides total quantities that can be used with slurry mass and concentration data to construct material balances on carbon- and nitrogen-bearing species.

DWPF has a limit of $0.65 \mathrm{lbs} \mathrm{H}_{2} / \mathrm{hr}$ in the SRAT cycle and $0.223 \mathrm{lbs} \mathrm{H}_{2} / \mathrm{hr}$ in the SME cycle. Lab-scale results are converted to DWPF-scale assuming that the volume of fresh sludge at the start of nitric acid addition is equivalent to 6,000 gallons of fresh sludge in the DWPF SRAT. SRAT volumetric scale factors are approximately 8,000, while SME scale factors are approximately 9,500. The change in scale factors is due to the volume of samples removed in the SRAT cycle which results in a relatively smaller SME cycle at lab-scale.

Hydrogen was not seen in the SB10 low acid run. Hydrogen was only seen in the last half hour of reflux in SCIX1 and the levels were low. Somewhat more hydrogen was seen in the intermediate blend run at low acid, SCIX3, but the amount would still be considered small (less than $6 \%$ of the DWPF limit). The SCIX3 data suggest that some unintentional excess acid was added in spite of the $100 \%$ target. The Koopman minimum acid equation is not without potential weaknesses and performs best when the input concentration measurements are accurate. The low acid SRAT cycle hydrogen data are shown in Figure 6 at DWPF-scale.

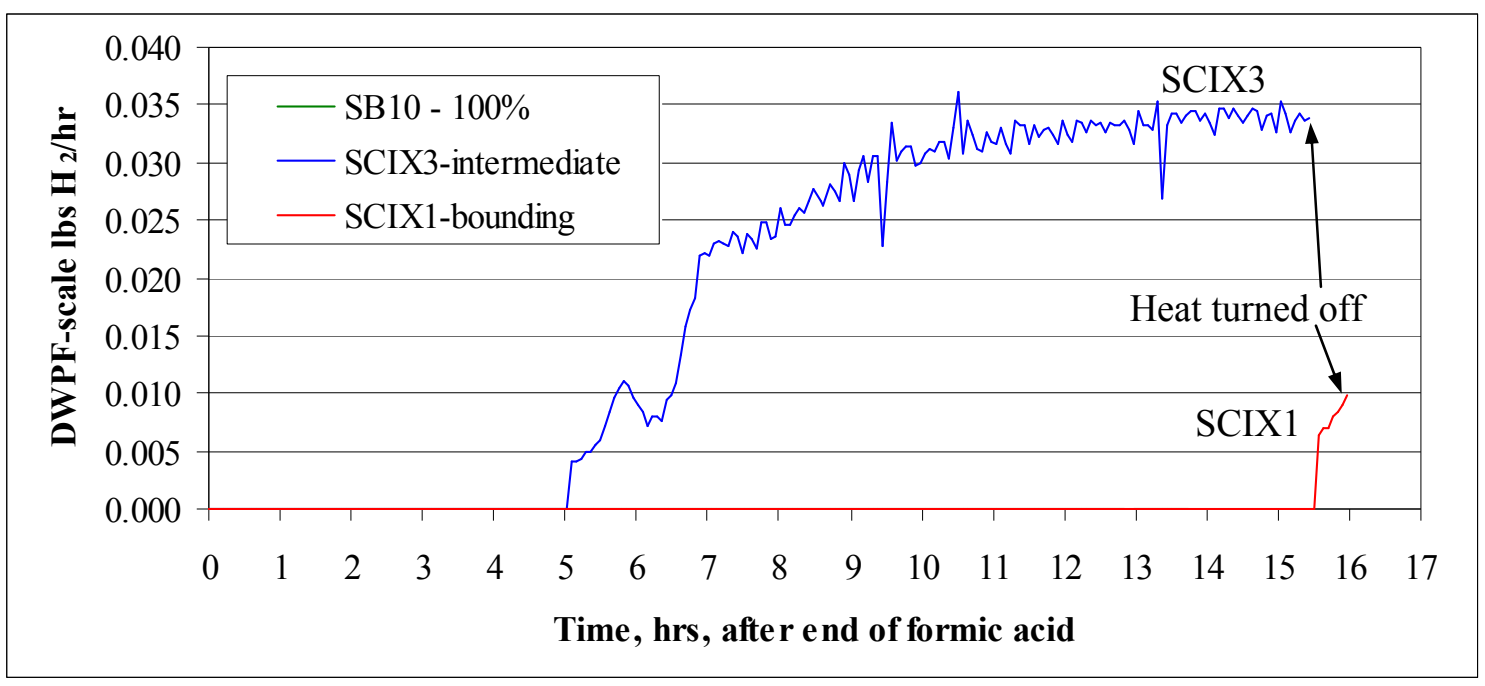

Figure 6. Low acid hydrogen generation comparison - SRAT

Hydrogen did not approach the DWPF limit for the SRAT. This is the expected outcome for runs with low stoichiometric factors (runs close to $100 \%$ ). SME cycle hydrogen generation data at low acid are given in Figure 7. These data are considered conservative relative to tests that include canister decon water additions and dewaterings prior to frit-formic acid-water slurry additions. 


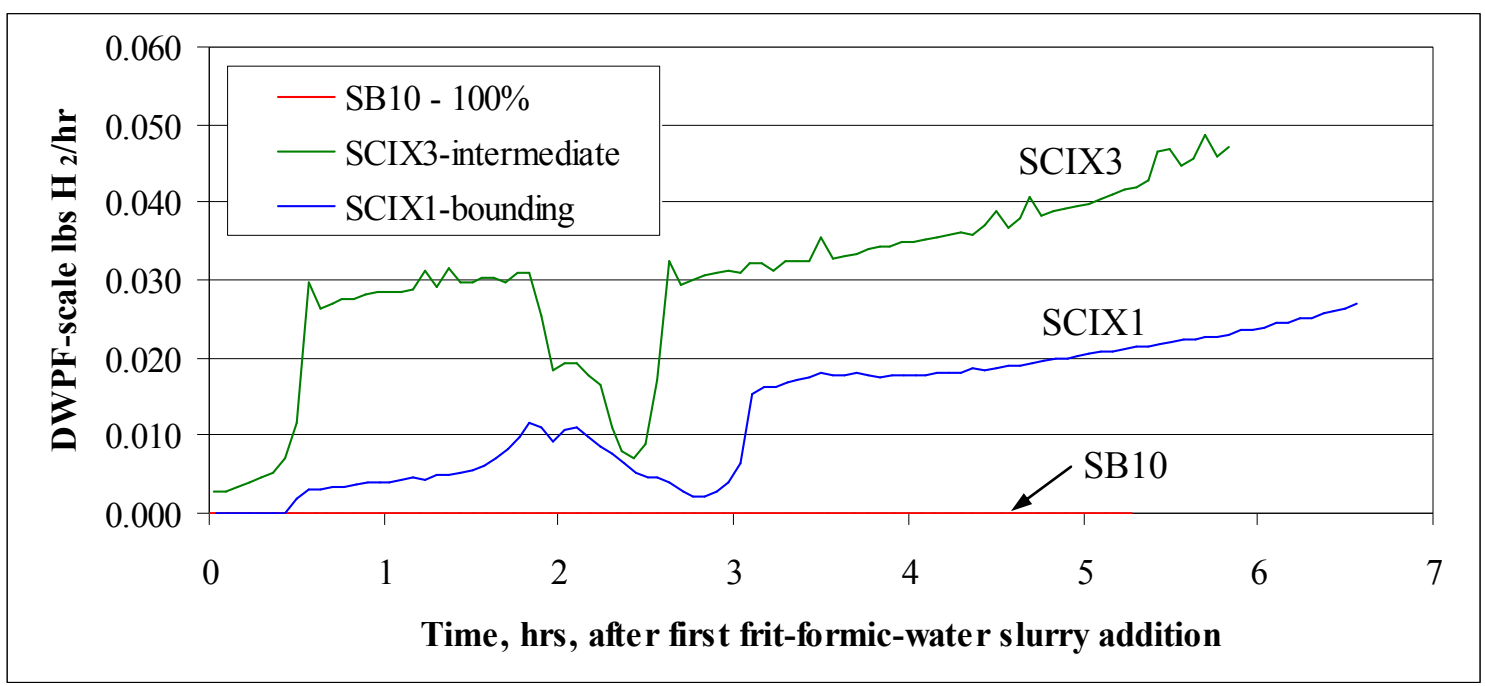

Figure 7. Low acid hydrogen generation comparison - SME

Formic acid in the frit slurry brings in additional excess acid for hydrogen generation relative to the SRAT cycle. The maximum hydrogen generation rates in the SME were higher than in the SRAT, but still well within DWPF limits ( $<25 \%$ of limits).

SRAT hydrogen generation rate data for the four high acid stoichiometry runs are given in Figure 8 at DWPF-scale.

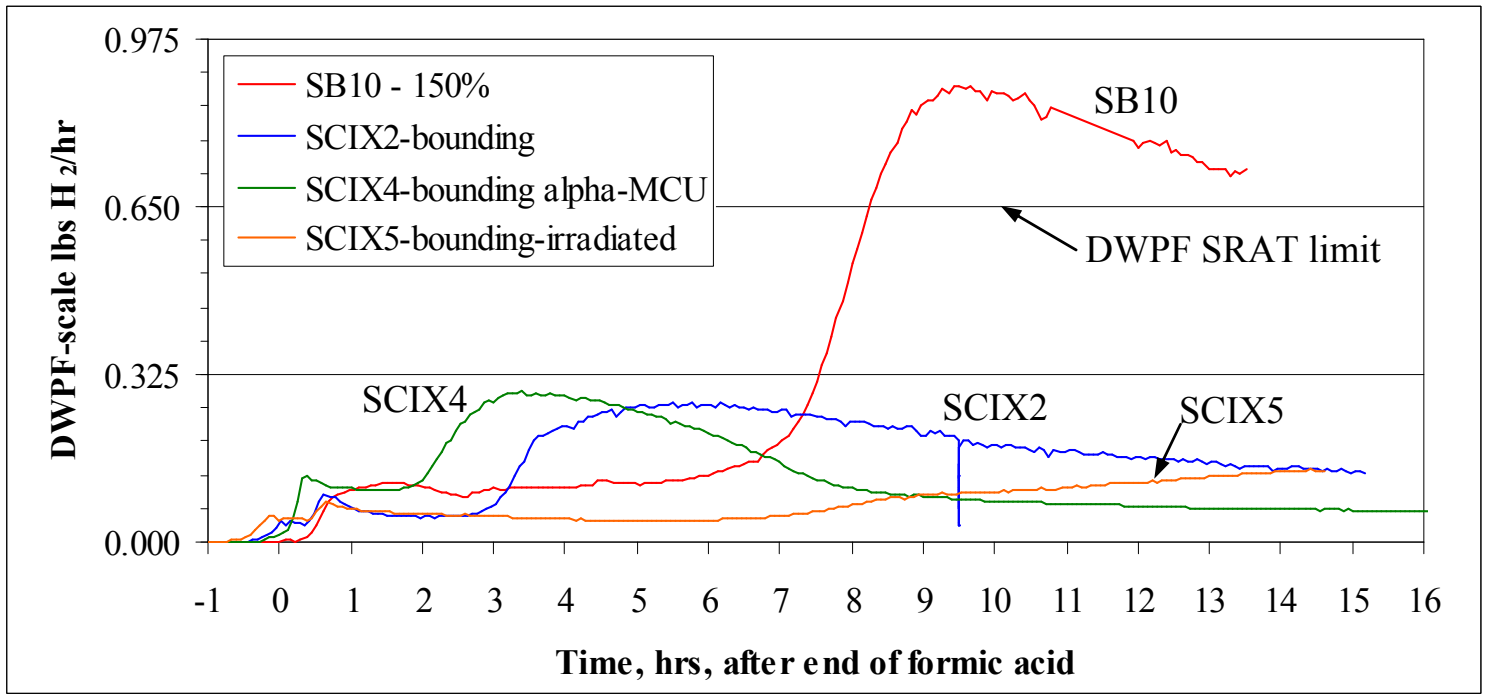

Figure 8. High acid hydrogen generation comparison - SRAT

The three SCIX tests at $150 \%$ acid stoichiometry processed at less than half the DWPF SRAT cycle limit for hydrogen $(<0.325 \mathrm{lbs} / \mathrm{hr})$. This performance was better than the baseline SB10 run which exceeded the SRAT limit by up to $36 \%$. Hydrogen generation maximums appeared to be dominated by ruthenium catalysis. The rhodium catalyzed hydrogen period appeared to occur between zero and one hour after the end of formic acid addition at $<0.15 \mathrm{lbs} / \mathrm{hr}$. SCIX5, the irradiated CST and MST test, had somewhat unusual behavior in that the hydrogen generation 
rate was still steadily increasing at the end of reflux, while the other three tests had all peaked and dropped back to lower rates that were in decline. While such hydrogen generation rate behavior has been seen before, it is not clear why it manifested only in the test with irradiated CST. SME cycle hydrogen results are given in Figure 9.

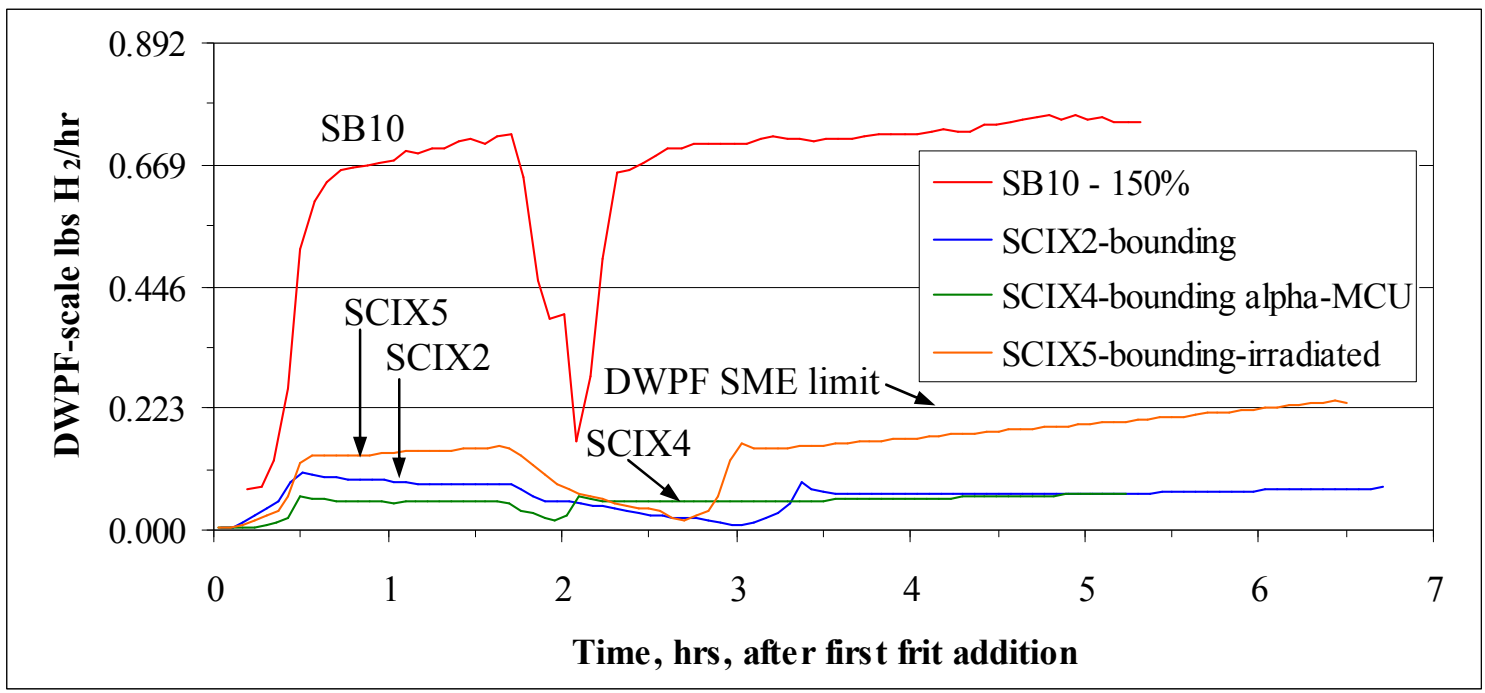

Figure 9. High acid hydrogen generation comparison - SME

The relative ranking at the end of the SRAT cycle was preserved into the beginning of the SME cycle. Maximum CPC hydrogen generation rates can occur in either the SRAT or SME depending on processing conditions. Both cases were observed here. The baseline simulant was well over the DWPF limit for most of the SME cycle. SCIX5 hydrogen generation rate continued to slowly increase through the SME cycle until it crept above the DWPF limit. This indicates that $150 \%$ acid stoichiometry was a bit too aggressive, but that there is still a fairly large range of acid stoichiometries that DWPF could use to process this material. The only other particularly distinctive aspect of SCIX5 was that it was improperly dewatered, so the solids were about $10 \%$ lower in concentration and the slurry was less viscous throughout the SRAT and SME cycles than the other tests. The reduced viscosity may have promoted the segregation of elemental mercury and changed the catalytic formate chemistry enough to account for the hydrogen generation rate trend shift.

SRAT cycle carbon dioxide data are given for the three low acid runs in Figure 10 for acid addition, dewatering, and the start of reflux. This is the period of maximum $\mathrm{CO}_{2}$ production. 


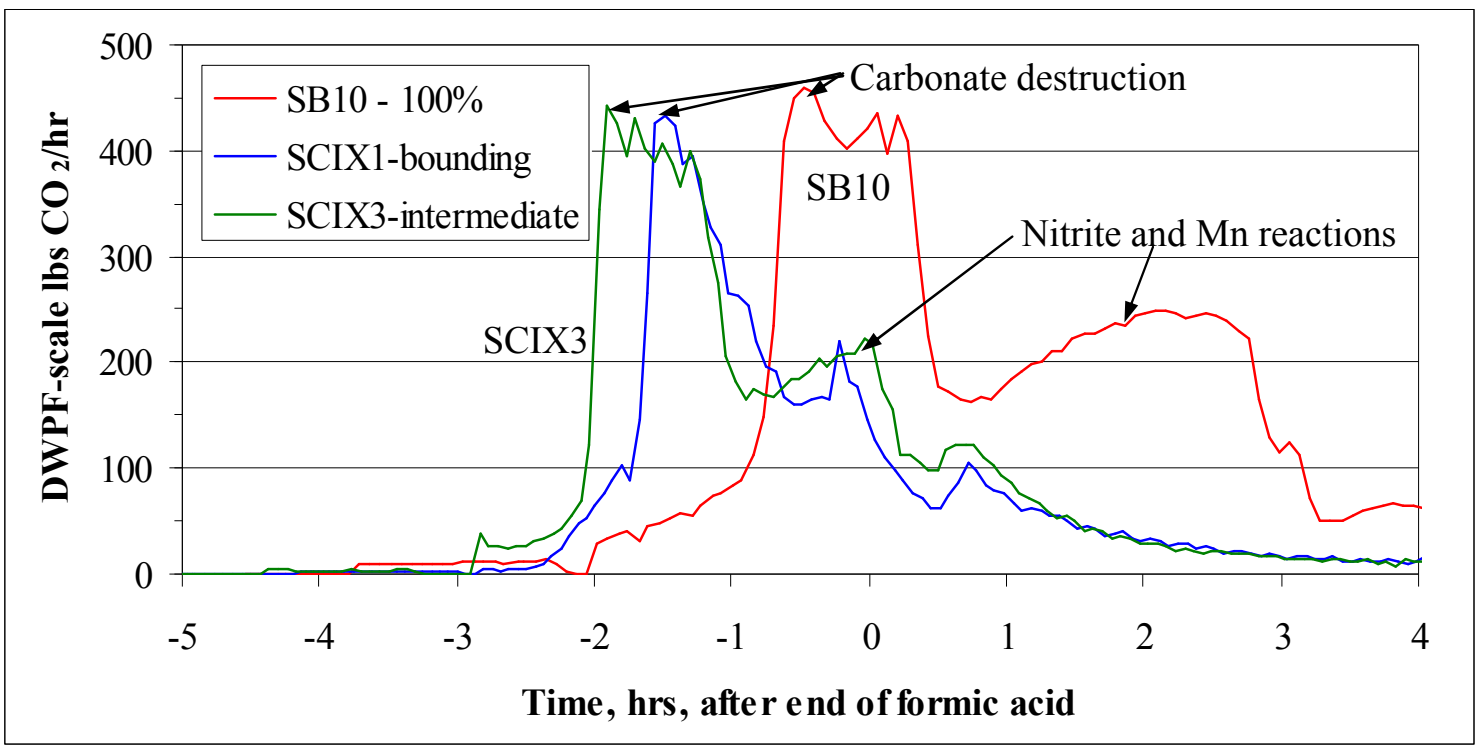

Figure 10. Low acid $\mathrm{CO}_{2}$ generation data - SRAT

The data show generally comparable magnitudes of carbonate destruction (the majority of carbonate was supernate carbonate in the three simulants and all supernates were essentially identical), but there is a significant offset in the timing for the SB10 baseline low acid run. The data indicate the likely under addition of acid in this run consistent with the SRAT product nitrite ion concentration of about $1,450 \mathrm{mg} / \mathrm{kg}$.

Corresponding results for the four high acid runs are given in Figure 11. Carbonate destruction occurred about an hour sooner than in the low acid runs relative to the arbitrary zero time at the end of formic acid addition due to the longer acid addition time at $150 \%$ stoichiometry. More nitrite destruction and manganese reduction occurred before the end of acid addition at $150 \%$ acid as well. These reactions are responsible for the lower, broader peak of $\mathrm{CO}_{2}$ generation from -2 to zero hours. 


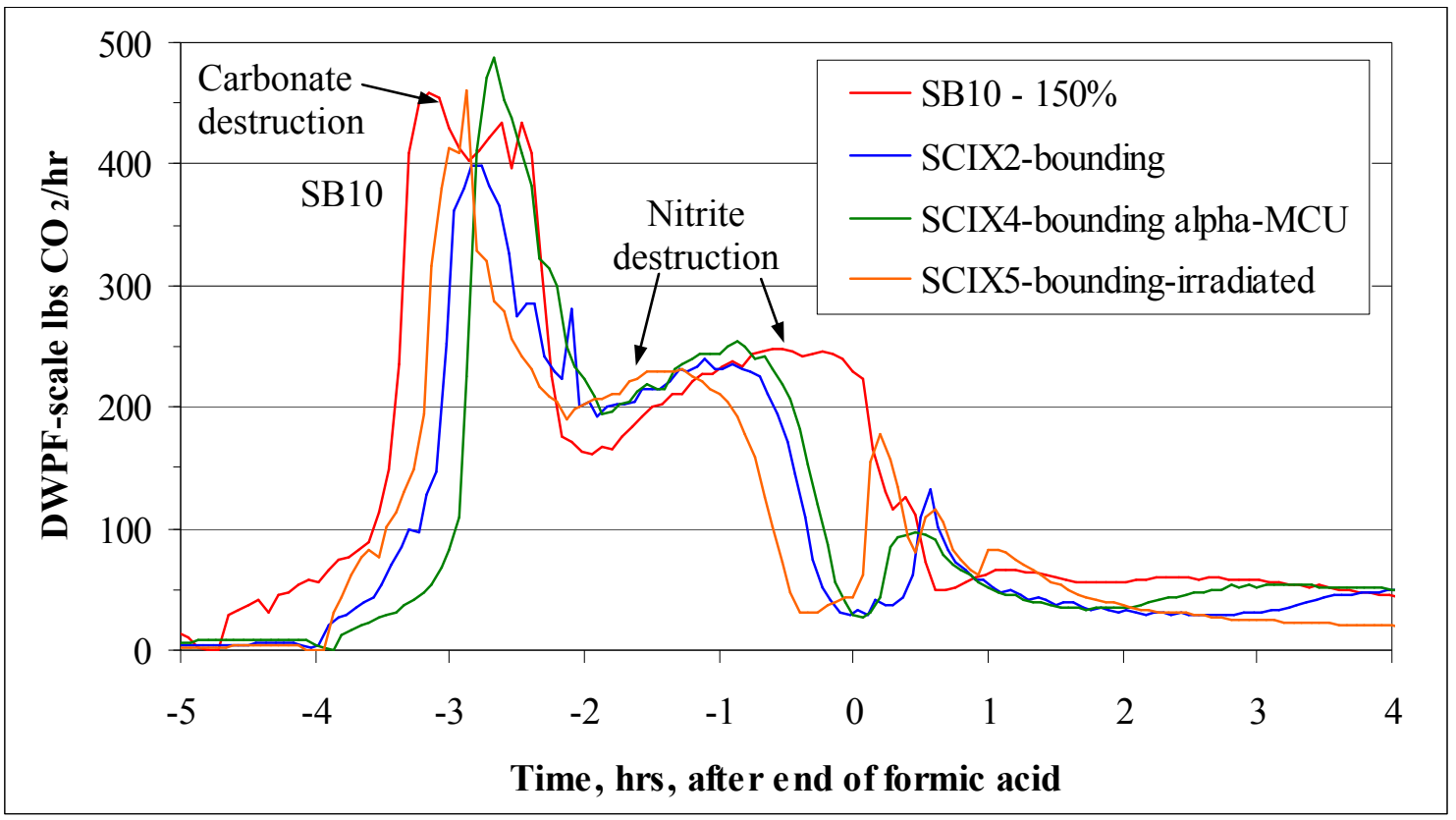

Figure 11. High acid $\mathrm{CO}_{2}$ generation data - SRAT

$\mathrm{CO}_{2}$ from carbonate destruction was very similar as expected. Nitrite destruction seemed to take longer in the SB10 run. The slower nitrite destruction could indicate lower catalytic activity during acid addition which would be the opposite of the trend in catalytic activity indicated by the hydrogen data. The presence of CST and MST did not appear to have any negative impacts on the $\mathrm{CO}_{2}$ generation profiles for either the low or the high acid cases. High acid data covering the full time at boiling is given in Figure 12.

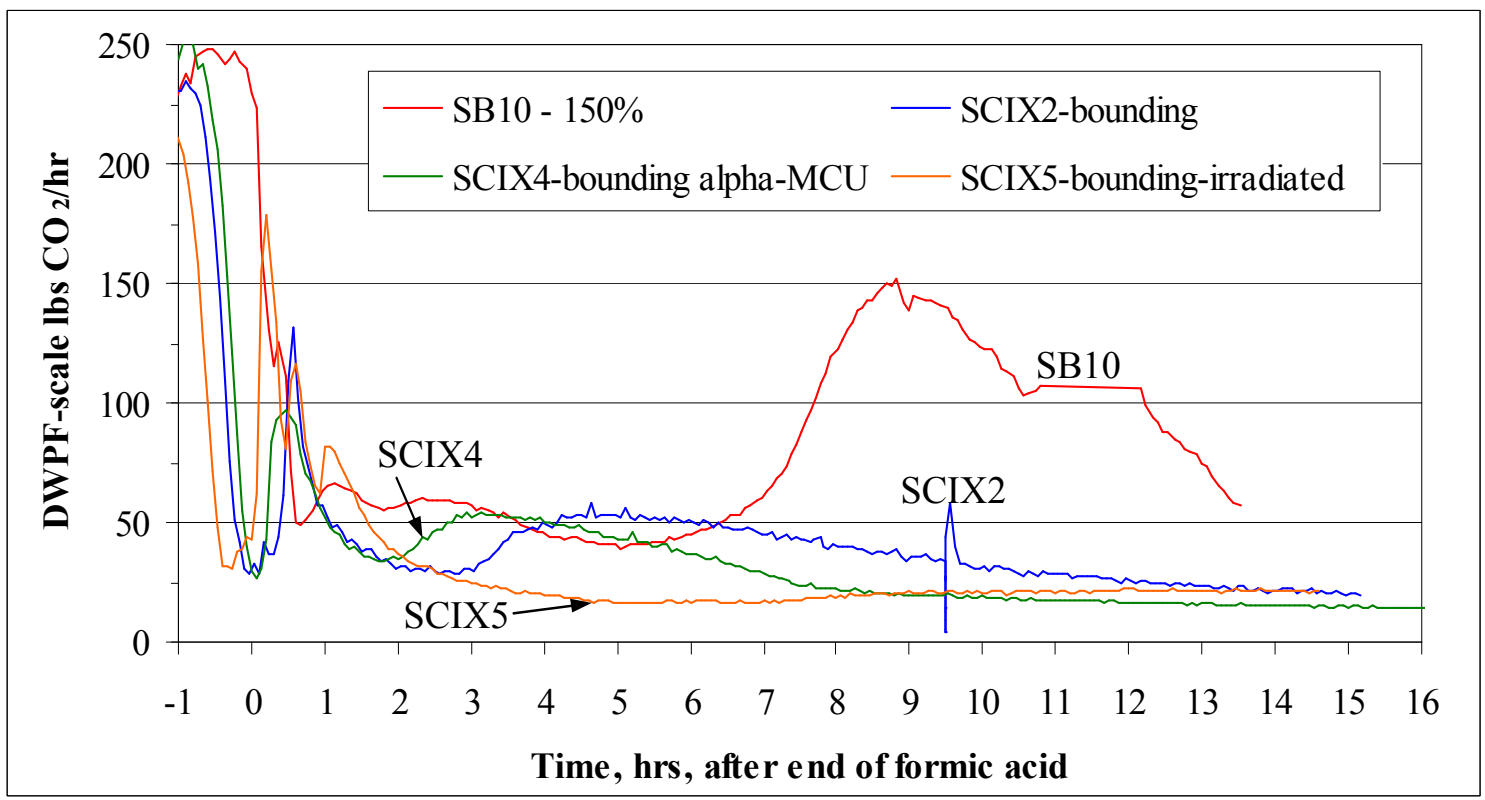

Figure 12. High acid $\mathrm{CO}_{2}$ generation data - SRAT boiling 
The $\mathrm{CO}_{2}$ data during reflux generally mirrored the hydrogen generation rate behavior and showed that the baseline high acid run was more catalytically active for formate destruction during boiling than the three runs with CST and MST. Formate destruction does not necessarily imply hydrogen generation, since formate is consumed by catalytic wet air oxidation to $\mathrm{CO}_{2}$ and water and also in the nitrogen reduction reaction sequence leading to ammonia formation from nitrate ion.

$\mathrm{CO}_{2}$ data for the low acid SME cycles are given in Figure 13. They follow normal patterns with peaks following the onset of boiling after each frit addition that return to fairly steady values during the rest of the dewatering time.

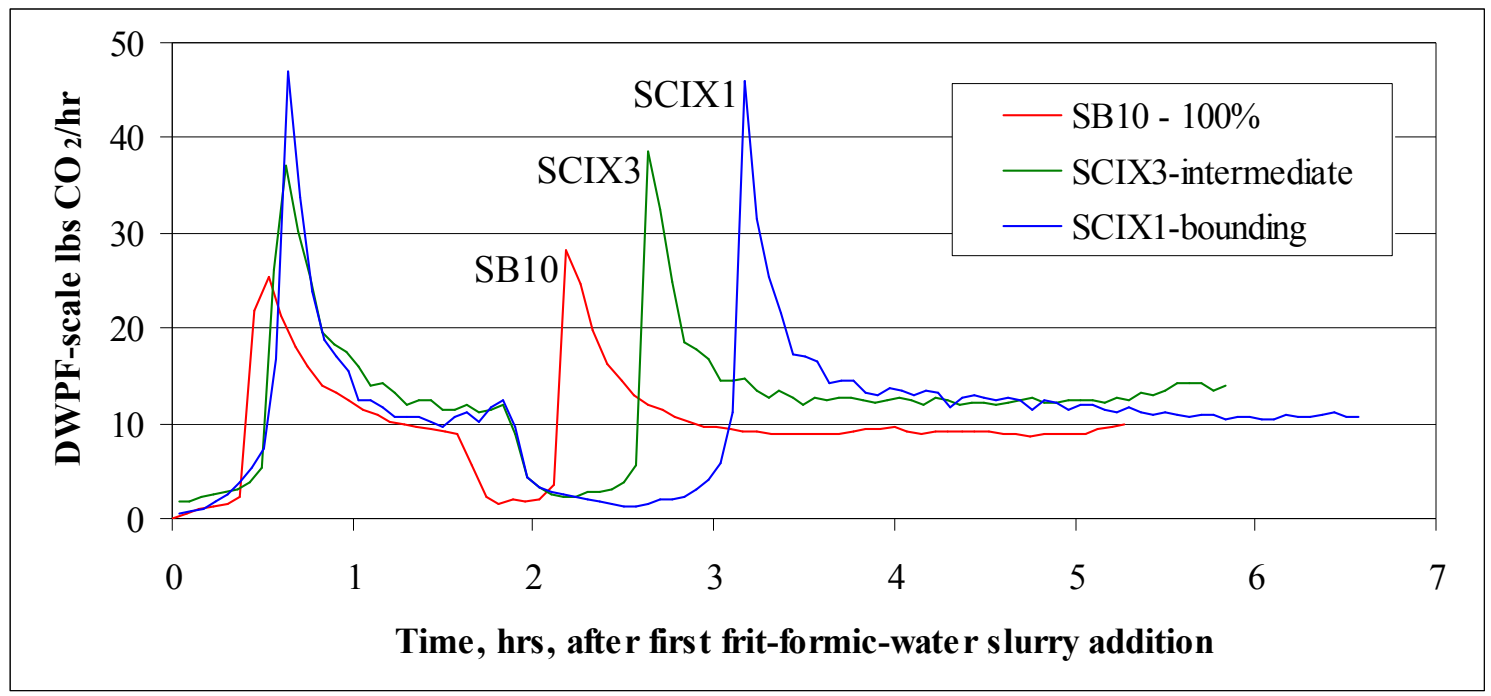

Figure 13. Low acid SME cycle $\mathrm{CO}_{2}$ generation

$\mathrm{CO}_{2}$ data for the high acid SME cycles are given in Figure 14. These data are also fairly normal and are bounded by the SB10 high acid baseline run.

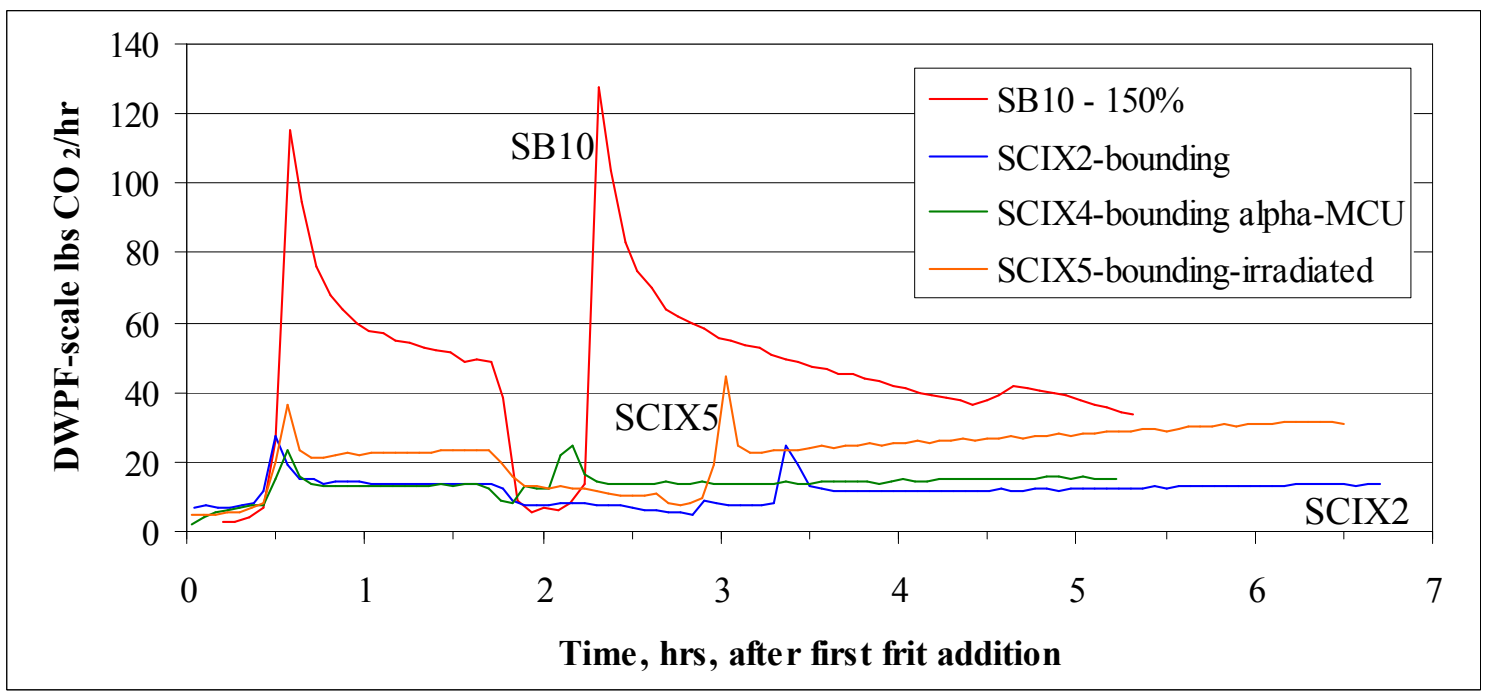

Figure 14. High acid $\mathrm{SME}$ cycle $\mathrm{CO}_{2}$ generation 
The SME cycle $\mathrm{CO}_{2}$ data generally mimics the hydrogen data in timing and relative magnitude. The fairly narrow range of $\mathrm{CO}_{2}$ generation rates (peaks in the $20-45 \mathrm{lb} / \mathrm{hr}$ range), excluding the high acid baseline run, indicate that frit formic acid was a primary driver for $\mathrm{CO}_{2}$ generation in at least six of the SME cycles.

SRAT cycle $\mathrm{N}_{2} \mathrm{O}$ data for the three low acid runs are given in Figure 15.

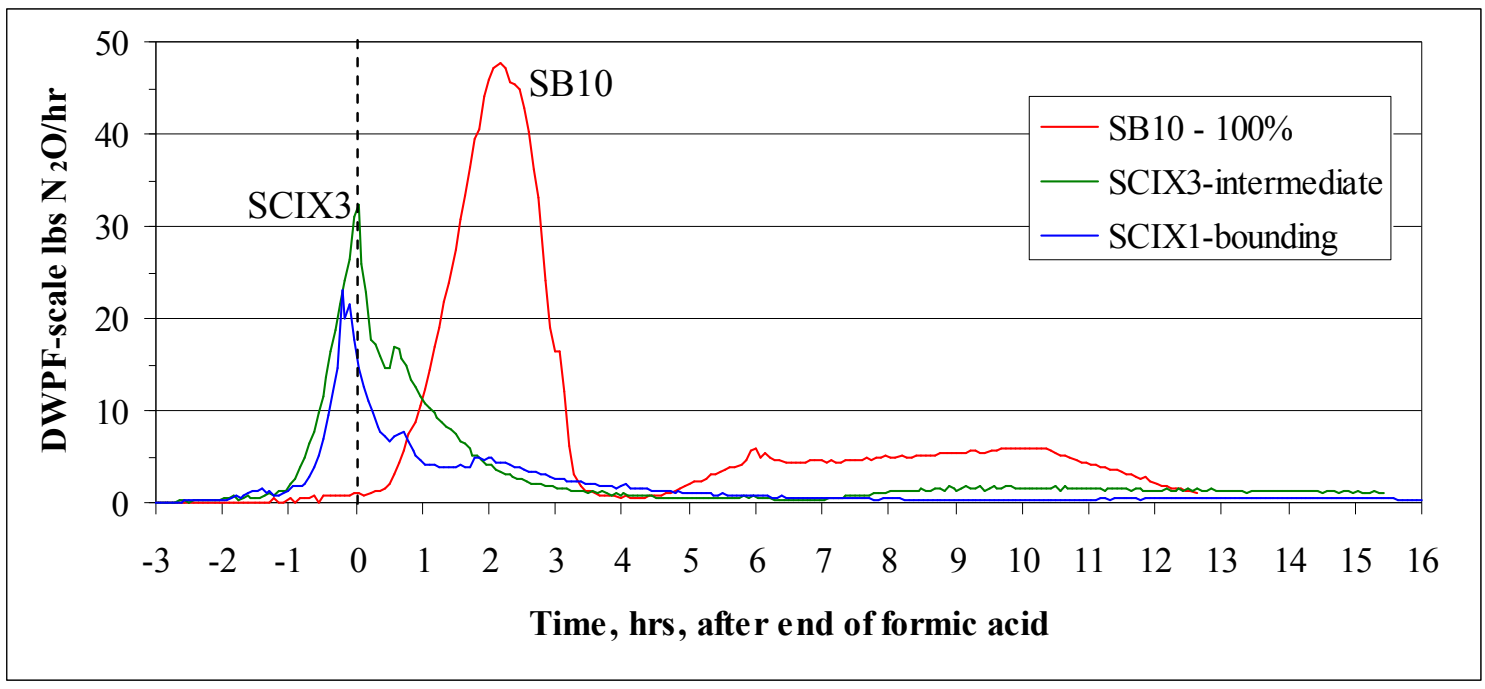

Figure 15. Low acid SRAT cycle $\mathrm{N}_{2} \mathrm{O}$ results

The $\mathrm{N}_{2} \mathrm{O}$ results confirm the $\mathrm{CO}_{2}$ indicators that the SB10 low acid run destroyed minimal nitrite ion until after formic acid addition was over (and ultimately that too little total acid was added). Considerable nitrite destruction occurred during boiling in the SB10-100 baseline run as indicated by the $\mathrm{N}_{2} \mathrm{O}$ formed between 4 and 12 hours after formic acid addition. Corresponding data for the four high acid runs are given in Figure 16. 


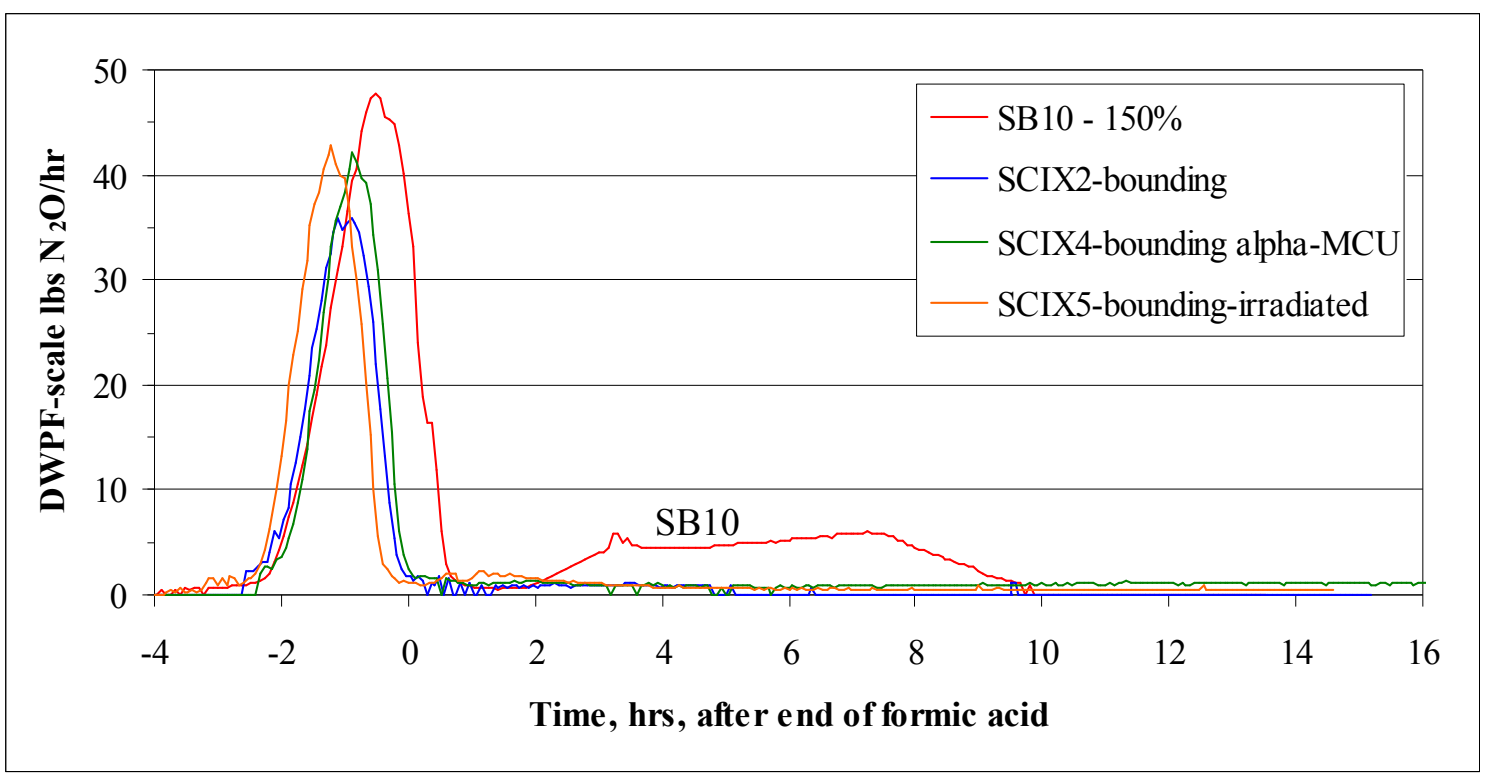

Figure 16. High acid SRAT cycle $\mathrm{N}_{2} \mathrm{O}$ results

The period from -3 to +1 hours relative to the end of formic acid addition shows the peaks from the destruction of nitrite ion in the four high acid runs. These peaks were all fairly similar. Since nitrite was in the supernate, and the supernate concentration of nitrite was very similar in all the simulants, there was essentially the same amount of nitrite to destroy in every run. In addition, the noble metal and mercury concentrations in the high acid runs were nearly identical. These are the catalysts that impact the relative distribution of the reaction by-products from nitrite destruction (nitrate, $\mathrm{NO}, \mathrm{NO}_{2}, \mathrm{~N}_{2} \mathrm{O}$ ). Consequently, it was expected that the $\mathrm{N}_{2} \mathrm{O}$ peaks in this period would be very similar unless the MST or CST was impacting nitrite destruction chemistry. Historically, when something significantly impacts nitrite destruction chemistry, the relative heights of the $\mathrm{N}_{2} \mathrm{O}$ peaks can easily vary by over a factor of two. MST and CST did not appear to impact nitrite destruction chemistry.

Additional $\mathrm{N}_{2} \mathrm{O}$ was formed between 2 and 10 hours after formic acid in the SB10 high acid run. Sample data indicated that all initial (SRAT receipt) nitrite had been destroyed prior to this, i.e. this was $\mathrm{N}_{2} \mathrm{O}$ from nitrate destruction. This run had a $27 \%$ nitrate loss according to sample analyses combined with material balance data (about 0.31 moles $\mathrm{N}$ ). $\mathrm{N}_{2} \mathrm{O}$ produced during reflux was about 0.085 moles of nitrogen or about $27 \%$ of the lost nitrate moles. It is likely that much of the balance lost was converted to nitrite that was destroyed to give $\mathrm{NO}$ rather than $\mathrm{N}_{2} \mathrm{O}$. Better off-gas analytical instrumentation would permit such chemistry to be studied in more detail. The runs with CST and MST produced lesser quantities of $\mathrm{N}_{2} \mathrm{O}$ during reflux, but material balance calculations indicate that enough nitrate destruction was occurring to negate any gain from earlier nitrite-to-nitrate conversion during acid addition. Very little $\mathrm{N}_{2} \mathrm{O}$ production occurred during any of the seven SME cycles. The most was seen in the high acid runs, Figure 17. 


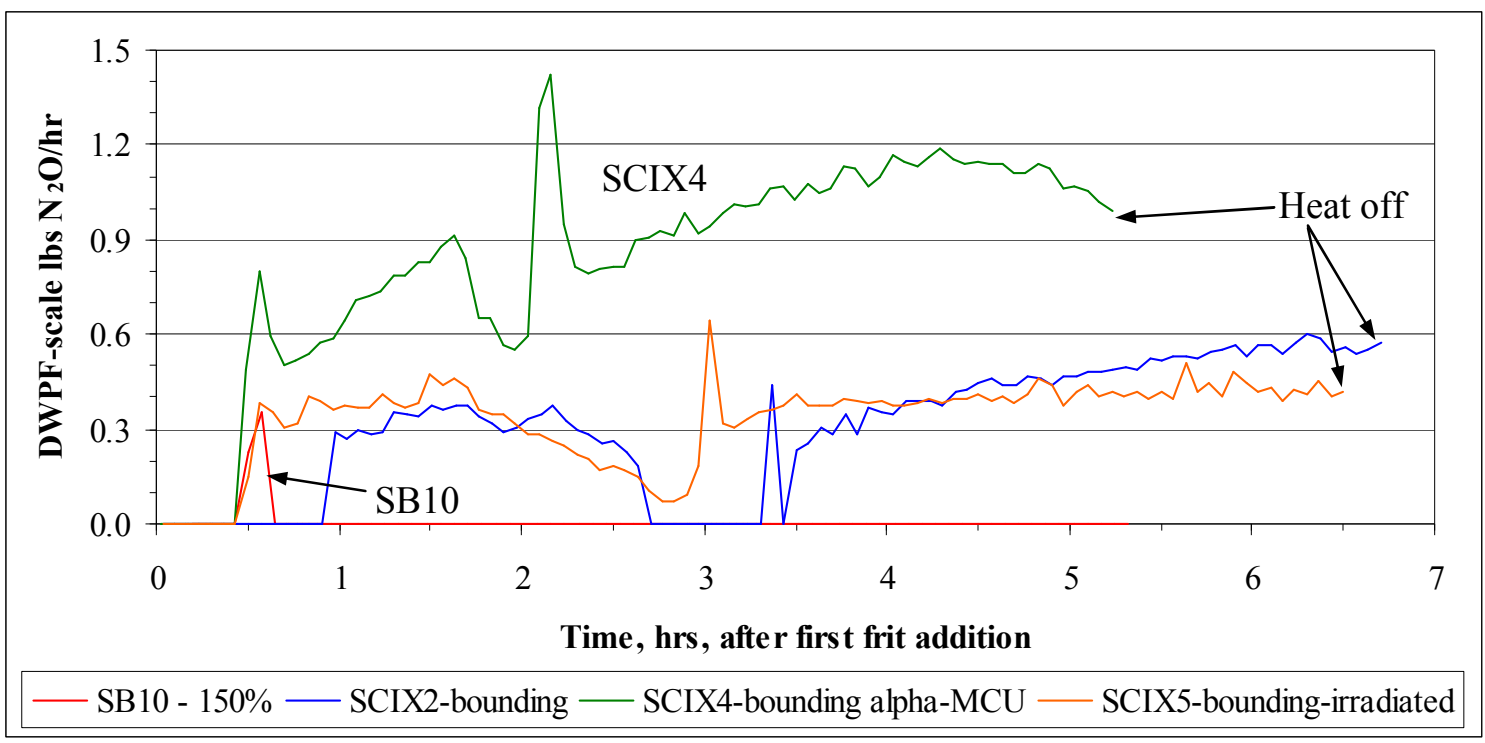

Figure 17. High acid SME cycle $\mathrm{N}_{2} \mathrm{O}$ generation

SCIX4 was producing the most $\mathrm{N}_{2} \mathrm{O}$ at the end of the SRAT cycle, and that ranking continued into the SME cycle. The SB10 $150 \%$ acid run had essentially stopped making $\mathrm{N}_{2} \mathrm{O}$ prior to the end of the SRAT and only one small burst was noted in the SME cycle following the first frit slurry addition.

Variations were seen in the off-gas data with and without MST and CST present. These variations, however, were not sufficient to raise any concerns about the impact of MST and CST on DWPF SRAT/SME processing with respect to off-gas generation. In the case of hydrogen, the presence of CST and MST and the overall impact of their presence on acid addition seemed to combine to actually decrease the maximum hydrogen generation rate in the SRAT cycle and in the SME cycle.

\subsubsection{Physical Property Measurements}

SRAT and SME product slurries were analyzed for total, calcined, and dissolved solids permitting the calculation of soluble and insoluble slurry solids. The samples were also analyzed for density, $\mathrm{pH}$, and rheology. Rheology results are discussed separately in Section 3.4. The remaining physical properties are discussed here. SRAT product properties are summarized in Table 24. 
Table 24. SRAT product properties

\begin{tabular}{|l|c|c|c|c|c|c|c|}
\hline & $\begin{array}{c}\text { SB10 } \\
\mathbf{1 0 0 \%}\end{array}$ & $\begin{array}{c}\text { SB10 } \\
\mathbf{1 5 0 \%}\end{array}$ & $\begin{array}{c}\text { SCIX1 } \\
\mathbf{1 0 0 \%}\end{array}$ & $\begin{array}{c}\text { SCIX2 } \\
\mathbf{1 5 0 \%}\end{array}$ & $\begin{array}{c}\text { SCIX3 } \\
\mathbf{1 0 0 \%}\end{array}$ & $\begin{array}{c}\text { SCIX4 } \\
\mathbf{1 5 0 \%}\end{array}$ & $\begin{array}{c}\text { SCIX5 } \\
\mathbf{1 5 0} \%\end{array}$ \\
\hline Wt\% total solids & 27.6 & 26.5 & 24.8 & 23.9 & 23.7 & 24.9 & 21.7 \\
\hline Wt\% dissolved solids & 13.0 & 13.0 & 13.4 & 13.5 & 12.7 & 13.9 & 12.5 \\
\hline Wt\% insoluble solids & 16.8 & 15.5 & 13.1 & 12.0 & 12.6 & 12.7 & 10.5 \\
\hline Wt\% soluble solids & 10.9 & 11.0 & 11.6 & 11.9 & 11.1 & 12.1 & 11.2 \\
\hline Wt\% calcined solids & 19.6 & 18.7 & 18.0 & 16.8 & 17.3 & 17.6 & 15.0 \\
\hline Slurry density, g/mL & 1.23 & 1.21 & 1.16 & 1.20 & 1.15 & 1.21 & 1.18 \\
\hline Suprnt density, g/mL & 1.09 & 1.09 & 1.08 & 1.10 & 1.08 & 1.10 & 1.09 \\
\hline pH & 7.4 & 7.9 & 8.2 & 5.4 & 7.9 & 5.7 & 4.7 \\
\hline
\end{tabular}

It was noted that the three high acid runs with CST and MST (SCIX2, 4, and 5) maintained lower $\mathrm{pH}$ values than the $150 \%$ acid baseline run. The low acid runs drifted to mildly caustic $\mathrm{pH}$ values in all three cases. The runs with CST and MST generally had higher wt $\%$ soluble solids and lower $\mathrm{wt} \%$ insoluble solids than the baseline runs. This was expected to lower the yield stress of the SRAT products with MST and CST relative to the baseline (see Section 3.4 for rheology data).

SCIX5 was low in total solids at $21.7 \mathrm{wt} \%$ due to a dewatering error. The rheological properties of the SCIX5 SRAT product slurry, given in Section 3.4, were impacted. The SCIX1 pH reading, 8.2, seems high given the 7.4 reading of the SCIX1 SME product. The pH generally held constant to within about $0.3 \mathrm{pH}$ units during the other six SME cycles. The SCIX1 vessel $\mathrm{pH}$ probe failed near the end of acid addition so the normal cross check is missing.

The SME product physical property measurements are summarized in Table 25.

Table 25. SME product properties

\begin{tabular}{||l|c|c|c|c|c|c|c||}
\hline & $\begin{array}{c}\text { SB10 } \\
\mathbf{1 0 0 \%}\end{array}$ & $\begin{array}{c}\text { SB10 } \\
\mathbf{1 5 0 \%}\end{array}$ & $\begin{array}{c}\text { SCIX1 } \\
\mathbf{1 0 0 \%}\end{array}$ & $\begin{array}{c}\text { SCIX2 } \\
\mathbf{1 5 0 \%}\end{array}$ & $\begin{array}{c}\text { SCIX3 } \\
\mathbf{1 0 0 \%}\end{array}$ & $\begin{array}{c}\text { SCIX4 } \\
\mathbf{1 5 0 \%}\end{array}$ & $\begin{array}{c}\text { SCIX5 } \\
\mathbf{1 5 0 \%}\end{array}$ \\
\hline Wt\% total solids & 53.3 & 54.3 & 51.6 & 52.1 & 50.8 & 53.6 & 40.9 \\
\hline Wt\% dissolved solids & 18.5 & 16.9 & 18.7 & 20.0 & 18.6 & 19.8 & 15.8 \\
\hline Wt\% insoluble solids & 42.7 & 45.0 & 40.4 & 40.2 & 39.5 & 42.1 & 29.8 \\
\hline Wt\% soluble solids & 10.6 & 9.3 & 11.1 & 11.9 & 11.2 & 11.5 & 11.1 \\
\hline Wt\% calcined solids & 45.6 & 46.6 & 45.5 & 45.0 & 44.3 & 46.5 & 34.4 \\
\hline Slurry density, g/mL & 1.50 & 1.51 & 1.46 & 1.44 & 1.46 & 1.49 & 1.34 \\
\hline Suprnt density, g/mL & n.a. & n.a. & 1.12 & 1.14 & 1.12 & 1.13 & 1.10 \\
\hline pH & 7.7 & 8.2 & 7.4 & 5.4 & 7.6 & 5.6 & 4.9 \\
\hline
\end{tabular}

n.a. - not analyzed

It was generally possible to concentrate the SME to over $50 \mathrm{wt} \%$ total solids and still maintain reasonable fluid motion in the lab-scale SRAT. SCIX5 SME product was subsequently decanted and trimmed with sodium nitrate and formate. The amounts added were designed to replace the masses lost through decanting (hold REDOX constant) while permitting comparable rheological measurements to the other systems. It also appears that this SCIX5 SME product sample may have been low in insoluble solids (perhaps because the slurry was not sufficiently viscous to keep the solids properly suspended; several independent lines of reasoning suggest that the SCIX5 SME product was actually closer to $45 \mathrm{wt} \%$ total solids than to $41 \mathrm{wt} \%$ total solids). 


\subsubsection{Mercury Stripping}

Mercury stripping has come to dominate the CPC cycle time due to the intrinsically higher mercury content of HM sludges combined with the concentrating impact of aluminum dissolution on the starting $w t \%$ of mercury in the feed to the SRAT. Increased attention has been given to mercury during simulant CPC processing starting with SB5 studies. SB6 and SB7 studies were fairly thorough in attempting to track mercury through the process.

Lab-scale observations indicate that elemental mercury is difficult to keep homogeneously dispersed in the SRAT slurry. Dried SB6 and SB7 SME products were regularly found to contain more elemental mercury than sample results had indicated. Two instances have occurred where a multi-element, mercury-rich, slushy/pasty material was formed (an amalgam or other material). Mercury-rich material coated onto the agitator blade in SB6 simulant testing. ${ }^{25}$ The mercury-rich paste contained most of the $\mathrm{Pd}$ and $\mathrm{Rh}$ in the system. Mercury-rich material was found underneath dried SME product solids in a pan following SB7 tests. In both of these cases, the acid stoichiometry was at a level that approached the hydrogen generation rate limits in the CPC.

The lab-scale difficulties in tracking mercury during processing continued in the SCIX program. SME product was needed for Melt Rate Furnace testing, various rheological studies, and REDOX measurements in addition to the usual sample analyses. Consequently, it was not possible to consume SME products in a search for missing mercury. The disappearance of mercury from the "well-mixed slurry" during SRAT processing was monitored with a series of samples in each of the tests. "Disappearance" includes elemental mercury lost through steam stripping (some mercury was recovered in the MWWT in every test), mercury converted to a volatile species, e.g. $\mathrm{HgCl}$, lost in the off-gas, and mercury coalesced on the equipment, e.g. mercury lying on the bottom of the SRAT as either elemental $\mathrm{Hg}$ or a dense multi-element form.

Mercury data are compared in Figure 18 and Figure 19. Though baseline data are somewhat limited, it appears that neither baseline run kept mercury dispersed in the slurry very well (disappearance rate exceeds likely stripping rate). If the two SB10 tests were like SB6 and SB7 tests, then the slurried mercury probably fell to less than 1 gram within a few hours after acid addition. 


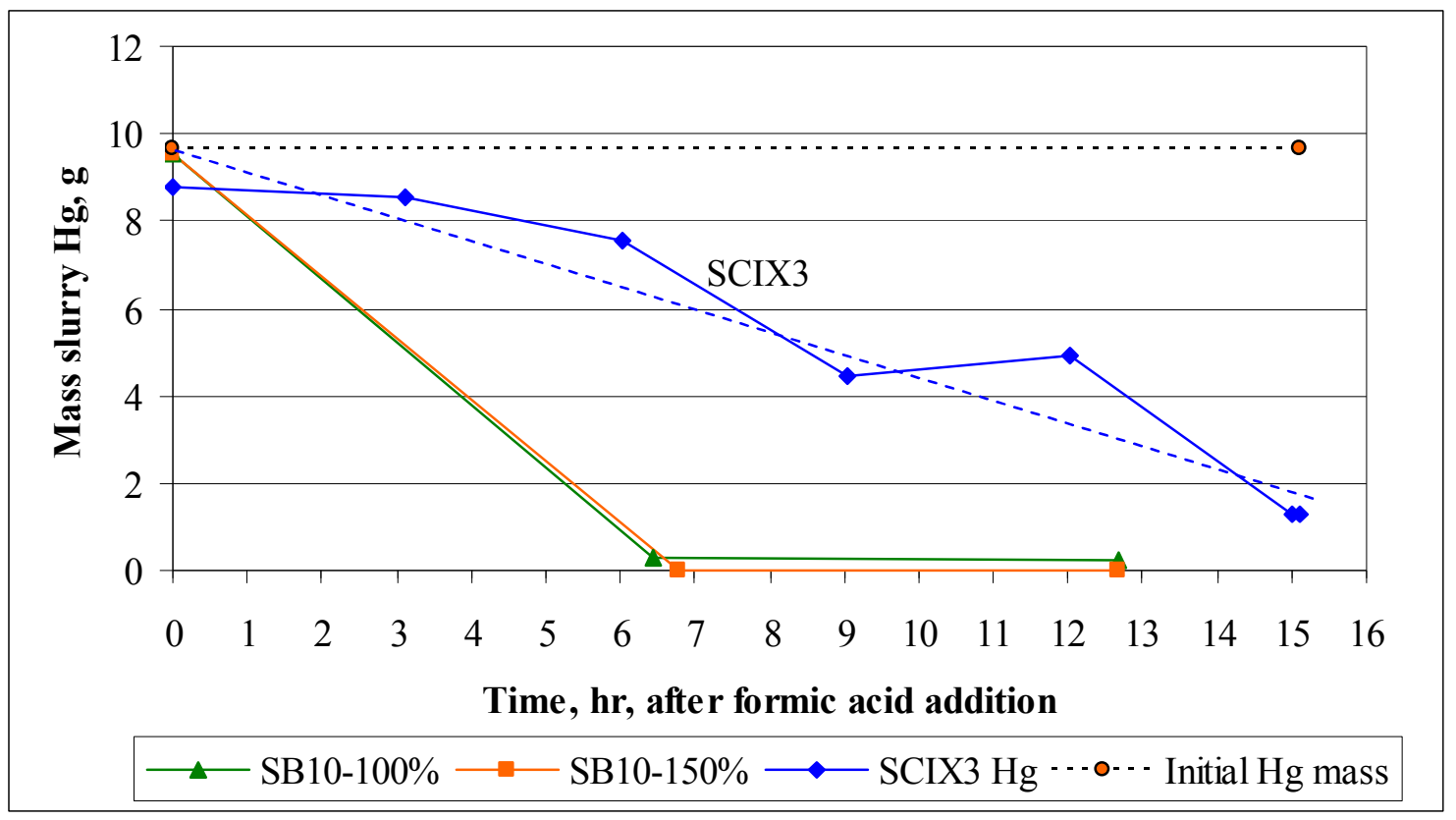

Figure 18. Baseline and intermediate case mercury data

The intermediate case above, SCIX3, and SCIX1 below in Figure 19, were both low acid runs. Mercury stripping appeared to be occurring in these runs in a more normal fashion, and mercury was apparently dispersed through reflux at reasonably high levels. In spite of that, the recoveries of elemental mercury were only about $25 \%$. The recovery level accounts for only a third of the mercury indicated to have left the slurry in SCIX3, but it was fairly close to matching the mercury slurry loss indicated for SCIX1. This result may indicate that the SCIX1 slurry supported Hg droplets better/longer than SCIX3, and the sample was more representative of the vessel contents. The SB10-100\% SME product sample indicated the presence of $0.6 \mathrm{~g}$ of suspended mercury even though the SRAT product analysis indicated that only $0.3 \mathrm{~g}$ were still slurried before starting the SME cycle. 


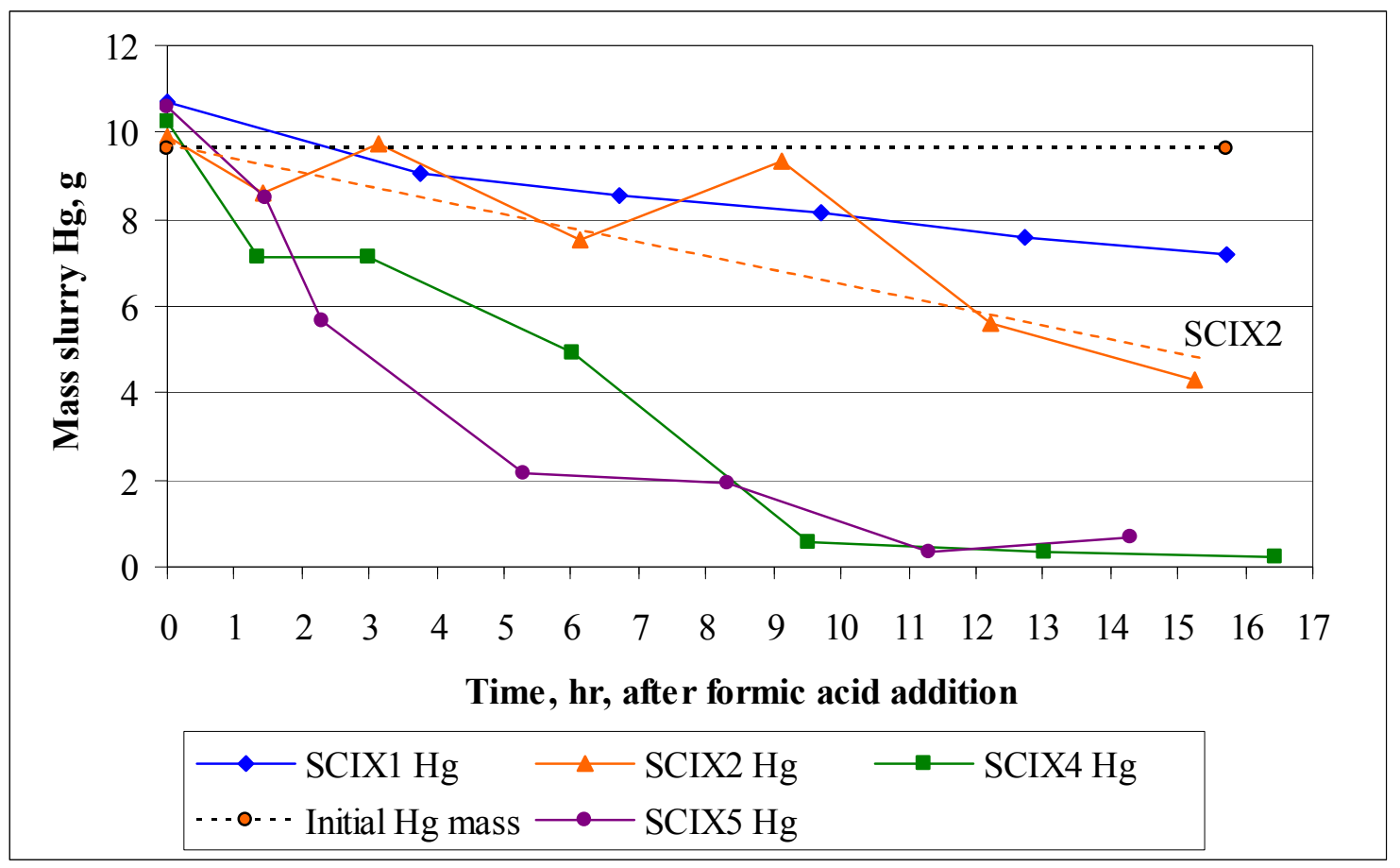

Figure 19. Bounding case mercury data

The bounding CST-MST case mercury at high acid stoichiometry followed the general trend of the baseline runs and other recent high acid flowsheet tests. SCIX2, however, seemed to hold mercury in the slurry longer than the other high acid runs. MWWT recovery was also above average in SCIX2 at nearly 50\% of that in the feed. MWWT recoveries in SCIX1, 3, and 4 were only about $25 \%$, and SCIX 5 recovery was only about $15 \%$. SCIX2 SME product data indicated that up to $7 \mathrm{~g}$ of mercury was still present even though the SRAT product analysis indicated that only $4.3 \mathrm{~g}$ remained following the SRAT reflux stripping period. Conversely, SCIX5 SRAT and SME product data gave almost identical mercury masses of about $0.66 \mathrm{~g}$. SCIX5 was the least viscous of the slurries and also had the lowest MWWT recovery.

SCIX2 had gray crud in the drain from the SRAT condenser to the MWWT Figure 20. 


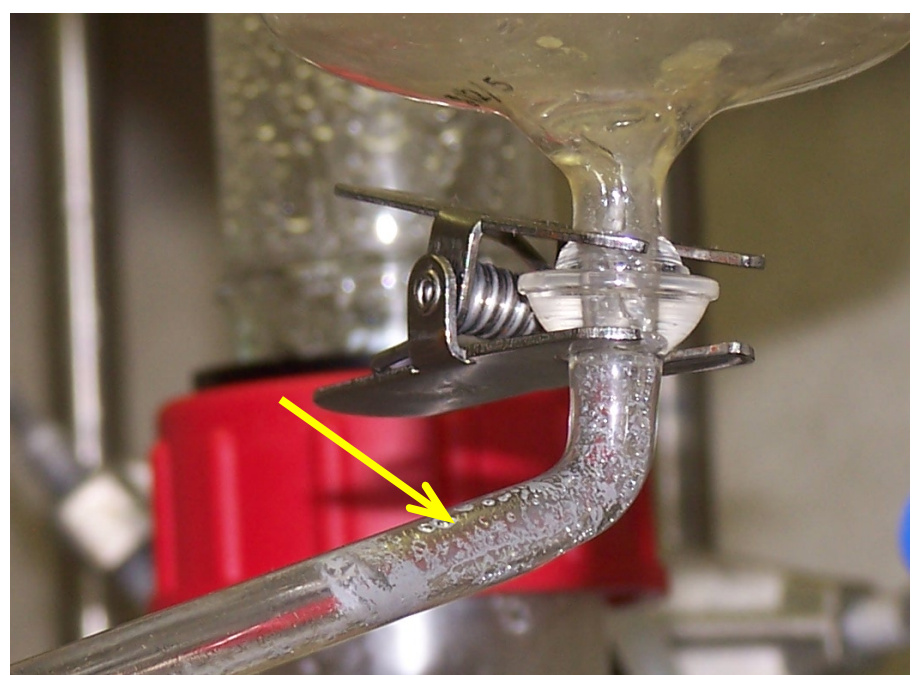

Figure 20. SCIX2 mercury-rich crud in feed line to MWWT

For comparison, the drain line in the low acid SCIX1 run is shown in Figure 21.

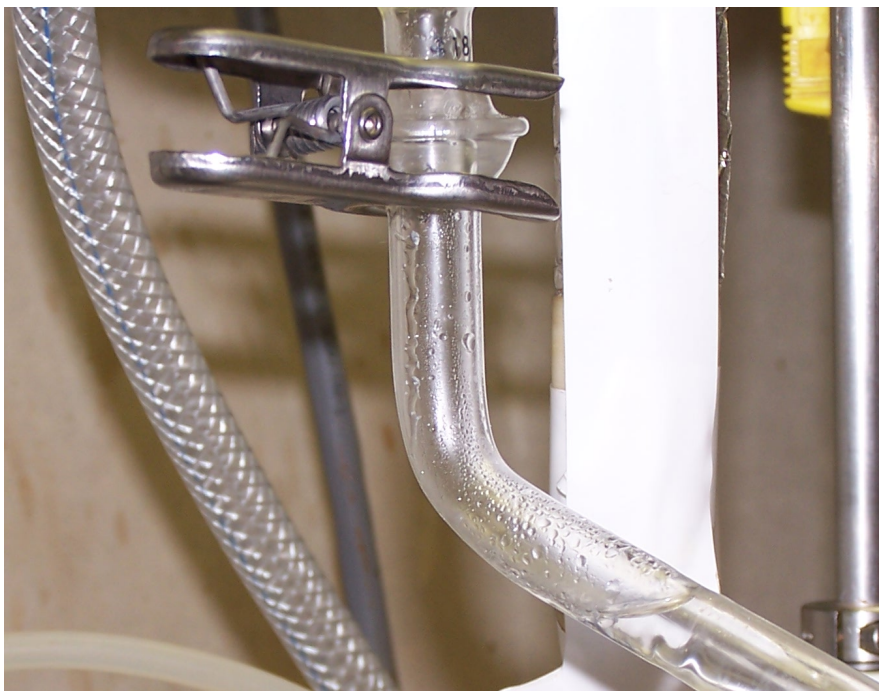

Figure 21. SCIX1 clean feed line to MWWT

The elemental mercury recovered in SCIX1 through SCIX4 was relatively bright and shiny in spite of the differences in crud observed in the feed line to the MWWT.

One remaining photo of potential interest is of the glass SRAT vessel in SCIX3, Figure 22. The image is several times larger than life-sized if this page is printed on $8.5 \times 11$ inch paper, and the image covers about 1 to 1.5 inches across the SRAT vessel diameter. Selective color balancing and contrast enhancement were used to highlight the shinier areas (the image is not natural color). The photo is through the lab-scale SRAT vessel wall from the outside toward the material sticking on the inner surface, so the material seen is in direct contact with the inner glass wall. 


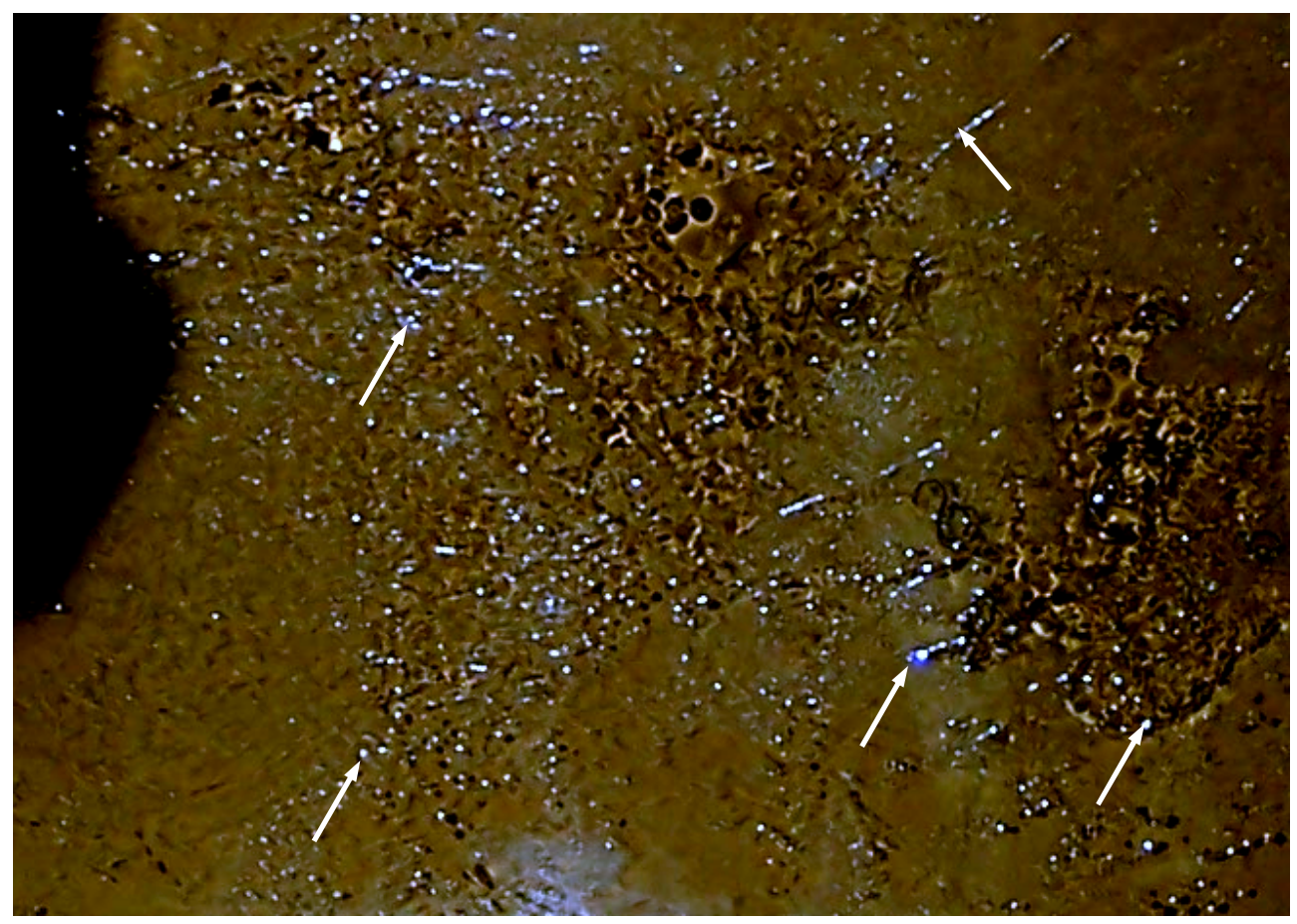

Figure 22. SCIX3 vessel wall showing reflective spots

There were dozens of small but mildly reflective spots trapped on the SCIX3 side wall in the slurry material that did not seem to be moving (may have been above the dewatered level at the time of the image; the spots may appear pale blue-gray to white against a brown background). The spots appear to be generally circular as would be expected for a dispersed liquid phase trapped on the wall (the spots are only about 5-7 digital picture elements across, but they appear to be round within the limits of resolution of the image). The spots appeared to be strung together to make short chains in some places. The spots were likely related to mercury. The spots appear to be too large to be MST or ground CST which are generally less than 50 microns across, i.e. much smaller than the spots. Mercury trapped this way may not be able to exert its vapor pressure properly for steam stripping, since it does not physically contact the vapor space. This, in turn, could limit the fraction of the initial mass of mercury that can be steam stripped.

SCIX5 had dark-colored mercury in addition to poor recovery in the MWWT. SCIX5 also had visible elemental mercury in the SRAT dewater condensate bottle. This is unusual. Elemental mercury is generally present during dewatering, but removal occurs through an overflow tube that generally excludes mercury droplets from being collected. The dewater bottle mercury differed from higher purity mercury beads by being stained dark and not spherical. Mercury was found in both SME cycle dewater bottles, though it may have originally stripped from the slurry during SRAT reflux and only dropped into the condensate during the SME cycle. Whether any of the SCIX5 mercury observations relate to the presence of irradiated MST and CST remains an open question.

Issues with the lab-scale SRAT mercury balance are actively being worked. The result will likely be one or more redesigns of the 4-L scale equipment to promote better mixing, permit bottom sampling, etc. These changes should improve the capability for performing and closing mercury material balances at lab-scale. 


\subsubsection{Melter Feed REDOX}

Samples of the five SME products from the SCIX runs were prepared and analyzed for the iron in glass REDOX potential as given by $\mathrm{Fe}^{2+} / \Sigma \mathrm{Fe}$. Analyses were performed in triplicate. The average of the triplicate analysis is compared to the current model prediction based on the SME compositional analysis in Table 26. ${ }^{15}$ The predictions are based on SME product sample measurements from the five SCIX runs for the inputs to the current DWPF REDOX equation (in this case formate, nitrate, and manganese).

Table 26. REDOX Comparison - Predicted versus Measured

\begin{tabular}{|l|c|c||}
\hline \hline & Predicted & Measured \\
\hline SCIX1 & 0.22 & 0.26 \\
\hline SCIX2 & 0.26 & 0.37 \\
\hline SCIX3 & 0.28 & 0.25 \\
\hline SCIX4 & 0.29 & 0.35 \\
\hline SCIX5 & 0.24 & 0.28 \\
\hline
\end{tabular}

The nominal REDOX target for all SCIX runs was 0.20. The difference between predicted and targeted REDOX reflects the impact of departures from the assumed formate loss and fate of nitrate relative to the pre-run values used in the acid calculation combined with potential analytical uncertainties (SCIX3 and SCIX4 samples were analyzed together and show a bigger than expected difference between predicted and targeted REDOX that may not be coincidental). Nitrate loss in the three SCIX high acid runs $(2,4,5)$ was larger than anticipated and explains about 0.03-0.04 of the 0.04-0.09 difference between the predicted and target values. Higher measured REDOX seemed to correlate with acid stoichiometry (more acid, higher REDOX).

\subsection{Rheology Results}

The impact of adding size-reduced CST and MST to baseline SB10 simulant on the Bingham plastic yield stress and consistency is shown in Table 27.

Table 27. Comparison of simulants with/without CST and MST

\begin{tabular}{||l|c|c|c||}
\hline & Yield Stress, Pa & Consistency, cP & Wt \% Insoluble Solids \\
\hline Baseline SB10 & 2.3 & 8.1 & 11.2 \\
\hline Intermediate & 1.5 & 6.2 & 13.6 \\
\hline Bounding & 1.0 & 5.1 & 12.9 \\
\hline
\end{tabular}

Even though the wt $\%$ insoluble solids increased slightly following the blending of SB10 simulant with supernate adjusted CST and MST, the Bingham plastic yield stress and consistency decreased (opposite of the effect that would be observed if SB10 simulant insoluble solids were concentrated by decanting or boiling).

CPC simulations with the intermediate and bounding simulants included two hours of caustic boiling to evaluate whether there was any indication of rapid sodium alumino-silicate formation with the combination of high $\mathrm{pH}(>11)$ and high temperature $\left(101{ }^{\circ} \mathrm{C}\right)$. Slurry samples following caustic boiling were used to generate fresh flow curves. These samples were $6-8 \%$ more dilute than the starting simulants, so a small reduction in yield stress and consistency might be expected. 
Results for caustic boiled (CB) simulants are compared to the matching starting simulant in Table 28.

Table 28. Impact of caustic boiling on simulants containing CST and MST

\begin{tabular}{|l|c|c|c|}
\hline & Yield Stress, Pa & Consistency, cP & Dilution \\
\hline Intermediate & 1.5 & 6.2 & None \\
\hline SCIX3 CB & 0.8 & 4.8 & $8 \%$ \\
\hline Bounding & 1.0 & 5.1 & None \\
\hline SCIX1 CB & 0.4 & 3.8 & $6 \%$ \\
\hline SCIX2 CB & 0.4 & 3.8 & $6 \%$ \\
\hline SCIX4 CB & 0.6 & 4.3 & $6 \%$ \\
\hline SCIX5 CB & 0.4 & 3.8 & $6 \%$ \\
\hline
\end{tabular}

The yield stress and consistency fell more than expected for dilution by $6-8 \%$ which indicates that there likely was a thermal aging impact on the SB10 sludge simulant component that tended to reduce its viscosity. No evidence for any significant formation of unusually viscous material was seen in the caustic boiled samples.

A benefit was obtained by targeting the same throughput of waste oxides per SRAT batch. CST and MST are already close to their oxide forms coming into the SRAT, i.e. have calcine factors approaching unity. Therefore, as sludge oxides decrease with increasing CST and MST, the mass of insoluble solids also decreases for a fixed target mass of calcined oxides per SRAT batch. The reduction in insoluble solids appears to be driving a reduction in the SRAT product yield stress as the amount of CST and MST blended into the sludge increases, Table 29. A reduction in yield stress with increasing acid stoichiometry is normal and not related to MST or CST.

Table 29. Comparison of SRAT products with/without CST and MST

\begin{tabular}{|l|c|c|c|c|}
\hline & $\begin{array}{c}\text { Acid } \\
\text { Stoichiometry } \\
\mathbf{\%}\end{array}$ & $\begin{array}{c}\text { Yield Stress, } \\
\text { Pa }\end{array}$ & $\begin{array}{c}\text { Consistency, } \\
\text { cP }\end{array}$ & $\begin{array}{c}\text { Wt \% } \\
\text { Insoluble } \\
\text { Solids }\end{array}$ \\
\hline SB10-100 & 100 & 14.7 & 13.6 & 16.8 \\
\hline Intermediate & 100 & 5.7 & 5.9 & 12.6 \\
\hline Bounding-SCIX1 & 100 & 5.7 & 11.6 & 13.2 \\
\hline SB10-150 & 150 & 1.6 & 8.5 & 15.5 \\
\hline SCIX2 & 150 & 0.3 & 4.9 & 12.0 \\
\hline SCIX4-extended & 150 & 0.7 & 5.9 & 12.7 \\
\hline SCIX5-irradiated & 150 & 0.3 & 4.0 & 10.5 \\
\hline
\end{tabular}

SME product slurries were studied in greater detail than the caustic sludges or SRAT products. Flow curves were generated on fresh SME product samples within a day or two of finishing the CPC simulation. An additional 550-mL of SME product was divided equally between two 300$\mathrm{mL}$ snap lid jars identical to those used in the SCIX mixing and rheology study. ${ }^{20,26}$ The SME slurry insoluble solids were allowed to settle for eight weeks. A vane yield strength determination was made on the settled SME solids to assess the relative potential difficulty in suspending the SME solids after extended particle-particle contact time. Each sample was large enough to provide a single measurement of the yield strength, so two results were obtained per SME product. Following the vane measurement, the settled solids were remixed with the 
supernate and an "aged" SME product flow curve was obtained. The following paragraphs present the bulk of the SME data in tabular form.

Bingham plastic model fits to the fresh SME product flow curves are given in Table 30.

Table 30. Comparison of fresh SME products with/without CST and MST

\begin{tabular}{|l|c|c|c|c|}
\hline & $\begin{array}{c}\text { Acid } \\
\text { Stoichiometry } \\
\mathbf{\%}\end{array}$ & $\begin{array}{c}\text { Yield Stress, } \\
\text { Pa }\end{array}$ & $\begin{array}{c}\text { Consistency, } \\
\text { cP }\end{array}$ & $\begin{array}{c}\text { Wt \% } \\
\text { Insoluble } \\
\text { Solids }\end{array}$ \\
\hline SB10-100 & 100 & 33 & 42 & 42.7 \\
\hline SCIX3-Intermediate & 100 & 19 & 36 & 39.5 \\
\hline SCIX1-Bounding & 100 & 20 & 30 & 40.4 \\
\hline SB10-150 & 150 & 27 & 34 & 45.0 \\
\hline SCIX2-Bounding & 150 & 10 & 29 & 40.2 \\
\hline SCIX4-Extended & 150 & 14 & 36 & 42.1 \\
\hline SCIX5-Irradiated & 150 & 17 & 43 & 42.8 \\
\hline
\end{tabular}

The SME products with CST and MST tended to have slightly lower wt $\%$ insoluble solids than the baseline sludge simulant SME products at the same acid stoichiometry, as well as lower yield stress values and comparable consistencies. This was also the case with the SRAT products. No obvious issues were seen that correlated with the presence of CST and MST.

Before discussing the vane measurements, the flow curve data on the aged SME products will be given, Table 31. Since the insoluble solids contents of the as-made SME products from the baseline simulants were higher than the SCIX products, the two baseline simulants were diluted before generating the second set of flow curve data in order to bring the wt $\%$ insoluble solids into closer agreement. Flow curve data were fit to the Bingham plastic equation over a shear rate range of $50-300 / \mathrm{s}$, as were the data in Table 30 .

Table 31. Comparison of aged SME products with/without CST and MST

\begin{tabular}{|l|c|c|c|c|}
\hline & $\begin{array}{c}\text { Acid } \\
\text { Stoichiometry } \\
\text { \% }\end{array}$ & $\begin{array}{c}\text { Yield Stress, } \\
\text { Pa }\end{array}$ & $\begin{array}{c}\text { Consistency, } \\
\text { cP }\end{array}$ & $\begin{array}{c}\text { Wt \% } \\
\text { Insoluble } \\
\text { Solids }\end{array}$ \\
\hline SB10-100 & 100 & 17 & 37 & 39.7 \\
\hline SCIX3-Intermediate & 100 & 22 & 37 & 39.5 \\
\hline SCIX1-Bounding & 100 & 22 & 36 & 40.4 \\
\hline SB10-150 & 150 & 27 & 34 & 38.8 \\
\hline SCIX2-Bounding & 150 & 10 & 29 & 40.2 \\
\hline SCIX4-Extended & 150 & 14 & 36 & 42.1 \\
\hline SCIX5-Irradiated & 150 & 11 & 29 & 39.2 \\
\hline
\end{tabular}

The low acid stoichiometry data had a small increase in yield stress in the aged SME products containing CST and MST compared to the baseline SME product, while the high acid stoichiometry data still showed a decrease in yield stress from the baseline to the SME products containing CST and MST in spite of a small increase in the $\mathrm{wt} \%$ insoluble solids.

Prior to the flow curve measurements in Table 31, the settled SME product solids were tested using the vane method to determine the yield strength of the settled solids. Identical vessels were 
used for all samples. Each sample vessel received close to $235 \mathrm{~mL}$ of SME slurry. The SME solids settled to roughly $80 \%$ of the initial slurry volume $(20 \%$ supernate over the top of the settled solids) in all the samples except SCIX5. SCIX5 had more supernate because it was not dewatered to the target $\mathrm{wt} \%$ total solids. This measurement appeared to be less sensitive to acid stoichiometry than the flow curve measurements, Table 32.

Table 32. Comparison of 8-week settled SME products with/without CST and MST

\begin{tabular}{|l|c|c|}
\hline & $\begin{array}{c}\text { Acid } \\
\text { Stoichiometry \% }\end{array}$ & $\begin{array}{c}\text { Vane Yield } \\
\text { Strength, Pa }\end{array}$ \\
\hline SB10-100 & 100 & 77 \\
\hline SCIX3-Intermediate & 100 & 66 \\
\hline SCIX1-Bounding & 100 & 61 \\
\hline SB10-150 & 150 & 77 \\
\hline SCIX2-Bounding & 150 & 56 \\
\hline SCIX4-Extended & 150 & 70 \\
\hline SCIX5-Irradiated & 150 & 117 \\
\hline
\end{tabular}

There was a mild decrease in the vane yield strength as the fraction of CST and MST was increased in the SME products from the three $100 \%$ acid stoichiometry runs. It is inferred from these data that the CST and MST solids might be thinning the sludge-frit matrix solids. Conversely, settled ground CST by itself has been observed to form a congealed mass, or cake, which is very difficult to resuspend using fluid shear only. The $150 \%$ acid data covers bounding levels of CST and MST processed with several variations along with the baseline run. Variations were seen in the yield strengths of the bounding cases, but the results were all lower than in the test with no CST and MST. It appears that there were sufficient other solid species present in the settled layer to prevent the CST from binding particles together into a congealed mass.

The SCIX5 test with irradiated CST and MST gave the highest vane yield strength of any test. The two SCIX5 values measured and averaged for Table 32 also showed more variation $(95,140)$ than seen in the other SCIX pairs. There were some very small clumps of solids on the vane after withdrawing it from the sample (suggesting some mild gelation), but that was not necessarily unique to SCIX5. Small lumps were seen when pouring out the sample jar as well. The lumps may partially explain the variability between the two measurements. Once the SCIX5 solids were remixed with the supernate, the slurry was no more viscous than the other CST-MST containing SME products, Table 31.

The general conclusion from the rheology testing was that the addition of MST and ground CST did not have a detectable negative impact on the rheology of the SB10 simulant during CPC processing. The MST and CST seem to have acted to lower the yield strength and yield stress of the slurries instead of to increase them. If this is a general trend, then DWPF might be able to process at higher wt \% solids levels with CST and MST present than they can today. Such a capability could potentially lead to an increase in the annual capacity of the CPC to produce melter feed (on an equivalent canister basis). 
SRNL-STI-2011-00075

Revision 0

\subsection{Conclusions}

A program was conducted to systematically evaluate potential impacts of the proposed SCIX process on the DWPF CPC. The program involved a series of interrelated tasks. Past studies of the impact of CST and MST on DWPF were reviewed. Paper studies and material balance calculations were used to establish reasonable bounding levels of CST and MST in sludge. Following the paper studies, SB10 simulant was modified to have both bounding and intermediate levels of MST and ground CST. The SCIX flow sheet includes grinding of the CST which is larger than DWPF frit when not ground. Nominal ground CST was not yet available, therefore CST ground previously in SRNL was used. It was believed that this CST was over ground and that it would bound the impact of nominal CST on sludge slurry properties.

Based on the testing, no significant adverse impacts were noted in the following areas:

- SRAT acid demand decreased slightly as MST and CST displaced sludge solids.

- SRAT and SME maximum hydrogen generation rates were lower at high acid stoichiometry even though CST and MST were not allowed to dilute the noble metal concentrations.

- CPC chemistry was only mildly impacted by the presence of CST and MST

- Sodium appeared to leach from the MST and CST into the supernate, but this should not adversely impact DWPF processing.

- CST and MST otherwise remained insoluble with detection limits, which was the expected behavior.

- CST and MST elements, other than silicon, were not found in the off-gas condensates (off-gas silicon is believed to come from antifoam degradation), so high carryover rates of CST and MST do not appear to be a concern.

- A small increase in iron solubility was noted that could impact criticality calculations that take credit for insoluble iron (also Ti could be included with the existing poisons).

- The caustic portion of solid MST did not cause an appreciable shift in predicted acid demand.

- Significant sodium alumino-silicate formation was not indicated.

- No significant impact of CST and MST irradiation was noted.

- Sludge, SRAT product, and SME product rheological properties under normal shear rates were improved (made less viscous) by the presence of CST and MST.

- The yield strength of settled SME product solids was lower with CST and MST indicating that the solids would probably be easier to resuspend than traditional SME product solids without CST and MST.

In addition, DWPF could experience a variety of potential benefits from the incorporation of CST and MST into the starting sludge. These include:

- Dilution of the sludge likely means dilution of mercury and noble metals. Dilution of mercury reduces stripping time in the SRAT, while dilution of noble metals reduces the risk of excessive hydrogen generation.

- Combining CST and MST with planned sludge batches increases the mass of waste oxides per sludge batch, which extends the duration of a sludge batch at a fixed canister 
production rate. The result is that the frequency of qualification of new sludge batches would decrease (fewer qualifications per unit time).

- The improvements in rheology seen with simulants indicate that there may be an opportunity to process higher total solid content slurries through DWPF once CST and MST are fully integrated into the SRAT receipt sludge. Processing at higher solids levels reduces the number of SRAT/SME cycles needed to support a given canister production target. If DWPF needs fewer, shorter SRAT cycles to meet canister production goals, then an opportunity to increase the DWPF canister production goals may arise once SWPF and SCIX are fully operational.

There are some potential operational issues associated with integrating SCIX with DWPF:

- Ground CST is to be transferred into the DWPF feed tank, e.g. Tank 40. Ground CST has shown a tendency to form a fairly shear resistant cake once it has been allowed to settle. CST transfers should be immediately blended into the feed tank sludge solids, since these solids appear to mitigate CST cake formation. Thorough flushing of the CST transfer lines may be necessary as well to prevent the lines from plugging over time.

- This study assumed no impact on the concentrations of dissolved species and no significant impact on the wt $\%$ insoluble solids from the CST transfers. Some dilution of both is more likely; especially if a lot of flush water is required to clear the CST to DWPF feed tank transfer piping. Consequently, it may become routine to decant supernate from the DWPF feed tank back to the Tank Farm in order to maintain the $\mathrm{wt} \%$ insoluble content of the DWPF feed at an acceptable level. Ground CST fines may be returned to the Tank Farm evaporators potentially creating additional issues there with alumino-silicate formation.

- Process data suggested some increased foaming sensitivity of the caustic SRAT receipt slurry to the presence of CST and MST. Caustic slurry foaming and its mitigation are not as well understood as acidic slurry foaming and mitigation. Simulant tests have consistently underestimated the foaminess of real caustic slurries in DWPF. Increased antifoam demand could lead to excessive melter feed total organic carbon content.

- Dissolution of iron above normal historical SRAT processing levels was observed in some runs. The observed increases were small, but may not have bound the phenomenon, in which case there could be a potential impact on the criticality calculations and assumptions for the CPC.

The SCIX CPC impact program was conducted in parallel with a program to evaluate the impact of SCIX on the final DWPF glass waste form and on the DWPF melter throughput. The studies must be considered together when evaluating the full impact of SCIX on DWPF. ${ }^{27}$ 
SRNL-STI-2011-00075

Revision 0

\subsection{Path Forward}

DWPF-Engineering is evaluating alternatives to the existing coupled flowsheet. The current flowsheet brings MST slurry (ARP product) into the SRAT prior to nitric acid addition, follows nitric acid addition with formic acid addition, then proceeds to dewatering and strip effluent stream addition with dewatering and/or reflux. DWPF-Engineering is looking for alternatives to formic acid in order to reduce/eliminate the hazards of handling formic acid and to mitigate potential catalytic hydrogen generation. Proposed flowsheet alternatives could lead to processing in $\mathrm{pH}$ ranges not studied in the present study. Solubilities of various species could change in ways that would need to be reevaluated. Additionally, flowsheet alternatives could bring in new solvents that are superior complexing agents. These solvents could work to break down more of the insoluble species in DWPF. If DWPF chooses to implement a major flowsheet modification, then the impact of SCIX on DWPF will likely need to be evaluated.

A number of the remaining sludge waste tanks contain aluminum-rich HM sludge. Some scenarios for future processing of HM sludges through DWPF involve in-tank aluminum dissolution at high sodium hydroxide concentration. High supernate aluminum concentrations have led to rheological concerns. Rheology is also the main area of concern for DWPF from aluminum dissolution. The presence of MST, and potentially CST, during aluminum dissolution could lead to further adverse changes in rheology. The need for further CPC testing would depend on the outcome of evaluations of the impact of aluminum dissolution on slurry rheology in the presence of MST and/or CST. 
SRNL-STI-2011-00075

Revision 0

\subsection{References}

${ }^{1}$ Fellinger, T. L., DWPF Chemical Processing Cell Evaluation and Testing for SCIX, HLWDWPF-TTR-2010-0029, rev. 0, 6-22-2010, Savannah River Site, Aiken, SC, 29808.

${ }^{2}$ Koopman, D. C., Task Technical and Quality Assurance Plan for Evaluating the Impact of CST Small Column Ion Exchange-Monosodium Titanate Flowsheet on the DWPF Chemical Processing Cell, rev. 0, SRNL-RP-2010-01045, 7-8-2010, Savannah River National Laboratory, Aiken, SC, 29808.

${ }^{3}$ Andrews, M. K., T. L. Fellinger, D. M. Ferrara, J. R. Harbour, and D. T. Herman, Vitrification of Cesium-loaded Crystalline Silicotitanate (CST) in the Shielded Cells Melter, WSRC-TR-9700314, September, 1997, SRS, Aiken, SC, 29808.

${ }^{4}$ Lambert, D. P. and P. R. Monson, Hydrogen Generation Rate During Melter Feed Preparation of Tank 42 Sludge and CST in the Defense Waste Processing Facility (DWPF), WSRC-TR-9800297, SRS, Aiken, SC, 29808.

${ }^{5}$ Koopman, D. C. and D. P. Lambert, Hydrogen Generation and Foaming During Tests in the GFPS Simulating DWPF Operations with Tank 42 Sludge and CST, WSRC-TR-99-00302, June 2001, SRS, Aiken, SC, 29808.

${ }^{6}$ Daniel, W. E., Hydrogen Generation Rate During Melter Feed Preparation of Tank 42 Sludge and Salt Washed Loaded CST in the Defense Waste Processing Facility, WSRC-TR-99-00277, rev. 0, August 1999, SRS, Aiken, SC, 29808.

${ }^{7}$ Edwards, T. B., Z. H. Qureshi, J. R. Harbour, and F. G. Smith, III, Hydragard ${ }^{\circledR}$ Sampling of Melter Feed Slurry Containing CST, WSRC-TR-2000-00378, rev. 0, September 2000, SRS, Aiken, SC, 29808.

${ }^{8}$ Eibling, R. E. and D. C. Koopman, CST Melter Feed Characterization in Support of the 1999 and 2000 Thermal Fluids Lab Hydragard Testing, WSRC-TR-2000-00445, rev. 0, SRS, Aiken, $\mathrm{SC}, 29808$.

${ }^{9}$ Hansen, E. K., D. C. Koopman, and P. R. Monson, Impact of CST on the Rheological Properties of DWPF Melter Feeds, WSRC-TR-2001-00069, SRS, Aiken, SC, 29808.

${ }^{10}$ Baich, M. A., C. C. Herman, D. C. Koopman, D. R. Best, T. K. Snyder, and M. F. Williams, Processing Options and Incorporation of ARP in the DWPF Process Flowsheet, WSRC-TR2003-00326, rev. 0, August 2003, SRS, Aiken, SC, 29808.

${ }^{11}$ Koopman, D. C., C. C. Herman, M. A. Baich, D. R. Best, T. K. Snyder, and M. F. Williams, Impact of a Bounding Quantity of ARP Waste on the DWPF Flow Sheet, WSRC-TR-2003-00403, rev. 0, September 2003, SRS, Aiken, SC, 29808.

${ }^{12}$ Herman, C. C., M. F. Williams, S. L. Crump, A. R. Marinek, T. L. White, D. R. Best, and E. K. Hansen, DWPF Flowsheet Studies with Simulants to Determine Modular Caustic Side Solvent 
Extraction Unit Solvent Partitioning and Verify Actinide Removal Process Incorporation Strategy, WSRC-TR-2006-00063, March 2006, SRS, Aiken, SC, 29808.

${ }^{13}$ Lambert, D. P., M. F. Williams, S. L. Crump, R. E. Eibling, T. L. White, and D. R. Best, DWPF Flowsheet Studies with Simulants to Determine MCU Solvent Build-up in Continuous Runs, WSRC-TR-2006-00154, May 2006, SRS, Aiken, SC, 29808.

${ }^{14}$ Campbell, S. G., Preliminary Material Balance for the Modular CSSX Unit, CBU-SPT-200400059, rev. 1, Savannah River Site, Aiken, SC, 29808.

${ }^{15}$ Jantzen, C. M. and M. E. Stone, Role of Manganese Reduction/Oxidation (RedOx) on Foaming and Melt Rate in High Level Waste Melters, WSRC-STI-2006-00066, March 2007, SRNL, Aiken, SC, 29808.

${ }^{16}$ Manual L29, Procedure ITS-00094, Rev. 3, Laboratory Scale Chemical Process Cell Simulations, 2006, SRNL, Aiken, SC, 29808.

${ }^{17}$ Koopman, D. C., Rheology Protocols for DWPF Samples, WSRC-RP-2004-00470, rev. 0, October 2004, SRS, Aiken, SC, 29808.

${ }^{18}$ P-ESR-J-00001, rev. 2, Salt Waste Processing Facility Project - Mass Balance Model Summary Description, October 2007, SRS, Aiken, SC, 29808.

${ }^{19}$ Lambert, D. P. and A. S. Choi, DWPF Coal-Carbon Waste Acceptance Criteria Evaluation Based on Experimental Work (Tank 48 Impact Study), SRNL-STI-2010-00589, rev. 0, October 2010, SRNL, Aiken, SC, 29808.

${ }^{20}$ Poirier, M. R., C. E. Ferguson, D. C. Koopman, and T. B. Edwards, Rheology of Settled Solids in the Small Column Ion Exchange (SCIX) Process, part 2, SRNL-STI-2011-draft, April 2011, SRNL, Aiken, SC, 29808.

${ }^{21}$ Koopman, D. C., A. I. Fernandez, and B. R. Pickenheim, Preliminary Evaluations of Two Proposed Stoichiometric Acid Equations, SRNL-L3100-2010-00041, rev. 0, SRNL, Aiken, SC, 29808.

${ }^{22}$ Koopman, D. C., DWPF Hydrogen Generation Study: Phase II - Form of Noble Metal Testing, WSRC-TR-2005-00420, rev. 0, SRNL, Aiken, SC, 29808.

${ }^{23}$ Koopman, D. C., D. R. Best, and B. R. Pickenheim, SRAT Chemistry and Acid Consumption during Simulated DWPF Melter Feed Preparation, WSRC-STI-2008-00131, rev. 0, December 2008, SRNL, Aiken, SC, 29808.

${ }^{24}$ Lambert, D. P., B. R. Pickenheim, M. E. Stone, and J. D. Newell, Glycolic-Formic Acid Flowsheet Final Report for Downselection Decision, SRNL-STI-2011-00523, rev. 0, February 2011, SRNL, Aiken, SC, 29808.

${ }^{25}$ Koopman, D. C., Sludge Batch 6/Tank 40 Simulant Chemical Process Cell Simulations, SRNLSTI-2010-00212, rev. 0, April 2010, SRNL, Aiken, SC, 29808. 
${ }^{26}$ Poirier, M. R., C. E. Ferguson, and D. C. Koopman, Rheology of Settled Solids in the Small Column Ion Exchange (SCIX) Process, SRNL-STI-2011-00054, rev. 0, January, 2011, SRNL, Aiken, SC, 29808.

${ }^{27}$ Fox, K. M., T. B. Edwards, and F. C. Johnson, Summary Report on Potential Impacts of Small Column Ion Exchange of DWPF Glass Formulation, SRNL-STI-2011-00198, rev. 0, April, 2011, SRNL, Aiken, SC, 29808. 
SRNL-STI-2011-00075

Revision 0

Appendix A - Additional Data 
The appendix includes SRAT product elemental analyses which are very similar to the analyses of the matching starting simulant as expected. Process $\mathrm{pH}$ profiles are also shown.

Table 33. Calcined wt\% SRAT product elements $\left(1100{ }^{\circ} \mathrm{C}\right)$

\begin{tabular}{|l|c|c|c|c|c|}
\hline & SCIX1 & SCIX2 & SCIX3 & SCIX4 & SCIX5 \\
\hline $\mathrm{Al}$ & 4.25 & 4.36 & 5.76 & 4.23 & 4.34 \\
\hline $\mathrm{Ba}$ & 0.12 & 0.12 & 0.18 & 0.13 & 0.12 \\
\hline $\mathrm{Ca}$ & 1.39 & 1.36 & 2.61 & 1.50 & 1.42 \\
\hline $\mathrm{Ce}$ & 0.41 & 0.41 & 0.57 & 0.41 & 0.36 \\
\hline $\mathrm{Cr}$ & 0.087 & 0.095 & 0.12 & 0.084 & 0.083 \\
\hline $\mathrm{Cu}$ & 0.053 & 0.044 & 0.036 & 0.023 & 0.036 \\
\hline $\mathrm{Fe}$ & 16.6 & 16.7 & 23.6 & 16.6 & 16.4 \\
\hline $\mathrm{K}$ & 0.26 & 0.25 & 0.26 & 0.26 & 0.26 \\
\hline $\mathrm{La}$ & 0.14 & 0.14 & 0.20 & 0.14 & 0.13 \\
\hline $\mathrm{Mg}$ & 0.18 & 0.17 & 0.26 & 0.18 & 0.17 \\
\hline $\mathrm{Mn}$ & 3.06 & 2.91 & 4.28 & 2.96 & 2.73 \\
\hline $\mathrm{Na}$ & 16.8 & 16.9 & 16.3 & 17.4 & 17.1 \\
\hline $\mathrm{Nb}$ & 2.8 & 2.8 & 1.2 & 2.56 & 3.44 \\
\hline $\mathrm{Ni}$ & 0.40 & 0.40 & 0.53 & 0.38 & 0.41 \\
\hline $\mathrm{Pb}$ & 0.20 & 0.20 & 0.22 & 0.19 & 0.20 \\
\hline $\mathrm{Si}$ & 3.09 & 3.08 & 2.53 & 3.01 & 3.03 \\
\hline $\mathrm{Ti}$ & 11.0 & 11.1 & 5.48 & 11.1 & 11.1 \\
\hline $\mathrm{Zn}$ & 0.035 & 0.034 & 0.061 & 0.038 & 0.040 \\
\hline $\mathrm{Zr}$ & 2.65 & 2.72 & 1.55 & 2.68 & 2.71 \\
\hline
\end{tabular}

Process $\mathrm{pH}$ profiles are given for the SRAT cycles. Low acid stoichiometry data are given first.

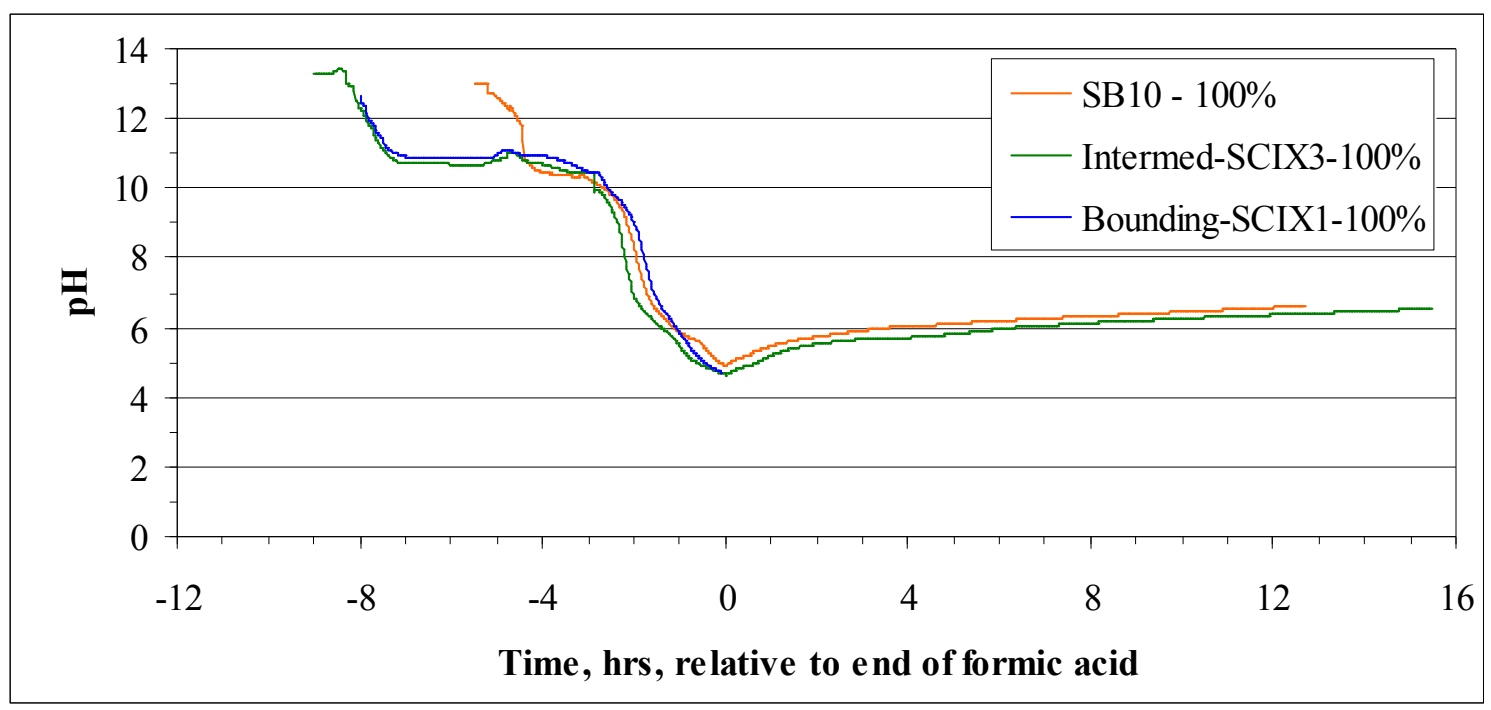

Figure A-1. pH profiles for low acid tests 
Profiles are fairly similar except for the period prior to nitric acid addition where the two SCIX runs had two hours of caustic boiling that were not included in the SB10 test. The SCIX1 probe failed near the end of formic acid addition, and the data for that run end there. High acid $\mathrm{pH}$ data are given next.

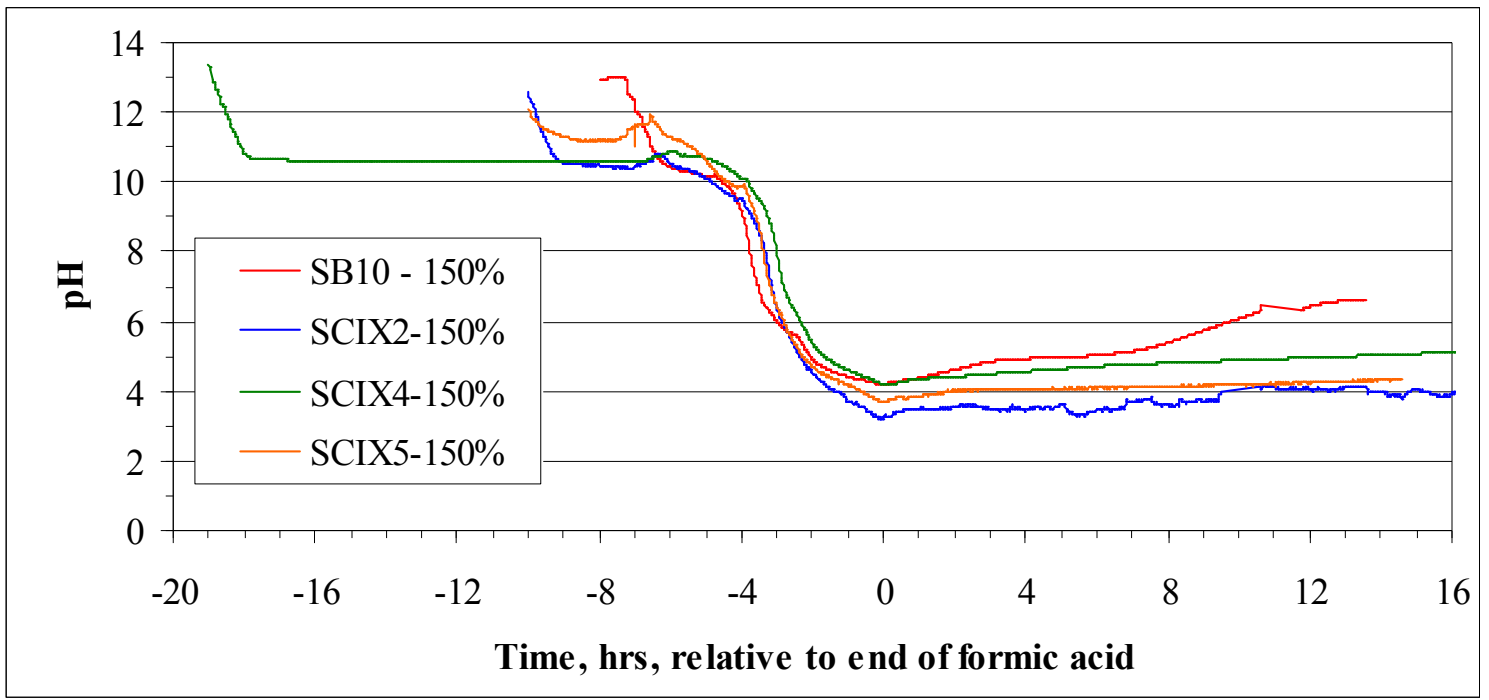

Figure A-2. pH profiles for high acid tests

The alpha strike addition in SCIX4 is responsible for its data trace starting that much sooner than the other two SCIX runs. The SB10 run has no caustic boiling, so its trace starts last. The $\mathrm{pH}$ rise during boiling following formic acid addition generally appears to mimic the amount of catalytic formate destruction in the various runs. 


\section{Distribution:}
A. B. Barnes, 999-W
D. A. Crowley, 773-43A
S. D. Fink, 773-A
B. J. Giddings, 786-5A
C. C. Herman, 999-W
S. L. Marra, 773-A
A. M. Murray, 773-A
F. M. Pennebaker, 773-42A
W. R. Wilmarth, 773-A
J. E. Occhipinti, 704-S
T. H. Huff, 773-66A
P. R. Jackson, 703-46A
R. E. Edwards, 773-67A
T. L. Fellinger, 704-26S
M. A. Rios-Armstrong, 773-66A
H. B. Shah, 766-H
A. V. Staub, 704-27S
J. F. Iaukea, 704-30S
J. W. Ray, 704-S
C. J. Bannochie, 773-42A
J. M. Gillam, 766-H
B. A. Hamm, 766-H
D. W. McIlmoyle, 766-H
M. E. Stone, 999-W
D. K. Peeler, 999-W
D. C. Sherburne, 704-S
J. M. Bricker, 704-27S
E. W. Holtzscheiter, 704-15S
B. R. Wingard, 704-27S
M. T. Keefer, 766-H
D. T. Herman, 735-11A
J. D. Newell, 999-W
D. P. Lambert, 999-W
B. R. Pickenheim, 999-W
J. M. Pareizs, 773-A
S. H. Reboul, 773-A
J. R. Zamecnik, 999-W
K. M. Fox, 999-W 